\title{
Neonatal polycythaemia: clinical symptoms, and disturbances in blood flow velocity and haemorheology
}

Citation for published version (APA):

Maertzdorf, W. J. (1993). Neonatal polycythaemia: clinical symptoms, and disturbances in blood flow velocity and haemorheology. [Doctoral Thesis, Maastricht University]. Rijksuniversiteit Limburg. https://doi.org/10.26481/dis.19921210wm

Document status and date:

Published: 01/01/1993

DOI:

10.26481/dis.19921210wm

Document Version:

Publisher's PDF, also known as Version of record

Please check the document version of this publication:

- A submitted manuscript is the version of the article upon submission and before peer-review. There can be important differences between the submitted version and the official published version of record.

People interested in the research are advised to contact the author for the final version of the publication, or visit the DOI to the publisher's website.

- The final author version and the galley proof are versions of the publication after peer review.

- The final published version features the final layout of the paper including the volume, issue and page numbers.

Link to publication

\footnotetext{
General rights rights.

- You may freely distribute the URL identifying the publication in the public portal. please follow below link for the End User Agreement:

www.umlib.nl/taverne-license

Take down policy

If you believe that this document breaches copyright please contact us at:

repository@maastrichtuniversity.nl

providing details and we will investigate your claim.
}

Copyright and moral rights for the publications made accessible in the public portal are retained by the authors and/or other copyright owners and it is a condition of accessing publications that users recognise and abide by the legal requirements associated with these

- Users may download and print one copy of any publication from the public portal for the purpose of private study or research.

- You may not further distribute the material or use it for any profit-making activity or commercial gain

If the publication is distributed under the terms of Article 25fa of the Dutch Copyright Act, indicated by the "Taverne" license above, 
NEONATAL POLYCYTHAEMIA:

clinical symptoms, and disturbances in blood flow velocity and haemorheology 


\section{NEONATAL POLYCYTHAEMIA:}

clinical symptoms, and disturbances in blood flow velocity and haemorheology

\section{PROEFSCHRIFT}

ter verkrijging van de graad van doctor aan de Rijksuniversiteit Limburg te Maastricht, op gezag van de Rector Magnificus, Prof. Mr. M.J. Cohen, volgens besluit van het College van Dekanen, in het openbaar te verdedigen op donderdag 10 december 1992 om 16.00 uur

door

Willem Johannes Maertzdorf

geburen 11 december 1940 


\section{Promotor:}

Prof. Dr. C.E. Blanco

\section{Co-promotores:}

Dr. D.W. Slaaf

Dr. G.J. Tangelder

\section{Beoordelingscommissie:}

Prof. Dr. R.S. Reneman (voorzitter)

Prof. Dr. G. Duc (Universitäts Kantonsspital, Zürich, Zwitserland)

Prof. Dr. J.M.A. van Engelshoven

Dr. M. Jacobs

Prof. Dr. A. Okken (Rijksuniversiteit Groningen)

Dr. L. Peeters

\section{CIP-DATA KONINKLIJKE BIBLIOTHEEK, DEN HAAG}

\section{Maertzdorf, Willem Johannes}

neonatal polycythaemia: clinical symptoms, and disturbances in blood flow velocity and haemorheology

Willem Johannes Maertzdorf

Thesis Maastricht-with reference list-with summary in Dutch ISBN 90-900564 I-6

Subject headings: neonatology/polycythaemia

Ontwerp, layout:

Snijders \& Partners BV, Baarn

Druk: 
To my Parents 


\section{CONTENTS}

chapter 1 .

General introduction

1.1 Neonatal polycythaemia and organ perfusion 8

1.2 Aims of the study

1.3 Outline of the thesis

chapter 2 .

Polycythaemia of the newborn infant: A review of the literature $\quad 10$

2.1 Neonatal polycythaemia 10

$\begin{array}{ll}2.2 \text { Circulating blood volume } & 19\end{array}$

2.3 Principles and definitions in haemorheology 21

2.4 Determinants of blood viscosity 24

$\begin{array}{ll}\text { 2.4. l haematocrit } & 24\end{array}$

$\begin{array}{ll}2.4 .2 \text { plasma viscosity } & 26\end{array}$

$\begin{array}{ll}2.4 .3 \text { red cell aggregation } & 28\end{array}$

$\begin{array}{ll}2.4 .4 \text { red cell deformability } & 29\end{array}$

chapler 3.

Survey of methods and assessments used in this study 30

$\begin{array}{ll}3.1 \text { Haematocrit } & 30\end{array}$

3.2 Blood flow velocity and red cell transport $\quad 30$

3.3 Partial plasma exchange transfusion 34

$\begin{array}{ll}3.4 \text { Circulating blood volume } & 35\end{array}$

$\begin{array}{ll}3.5 \text { Plasma viscosity } & 36\end{array}$

chapter 4 .

Effects of partial plasma exchange transfusion on cerebral blood flow velocity in polycythaemic preterm, term and small-for-date newborn infants

chapter 5 .

Effects of partial plasma exchange transfusion on blood flow velocity in large arteries of arm and leg and in cerebral arteries in polycythaemic newborn infants

chapter 6 .

Circulating blood volume in appropriate- and small-for-gestational age full term and preterm polycythaemic infants 
chapter 7.

Plasma viscosity in polycythaemic newborn infants

chapter 8 .

Clinical symptoms in polycythaemic newborn infants

chapter 9.

General discussion and conclusions

List of references

104

Summary

114

Samenvatting

116

Nawoord

119

Curriculum vitae

120 


\section{GENERAL INTRODUCTION}

\subsection{Neonatal polycythaemia and organ perfusion}

Since the last few decades mortality rates have decreased considerably in newborn infants and especially in very low birth weight infants. However, morbidity is still high with often persistent retardation in motor and mental development (van Zeben-van der Aa, 1989). Morbidity is prominent in preterm and small-for-gestational age infants. As a possible factor for producing central nervous system morbidity, the influence of haemodynamic disturbances or abnormalities in haemostasis on cerebral blood flow has been studied by many investigators (Wigglesworth and Pape, 1980; Beverley et al, 1984; Perlman et al, 1985; Andrew et al, 1987; Miall-Allen et al, 1989).

Polycythaemia is one of the disturbances which may be associated with neurological morbidity in newborn intants. It is usually defined as a peripheral venous haematocrit of more than $65 \%$, and thus defined, occurs in $2-5 \%$ of all newborn infants. The increased number of circulating red blood cells leads to an increased viscosity and, hence, a decreased fluidity of the blood. Decreased blood fluidity may cause malperfusion of different organ systems, resulting in clinical manifestations. Neonatal polycythaemia has several aetiologies and it may affect the central nervous system and several other organs in varying degrees of severity (Black et al, 1985; Rosenkrantz and Oh, 1986).

Although red cell mass is usually the most important factor determining blood viscosity, other parameters like plasma viscosity, red cell aggregation and red cell deformability contribute to it as well. New microrheological test methods have made it possible to assess rheological parameters, using small amounts of blood (Schmid-Schönbein et al, 1982). This has allowed the study of the hyperviscosity syndrome in the neonatal period (Walker, 1988; Rampling et al, 1989). Using these methods it has become possible to extend the scope of "haemorheology", the science that studies the determinants of blood flow, to neonates.

Partial plasma exchange transfusion is used to lower the haematocrit in newborn infants with polycythaemia. However, it is still controversial whether a haematocrit reduction by haemodilution should be performed in polycythaemic newborn infants and whether organ perfusion actually can be improved by this procedure (Black et al, 1985; Bada et al, 1992). Furthermore, no distinction has been made so far with regard to the significance of impaired organ perfusion due to decreased fluidity of the blood, between preterm, and small- and appropriate-for-gestational age term infants. Hypothesis: given the negative effect of polycythaemia on blood viscosity and, with it, blood flow characteristics it is postulated that haemodilution, performed by a partial plasma exchange transfusion, normalizes the adverse effects of polycythaemia in newborn infants.

\subsection{Aims of the study}

1. To determine the influence of polycythaemia and the effects of haemodilution, produced by partial plasma exchange transfusion, on blood flow velocity and red cell transport in major arteries of brain, arms and legs.

2. To study the impact of polycythaemia on blood flow velocity in different groups of newborn infants: preterm, small- and appropriate-for-gestational age term infants. 
3. To determine the possibilities and limitations of a new method for accurate calculation of the required exchange volume during haemodilution and to assess the circulating volume in the different groups of polycythaemic newborn infants.

4. To study plasma viscosity in different groups of polycythaemic newborn infants.

5. To study the relationship between clinical symptoms and specific abnormalities in blood flow velocity and haemorheological parameters in polycythaemic newborn infants.

\subsection{Outline of the thesis}

Chapter 2 presents a review of the literature on neonatal polycythaemia, its possible consequences for blood flow, the controversy on the use of a partial plasma exchange transfusion and factors influencing circulating blood volume. In addition, the different determinants of blood viscosity and the methods used to measure them are discussed.

Chapter 3 presents a survey of the methods used in our study: the method of blood sampling and haematocrit determination; the technique used for determination of blood flow velocity by Continuous Wave Doppler; the procedure of haemodilution with partial plasma exchange transfusion; a method to determine the required exchange volume; and an introduction to the micromethods used for the measurement of plasma viscosity.

Chapter 4 describes the effects of haemodilution on cerebral blood flow velocity in different groups of polycythaemic newborn infants.

Chapter 5 describes the blood flow velocity in large arteries of arm and leg and in the cerebral arteries of the same polycythaemic infants. Changes in blood flow velocity after partial plasma exchange transfusion are also described.

In chapter 6 a method is discussed by which circulating blood volume can be estimated, using the stepwise decrease in haematocrit during sequential exchange transfusion. Differences in circulating blood volume between smallfor-gestational age and appropriate-for-gestational age polycythaemic newborn infants are reported. For each of the groups, the impact of differences in circulating volume on the determination of the exchange volume is discussed.

Chapter 7 presents data on plasma viscosity in different groups of newborn infants in relation to various levels of haematocrit and the influence of plasma viscosity on clinical manifestations of impaired organ perfusion in polycythaemic newborn infants.

In chapter 8 the relationship between clinical symptoms and alterations in blood flow velocity, red cell transport and some haemorheological parameters are discussed.

The thesis ends with a general discussion (chapter 9), a list of references and a brief summary with some final remarks. 


\section{POLYCYTHAEMIA OF THE NEWBORN INFANT: A REVIEW OF THE LITERATURE}

\subsection{Neonatal polycythaemia}

\section{Definitions and incidence}

Polycythaemia of the newborn is still a problem for which many questions remain concerning incidence, aetiology, diagnosis, pathophysiology, management and outcome. Neonatal polycythaemia is usually defined as a peripheral venous haematocrit $(\mathrm{Hct})$ of more than $65 \%$. According to this definition, the incidence of neonatal polycythaemia varies between $2-5 \%$ (Wirth et al, 1979; Ramamurthy and Brans, 1981; Reisner et al, 1983). Lack in standardisation of sampling site, moment of sampling, and differences in race and social conditions may be reasons for the variations in the reported incidence. Since the haematocrit level depends on the site of sampling, the blood used for the determination of the haematocrit should be taken from a peripheral vein. The haematocrit in capillary blood obtained by heel stick is consistently higher than that of blood from a peripheral vein. Still, the difference between heel stick haematocrit and peripheral vein haematocrit is unpredictable (Oh and Lind, 1966).

A high haematocrit can result in an increased viscosity and, hence, a reduced fluidity of the blood, leading to an increased resistance to flow and a reduction in organ perfusion. There is a more or less linear relation between haematocrit and blood viscosity up to haematocrit values of about $60 \%$. When

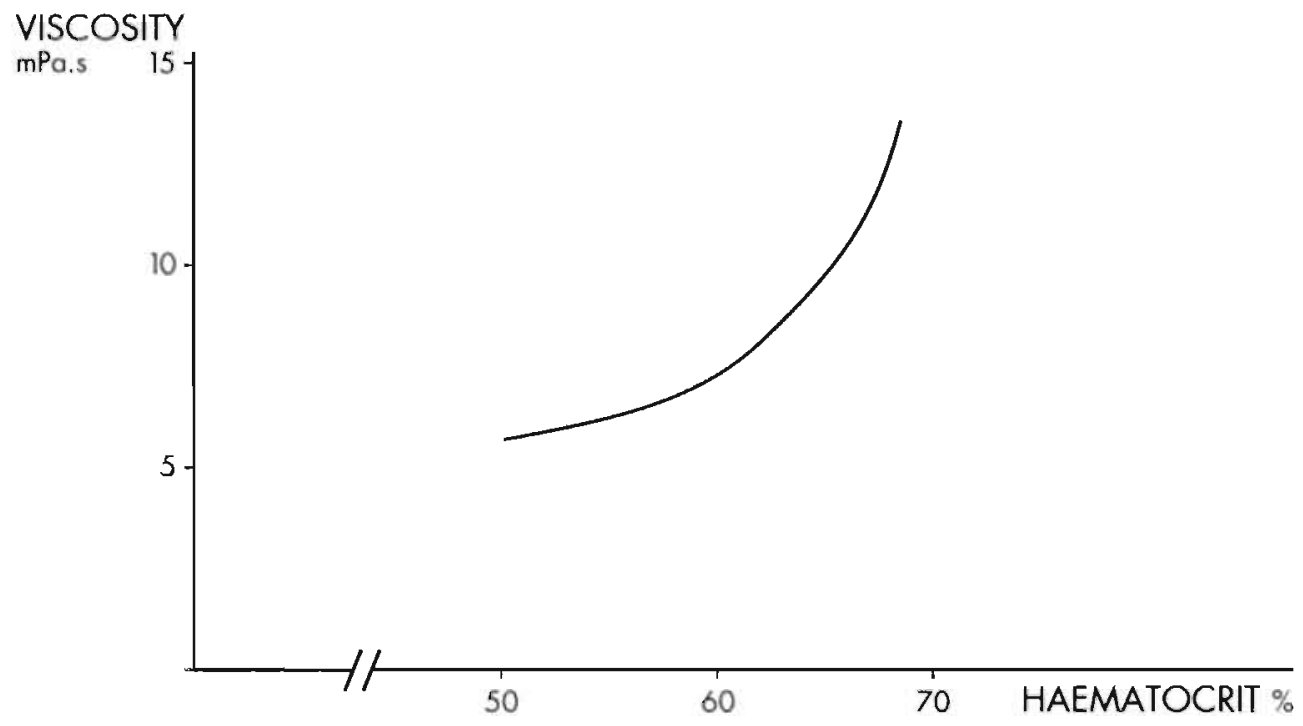

fig. 2.1.1. Non-linear relationship between haematocrit and whole blood viscosity. Viscosity was measured at a shear rate of $95 \mathrm{~s}^{-1}$. (Constructed of data obtained from Chien et al, 1966) 
the haematocrit increases to values above $65 \%$, the slope of the relationship with viscosity of the blood increases (see figure 2.1.1). Because of its relatively high incidence and its frequent association with clinical manifestations, polycythaemia is an important factor to consider as a cause of impaired organ perfusion.

Whole blood viscosity is determined by differcnt parameters. An increased viscosity of the blood may be caused not only by a high haematocrit, but also by altered properties of the red cells and the suspending plasma. The incidence of neonatal hyperviscosity is slightly higher than that of polycythaemia. About $1 \%$ of newborn infants with haematocrit values lower than $65 \%$ may present clinical signs of hyperviscosity as well (Wirth et al, 1979). This situation is observed when there is an increase in plasma macroglobulin concentration, which elevates plasma viscosity, or when the rheological properties of the red blood cells have been changed. However, in clinical practice neonatal polycythaemia is found to be the most common cause found of hyperviscosity. This might in part be due to the fact that haematocrit measurements are easy to perform, whereas accurate measurements of the other rheological parameters are complicated and time consuming.

\section{Aetiology}

Neonatal polycythaemia may occur in a number of clinical situations (see table 2.1.1.). Three major factors leading to polycythaemia are: delayed cord clamping, chronic fetal distress, and maternal diabetes mellitus (Mentzer, 1978).

table 2.1.1. Causes for neonatal polycythaemia
Abnormal placental transfusion
- delayed cord clamping
- maternal-fetal transfusion
- fetal-fetal transfusion (twins)
Chronic fetal distress/hypoxia
- placental insufficiency
- maternal smoking
Endocrine dysfunctions
- hyperinsulinaemia
- maternal diabetes mellitus
- Beckwith-Wiedemann syndrome
- adrenal hyperplasia
- thyrotoxicosis

\section{Other factors}
- trisomy 
Delayed cord clamping will result in an increased postnatal transfusion from the placental blood content to the newborn infant (Usher and Lind, 1965; Yao and Lind, 1974; Linderkamp, 1984). During the first hours after birth fluid shifts from the intravascular to the extravascular spaces occur, leading to a concomitant decrease in circulating volume and an increase in haematocrit. The extent of fluid extravasation depends largely on the amount of postnatal transfusion. The influence of cord clamping time on circulating volume is discussed in detail in section 2.2 .

Chronic fetal distress due to placental insufficiency is associated with a high incidence of polycythaemia, especially in small-for-gestational age infants. In a group of 79 small-for-gestational age infants born after a long period of fetal distress, Hakanson and Oh (1980) found 14 polycythaemic infants (18\%). Other authors (Wirth et al, 1979; Wiswell et al, 1986) reported an incidence of polycythaemia in small-for-gestational age infants of $12 \%$ and $8 \%$, respectively. The high incidence in this group of infants can be explained by a chronic placental insufficiency with concomitant chronic hypoxaemia, leading to an increase in erythropoietin levels with an increased production of red cells (Widness et al, 1982).

Infants of mothers with diabetes mellitus may also be at greater risk for polycythaemia because these infants show an increased erythropoietin production. Philipps and colleagues (1982), and Bard and Fouron (1989), studying hyperglycaemic fetal lambs, reported a concomitant fetal hypoxia, resulting in an increased erythropoietin production.

Less frequent aetiologies of polycythaemia are maternal to fetal blood transfusions or (in twins) fetal to fetal transfusions. Although these transfusions may occur often, no data on the incidence of polycythaemia in these groups of infants are available. Chromosomal abnormalities, Beckwith-Wiedemann syndrome and some endocrine dysfunctions are rare causes of neonatal polycythaemia. The cause of polycythaemia in infants with BeckwithWiedemann syndrome might be due to the presence of concomitant hyperinsulinaemia. The mechanisms leading to polycythaemia in the other cases are unknown.

\section{Clinical symptoms}

Polycythaemia associated with increased blood viscosity can produce characteristic clinical symptoms. These symptoms seem to indicate dysfunction of various organ systems (see also table 2.1.2. and figure 2.1.2.). 
table 2.1.2. Organ systems involved in neonatal polycythaemia

Centrall nervous system

- lethargy

- jitteriness

- seizures

Cardiac/pulmonary system

- pulmonary hypertension

- respiratory distress

Renal system

- renal failure

Blood

- hyperbilirubinaemia

Gastro-intestinal tract

- necrotizing entero-colitis

Skin

- plethora

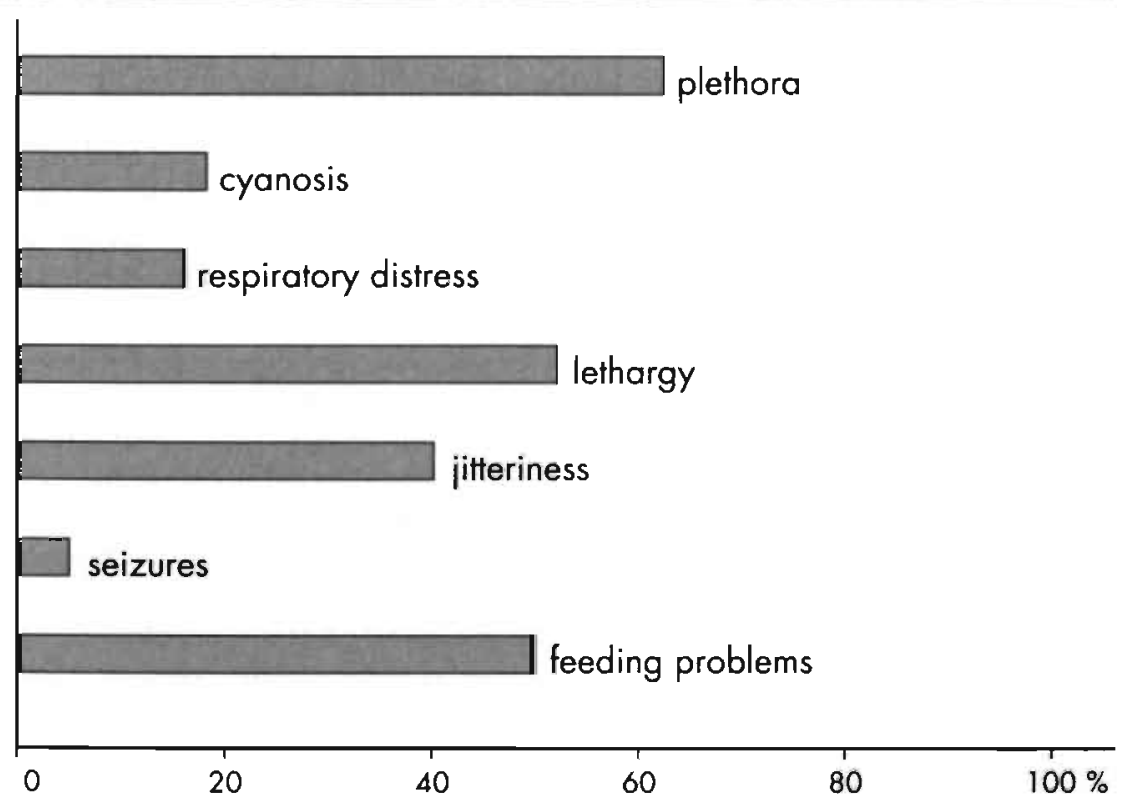

fig. 2.1.2. Distribution of clinical symptoms in polycythaemic newborn infants. Infants may have more than one clinical symplom.

(Constructed of data oblained from Rosenkrantz and Oh, 1986). 
A direct consequence of polycythaemia is a rise in viscosity, which in turn, at a given perfusion pressure, leads to a reduced blood flow. This implies a decrease of capillary perfusion. The possible role of a vasodilatory response in polycythaemic infants is still uncertain. Although more red cells are available for oxygen transport, the overall decreased flow velocity may result in a net reduction of oxygen delivery to the tissues. To guarantee optimal oxygen delivery to the tissues, blood flow velocity and oxygen carrying capacity should be in proper balance. It has been suggested that in adults the optimal venous haematocrit for maximal oxygen delivery is 30\% (Messmer and SchmidSchönbein, 1972). Humphrey and colleagues (1979) reported that in adults after reduction of the haematocrit from $50 \%$ to $45 \%$ (a decrease of $11.2 \%$ ), cerebral blood flow increased from $44.9 \mathrm{ml} / \mathrm{kg} / \mathrm{min}$ to $59.7 \mathrm{ml} / \mathrm{kg} / \mathrm{min}$. This means an increase in red cell flux of $22 \%$. In other words, although oxygen content decreased, oxygen delivery improved. The optimal haematocrit level for different groups of newborn infants is unknown. Massik et al (1987) induced polycythaemia in newborn lambs by infusion of red cells containing methaemoglobin to keep the oxygen content constant and studied its effects on cerebral blood flow by the radiolabeled microsphere technique. They observed a decrease in cerebral blood flow and concluded that this was due to increased blood viscosity and not to a change in arterial oxygen content. On the other hand, Rosenkrantz and colleagues (1984) reported that the reduction in cerebral blood flow in polycythaemic lambs is a physiologic response to the increased arterial oxygen content and not the result of hyperviscosity. In the latter study cerebral blood flow was measured using radionuclide-labeled microspheres. Polycythaemia was induced by an exchange transfusion with packed cells and this resulted in a decrease in cerebral blood flow. When sodium-nitrite was infused to reduce arterial oxygen content to baseline levels, cerebral blood flow returned to the levels during normocythaemia. It seems therefore that increased red cell mass and the concomitant blood viscosity, as well as increased oxygen content may decrease cerebral blood flow.

The manifestations of hyperviscosity are usually not evident at birth, but develop during the first hours after delivery when haematocrit rises as a consequence of the physiological decrease in plasma volume. At approximately three hours after birth the haematocrit reaches its highest level (see figure 2.1.3.). 


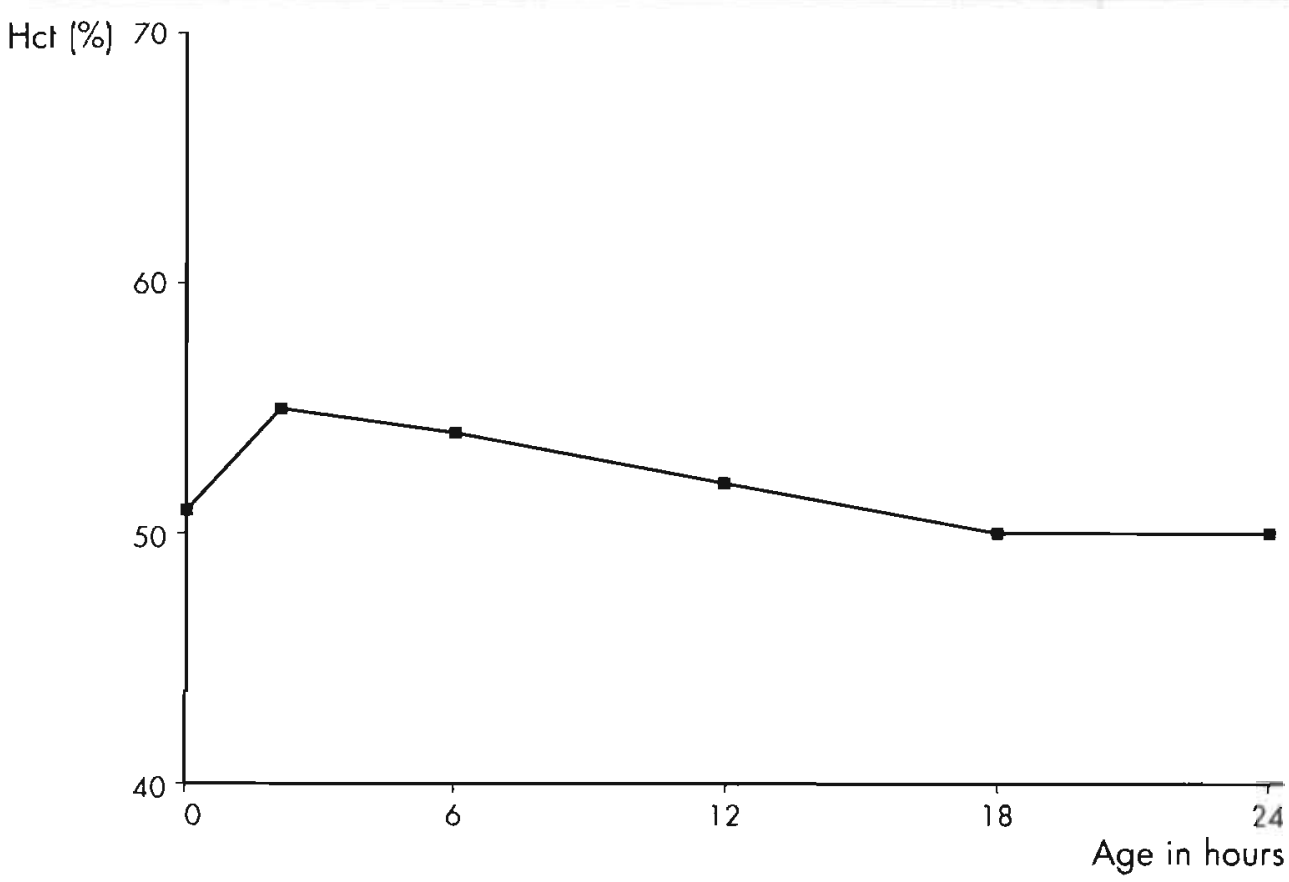

fig. 2.1.3. Course of peripheral venous haematocrit levels during the first day of life. (Constructed of data obtained from Ramamurthy and Berlanga, 1987)

Cardio-pulmonary and skin symptoms: frequently reported findings in these organ systems are cyanosis, plethora, cardiomegaly and respiratory distress. A characteristic red-blue color of the skin, known as plethora, is mentioned as the most frequent clinical symptom (Gatti et al, 1966; Gross et al, 1973; Saigal and Usher, 1977; Ramamurthy and Brans, 1981; Wiswell et al, 1986). Although these infants are cyanotic due to a blood content of more than five grams unsaturated haemoglobin, they are not necessarily hypoxic because oxygen supply is normal. Respiratory distress is manifested by tachypnea and intercostal retractions. The increased ventilatory efforts are due to elevated pulmonary blood pressure and an increased fluid content in the lungs caused by plasma transudation. The elevated arterial pulmonary pressure may eventually lead to ductal shunting from right to left and persistence of fetal circulation.

Neurological symptoms: a variety of neurological manifestations has been reported, such as lethargy, jitteriness, seizures and irritability (Gross et al, 1973; Saigal et al, 1977; Goldberg et al, 1982; Black et al, 1982; Wiswell et al, 1986). Whether the neurological symptoms are due to an inpaired blood flow or to the factors that are responsible for the polycythaemia (for example, chronic fetal hypoxaemia) is not clear. Hypoglycaemia, which is frequently found in polycythaemic newborn infants might also contribute to the presence of these clinical symptoms. 
Infants with polycythaemia have a decreased cerebral blood flow and increased vascular resistance (Rosenkrantz and $\mathrm{Oh}, 1982$ ). Intracranial infarcts and haemorrhages are described in term polycythaemic newborn infants (Amit and Camfield, 1980; Miller et al, 1981; Wiswell et al, 1986). Fluctuations in cerebral blood flow and disturbances in blood coagulation which sometimes are present during polycythaemia (see haematological symptoms), might be of importance in the pathogenesis of such cerebral vascular accidents (Perlman et al, 1983).

Moreover, the beneficial effect of haemodilution on neurological outcome, as reported in some studies (Black et al, 1985), supports a negative role of hyperviscosity on cerebral perfusion.

Gastro-intestinal symptoms: poor feeding and vomiting are frequent symptoms (van der Elst et al, 1980; Høst and Ulrich, 1982). Wiswell and colleagues (1986) reported an incidence of $22.8 \%$ of feeding problems in polycythaemic newborn infants. Moreover, these infants carry a significant risk of developing necrotising entero-colitis (Le Blanc et al, 1984; Leake et al, 1975; Hakanson and $\mathrm{Oh}, 1977)$. It is still not clear whether there is a direct relation between polycythaemia and necrotizing entero-colitis or whether other factors may also play a role. It is possible that the increased blood viscosity leads to a decrease in intestinal blood perfusion causing a relative ischaemia of the wall of the gut. Another explanation might be that invasive procedures, such as partial plasma exchange transfusion, obstruct venous return from the gut or cause swings in blood perfusion of the gut due to alternating withdrawal and injection of blood. The factors responsible for the polycythaemia itself might also play a role.

Renal symptoms: renal vein thrombosis or acute renal failure is seldom reported (Aperia et al, 1974; Herson et al, 1982). The precise mechanism involved is unclear. Perinatal hypoxia, which is often associated with polycythaemia, might directly cause renal damage. Decreased blood flow with impaired renal perfusion can be responsible for renal failure.

Metabolic symptoms: hypoglycaemia is frequently found in polycythaemic newborn infants. The mechanisms leading to hypoglycaemia are not clear and have not been elucidated by experiments in polycythaemic lambs (Leake et al, 1980; Creswell et al, 1981). One explanation is that glucose is found almost exclusively in the plasma fraction. As this plasma fraction is reduced in polycythaemia, glucose availability decreases. Philipps and colleagues (1982) found in fetal lambs an association between hyperglycaemia, hyperinsulinaemia and a decrease in arterial oxygen content. Infants of mothers with diabetes mellitus and exposure to transplacental hyperglycaemia might therefore be chronically hypoxic, resulting in increased erythropoiesis. Green and colleagues (1992) found a positive correlation between neonatal venous haematocrit and glycosylated haemoglobin level in mothers with poor controlled insulin dependent diabetes.

Haematological symptoms: several reports mention the association of polycythaemia with thrombocytopenia, disseminated intravascular clotting and low antithrombin-III levels (Henriksson, 1979; Katz et al, 1982).

Thrombocytopenia is probably due to a predominance of fetal erythropoiesis in 
chronic fetal distress or to an enhanced disappearance of the platelets from the sluggish circulation (Shaikh and Erslev, 1978). Hyperbilirubinaemia is a frequent complication of polycythaemia due to the large amount of bilirubin released by an increased number of destructed red cells.

\section{Management}

Effect: it is still a matter of debate whether or not polycythaemia in the newborn may cause long-term developmental sequelae and, if so, which infants require treatment with haemodilution. It is difficult to evaluate whether any delay in child development could have been caused by a period of disturbed cerebral blood perfusion due to hyperviscosity, or by the perinatal circumstances predisposing to hyperviscosity. Randomized controlled studies evaluating the effect of haemodilution on long-term neurodevelopnnental outcome are limited.

Van der Elst and colleagues (1980) randomized 49 polycythaemic newborn infants to receive either treatment with haemodilution or supportive care. They found no differences in neurodevelopmental outcome between the 2 groups consisting of infants of 8 months. However, in the latter study the duration of the hyperviscous state is not mentioned and the groups can hardly be compared, as the group that received no treatment showed significantly fewer symptoms than the group that did.

Høst and Ulrich (1982) examined 113 children of 2.5 years. Three hours after birth 83 of them had a haematocrit range between $60-65 \%$ and 30 had a haematocrit range between $65-72 \%$. All newborns got normal supportive care. No differences in developmental outcome between the two groups were found and it was concluded that a preventive haemodilution in polycythaemic newborns is not indicated. It should be mentioned, however, that only 3 of the 30 polycythaemic infants showed minor clinical symptoms and that the remaining 27 infants were asymptomatic.

Bada and colleagues (1992) studied 45 newborn infants with polycythaemia. Those without clinical symptoms $(n=28)$ were randomly selected either to have haemodilution or to be observed. No beneficial effects of haemodilution on long-term outcome were found and it was concluded that other perinatal risk factors rather than polycythaemia influence long-term outcome.

Goldberg and colleagues (1982) reported that among infants with hyperviscosity abnormal outcomes were more frequent than among matched controls, but they found no differences between treated and non-treated infants. However, the number of randomly assigned polycythaemic infants was small $(n=20)$ and the exchange was performed with fresh frozen plasma, which is known to have a relatively high viscosity. 
Delaney-Black and colleagues (1985) evaluated the long-term effects of polycythaemia in 49 newborns, randomly assigned to receive either haemodilution or symptomatic care. At the age of seven polycythaemic infants had a significantly lower school-age performance than a control group. No differences were found between the polycythaemic group treated with haemodilution and the group which only received supportive care. In the latter study, however, haemodilution was performed with fresh frozen plasma at an average age of 10.2 hours after birth.

It appears that polycythaemia is associated with poor developmental outcome, but there is no evidence that haemodilution may prevent a poor outcome. The conclusions of the studies mentioned above must be contenplated carefully, since the time the treatment was started and the way it was done, are disputable.

Technique: the most common treatment for polycythaemia is a partial plasma exchange transfusion which lowers the red cell mass. A catheter is introduced in the umbilical vein and advanced into the inferior vena cava. The procedure consists of withdrawing blood from the patient and infusing plasma in isovolaemic quantities. The whole procedure takes 5-7 steps. A partial plasma exchange transfusion is an invasive procedure and many precautions have to be taken to avoid complications, such as infection, vessel perforation, malposition of the catheter, etc. The required exchange volume is usually calculated from the equation:

$$
\begin{aligned}
& \mathrm{EV}=\mathrm{CV} \times \frac{(\text { Hct measured }- \text { Hct desired })}{\text { Het measured }} \\
& \mathrm{EV}=\text { exchange volume } \\
& \mathrm{CV}=\text { circulating volume }
\end{aligned}
$$

The circulating volume is not known, but a fixed relative circulating volume of $85 \mathrm{ml} / \mathrm{kg}$ body weight is generally used. This is a potential source of error, since circulating volume may differ in different groups of infants and it will strongly depend on unknown amounts of placental transfusion. Since knowledge of circulating volume is of paramount importance for partial plasma exchange transfusion it is discussed in detail in subsection 2.2.

Exchange transfusion is often performed using fresh frozen plasma obtained from adult donors. Since adult plasma has a higher viscosity than neonatal plasma (Buchan, 1984; Linderkamp et al, 1984), it is possible that a concomitant rise in plasma viscosity hampers the beneficial effect of haemodilution. Therefore, some prefer to use a $5 \%$ albumin solution for the exchange procedure.

At present, most clinicians determine the haematocrit in every newborn with high risk for polycythaemia or with suspicious clinical symptoms, and perform a partial plasma exchange transfusion when venous haematocrit is above $65 \%$. 


\subsection{Circulating blood volume}

Blood volume per unit body mass is higher in newborn infants than in adults (Mollison et al, 1950). Blood volume after birth varies widely, presumably because of varying placental transfusion or cord clamping time (Usher et al, 1963). Placental transfusion is accelerated by positioning the infant below the placental level (Sisson et al, 1973), by uterine contractions (Yao et al, 1968) and by expansion of the lungs (Philip and Teng, 1977). Placental transfusion is less pronounced when the infant is positioned above the placental level (Sisson et al, 1973), in case of a tight nuchal cord or acute intrauterine asphyxia (Linderkamp, 1984). Chronic intrauterine hypoxaemia results in prenatal transfusion from placenta to the fetus (Yao and Lind, 1972). The most important factor determining neonatal blood volume is cord clamping time. (Usher et al, 1963; Oh et al, 1966; Yao and Lind, 1974). When cord clamping was delayed for three to five minutes ("late clamped"), the infant's circulating volume, as assessed at 15 minutes of age, was $33 \%$ higher than that of infants whose umbilical cords were clamped directly ("early clamped") after birth (Usher et al, 1963; Yao et al, 1969).

During the first hours after birth a fall in circulating volume is observed in late clamped infants (Oh et al, 1966). This reduction in blood volume is due to a shift of plasma from the intravascular to the extravascular spaces, resulting in an increase of haematocrit (fig 2.1.3.). However, in early clamped infants no changes in circulating blood volume occurred during the same age period.

Several studies reported measurements of relative circulating blood volume values in newborn infants (Usher et al, 1963; Saigal et al, 1972; Brans et al, 1981; Rawlings et al, 1982). The values reported are difficult to compare, since the time of cord clamping, age of the infants at blood sampling, and the methods used to assess blood volume were not standardised. However, there is general agreement that a large pre- or postnatal placental transfusion results in an increased relative circulating volume. This in turn results in an increased plasma shift, which coincides with a postnatal increase in haematocrit. Table 2.2.1 summarises the relative circulating volumes reported by Usher and colleagues (1963) and Saigal and colleagues (1972), using albumin tagged with radio-active iodine. Cord clamping time and time of measurement in their studies are well documented, also indicating haematocrit values. 
table 2.2.1. Relative circulating volume (RCV) and haematocrit $(\mathrm{Hct} ; \%)$ in early clamped and late clamped newborn infants al several times after delivery (data after Usher et al, 1963; Saigal et al, 1972). The 15'values in Saigal's study have been linearly extrapolated from values at $30^{\prime}$ and ot $60^{\prime}$.

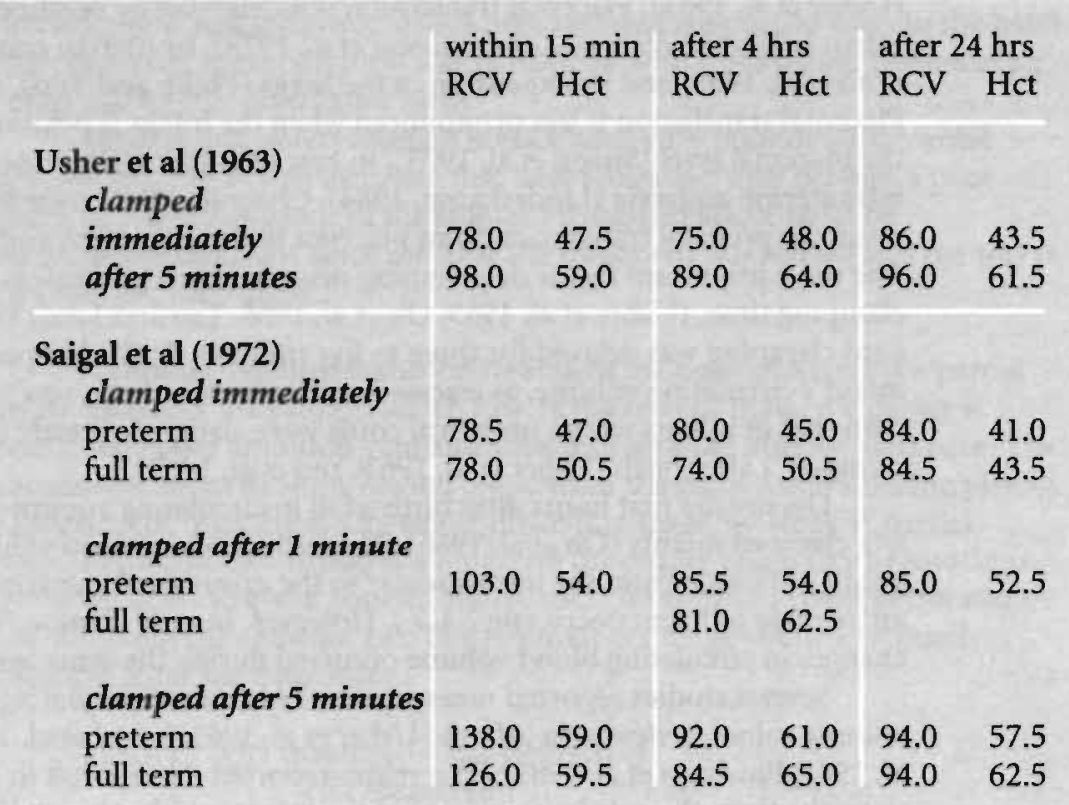

The relative circulating volume at 15 minutes after birth in late clamped infants was higher than in early clamped infants. During the first hours after birth relative circulating volume in late clamped infants decreased, whereas it remained stable in early clamped infants. Although at 24 hours after birth relative circulating volume in late clamped infants was still higher than in early clamped infants, the difference was less than at 15 minutes after birth.

Haematocrit levels at 15 minutes after birth in late clamped infants were higher than in early clamped infants. This suggests that plasma shifts with concomitant increase in haematocrit begin directly after birth. The increase in haematocrit in late clamped infants continued as long as 4 hours after birth. At 24 hours after birth haematocrit levels in late clamped infants were still considerably higher than in early clamped infants. No differences between preterm and full term infants could be noticed.

The positive correlation between haematocrit and circulating volume has also been noted in other studies (Mollison et al, 1950; Brans et al, 1974). Brans and colleagues (1981) reported hypervolaemia in a group of 73 polycythaemic newborn infants. They found a mean relative circulating volume of $100.0 \pm$ $15.8 \mathrm{ml} / \mathrm{kg}$. This finding suggests that placental transfusion might have been the causative factor for polycythaemia. By contrast, Rawlings and colleagues (1982) found no increase in relative circulating volume $(88.4 \pm 23.5 \mathrm{ml} / \mathrm{kg})$ in 164 polycythaemic newborn infants as compared to controls. They did find a highly 
significant negative correlation between relative circulating volume and birth weight, but no correlation was found between haematocrit and relative circulating volume. However, in the studies of Brans and colleagues (1.981) and Rawlings and colleagues (1982) cord clamping time was not standardized, so that the results are difficult to compare.

In order to prevent the occurrence of hypovolaemia, hypervolaemia or polycythaemia in the neonatal period, Linderkamp (1984) recommended the following times for cord clamping:

$\begin{array}{ll}\text { normal term infants } & \text { : between } 30 \text { and } 60 \mathrm{sec} \\ \text { after caesarean section } & : \text { within } 30 \mathrm{sec} \\ \text { chronic fetal distress } & : \text { as soon as possible } \\ \text { acute asphyxia } & : 30 \text { and } 60 \mathrm{sec} \text { after cord stripping } \\ \text { preterm infants }>1500 \mathrm{~g} & : \text { as term infants } \\ \text { preterm infants } \leq 1500 \mathrm{~g} & : \text { after cord stripping } \\ \text { mother with diabetes } & \text { : as soon as possible }\end{array}$

The inter-individual variability in circulating volume in newborn infants should be taken into account, when a partial plasma exchange transfusion is employed in the clinical management of affected infants, since the total exchange volume depends on the circulating volume.

\subsection{Principles and definitions in haemorheology}

"Rheology" originates from the Greek word, rhein, a verb which means to flow. It refers to the science dealing with the flow and deformation of matter. In 1687 Newton wrote in his PRINCIPIA: "The resistance which arises from the lack of slipperiness of the parts of a liquid, is proportional to the velocity with which the parts of a liquid are separated from each other". This "lack of slipperiness" we now call "viscosity".

The viscosity of a fluid, or its resistance to flow, is the measure of friction between laminarly flowing layers of fluid adjacent to and sliding over each other. Fig 2.3.1. shows parallel layers of fluid separated by a distance "dx" and moving in the same direction at different velocities " $\mathrm{vl}$ " and " $\mathrm{v} 2$ ". The velocity gradient between two adjacent fluid layers, $\mathrm{dv} / \mathrm{dx}$, describes the shearing the liquid experiences and is called the shear rate. The force per unit area applied to a fluid layer which produces its movement relative to an adjacent layer is called shear stress and is expressed in Pascal (Pa). In case of blood, because of the small stresses involved, millipascals $(\mathrm{mPa})$ are used rather than pascals. 


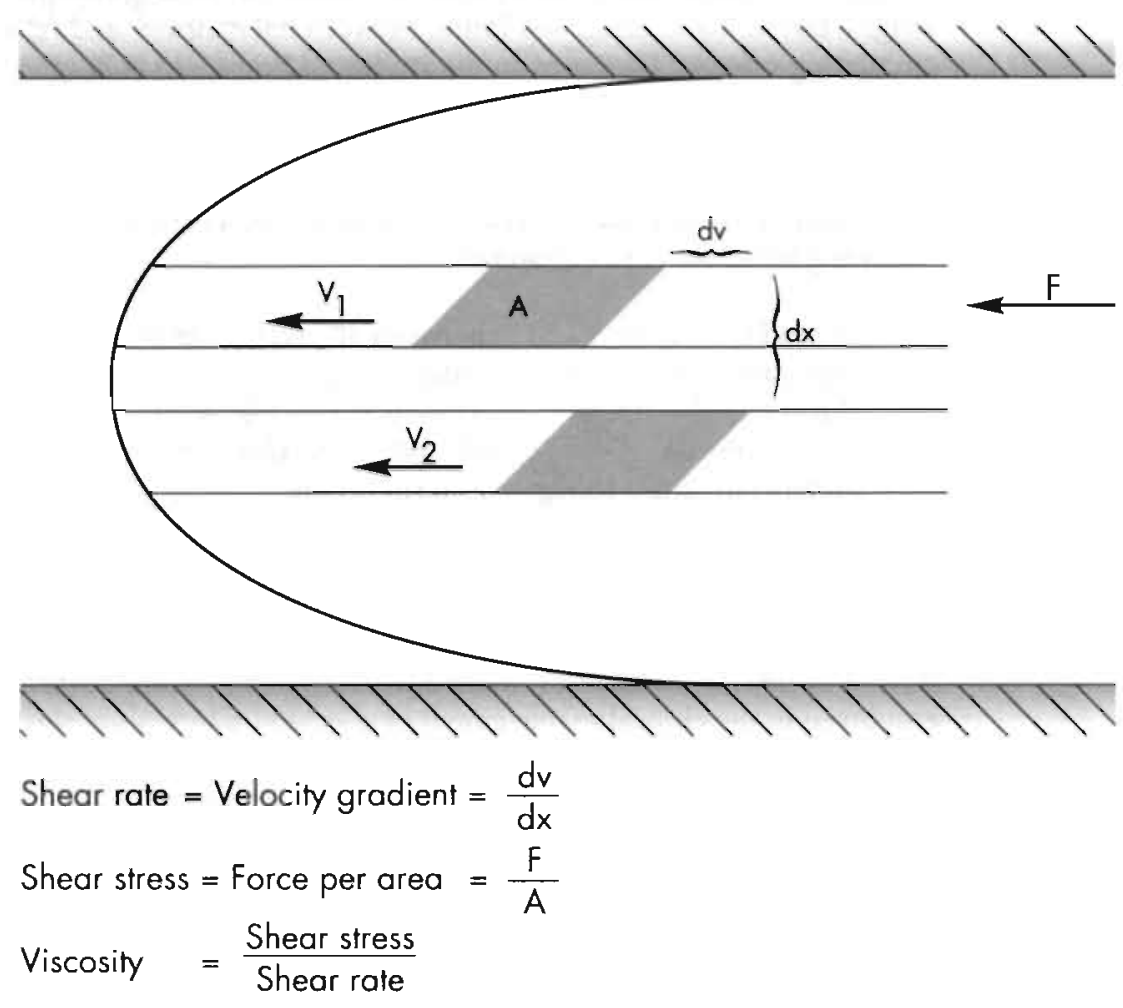

fig. 2.3.1. Cross section of a vessel with schematical presentation of the concept of shear.

The viscosity of a fluid is the proportionality factor between shear stress and shear rate and is defined as shear stress divided by shear rate. Viscosity is expressed as $\mathrm{mPa} / \mathrm{s}^{-1}$ or $\mathrm{mPa}$.s.

Newton assumed that, at a given temperature, the viscosity of a fluid is independent of the rate of shear. This is true for water, most oils and blood plasma. If one wishes to move such a fluid twice as fast, it will take twice as much force to do so. Such liquids with a constant viscosity, are called Newtonian fluids. In contrast, blood does not follow Newton's law. It is a suspension of cells in a fluid containing proteins with different molecular weights. Blood and other non-Newtonian liquids do not have a fixed viscosity. The ratio of shear stress to shear, i.e. viscosity, is not constant, but varies with the shear rate. Figure 2.3.2. represents graphically the distinction between Newtonian fluids (e.g. plasma and water) and a non-Newtonian fluid (blood). 


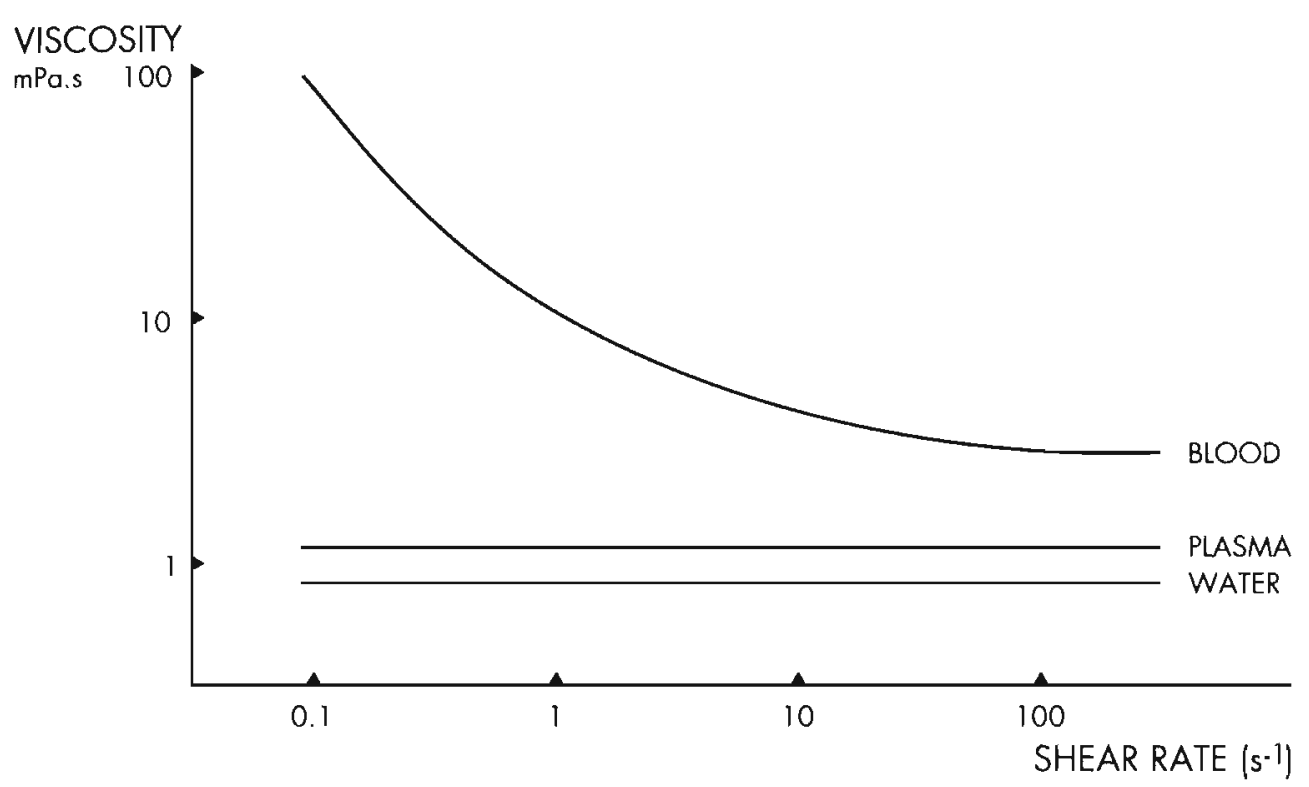

fig. 2.3.2. Distinction between viscosity profiles of Newtonian (water and plasma) and non-Newtonian (blood) fluids.

(With permission obtained from Lowe and Barbanel, 1988)

The straight horizontal line of plasma shows that in case of a Newtonian fluid the ratio between shear stress and shear rate remains constant. In a nonNewtonian fluid the viscosity increases with decreasing shear rate. At high shear rates such a fluid almost behaves like in a Newtonian fluid. In other words, it requires a relatively greater force to make blood move slowly than to make it move rapidly.

Shear rates vary considerably throughout the circulation. In addition, shear rates change depending on haemodynamic conditions. In order to fully characterize the flow behaviour of blood, measurements of blood viscosity have to be carried out at several levels of shear rate. It is generally agreed that the shear rate increases down the arterial tree, reaching its maximum in the arterioles. Shear rates are low in the veins.

In Greek antiquity it was well known that an abnormal composition of the blood might disturb its fluidity. In the 17th century Boerhave was convinced that "abnormal mixture of the elements of blood led to disturbances in circulation and obstruction of organs". A healthy circulation efficiently minimizes the potential flow resistance of blood by ensuring high shear forces or increasing the vascular diameter. In abnormal circumstances, however, vascular compensation may reach its limits. In these cases, manipulation of the different determinants of the flow properties of blood might be a useful addition to current therapeutic strategies. 


\subsection{Determinants of blood viscosity}

In recent years, the emphasis has changed from the study of flow behaviour of bulk blood, to the study of the different determinants which determine the flow properties of blood i.e.

1. Haematocrit

2. Plasma viscosity

3. Red cell aggregation

4. Red cell deformability

\subsection{Haematocrit}

The haematocrit or volume fraction of blood cells (mainly red cells) is by far the most critical determinant of blood viscosity (Rosenkrantz and Oh, 1986 ). Within a haematocrit range of $20 \%$ to $60 \%$ there is a virtually linear increase in blood viscosity with an increase in haematocrit. At haematocrit levels greater than $60 \%$, this relationship does not appear to be valid anymore (Wells et al, 1961; Chien et al, 1966), as then the relationship becomes exponential (figure 2.1.1.). Huber and colleagues (1964) found this curvilinear relationship above a haematocrit level of $50 \%$, whereas Leblond (1987) found a level of $65 \%$ as the critical point beyond which viscosity increased in a nonlinear way.

The increase in viscosity with increasing haematocrit is greater as the shear rate decreases. At low shear rates an increase in haematocrit may have a dramatic effect on blood viscosity, whereas this influence is limited at high shear rates (Wells et al, 1961). Changes in haematocrit strongly influence apparent blood viscosity, mostly in veins, because shear rates are low in these vessels (Driessen et al, 1979; Kiesewetter et al, 1979). The question then arises "what is the optimal haematocrit?" (Voerman and Groeneveld, 1989). If the haematocrit rises above levels of approximately $60 \%$, systemic oxygen transport capacity increases linearly, whereas blood viscosity increases progressively. This implies that at high haematocrit levels the flow rate may be reduced more than the oxygen transport capacity is enhanced, resulting in a reduction of oxygen delivery. This deleterious effect of a high red cell mass may be greater if shear forces are low. Bergqvist (1974) studied the relationship between blood viscosity and shear rate for different haematocrit levels. He found that small changes in haematocrit result in large changes in viscosity at lower shear rates. So, the optimal haematocrit for tissue oxygen delivery under low shear conditions, for example in shock, is lower than under normal circumstances.

Local haematocrit levels vary throughout the vasculature (Gaehtgens, 1980). When red cells approach the microvessels, they tend to migrate towards the centre of the vessel, thereby creating a "cell-poor" plasma layer at the wall and a relatively "cell-rich" central core. The ratio of the "cell-poor" wall layer to the vessel diameter increases as the vessel diameter decreases (Gupta and Seshadri, 1977). Because the flow velocity increases from the vessel wall towards the centre of the vessel, the central "cell-rich" core leaves the vessel more rapidly than the slower flowing plasma-rich layer near the wall. This results in a locally decreased haematocrit. The resulting decrease in viscosity, 
called the Fåhraeus-Lindqvist effect (Fåhraeus and Lindqvist, 1931) can be so pronounced that the blood viscosity in rapidly perfused capillaries is only slightly higher than plasma viscosity (Zilow and Linderkamp, 1989). Therefore, since haematocrit differs along the vascular tree, it is important to mention the vessel from which a blood sample is taken. Usually, the haematocrit is determined in a blood sample obtained from freely flowing peripheral venous blood (International Committee for Standardisation in Haematology, 1984). If this haematocrit is used to represent total body haematocrit, a correction factor of 0.87 is generally used (Mollison et al, 1950; Usher and Lind, 1965). Studies on red cell mass with ${ }^{32} \mathrm{P}$ (Mollison et al, 1950) and ${ }^{51} \mathrm{Cr}$ labeled red cells (Huber et al, 1964) demonstrated that the real red cell mass increased exponentially when venous haematocrit exceeded $55 \%$. This finding emphasizes that the "total body haematocrit" and its influence on blood viscosity might be higher than expected when the venous haematocrit exceeds $55 \%$.

There is ample evidence that in newborn infants the haematocrit as measured in blood obtained from a heel stick may be considerably higher than in freely flowing peripheral venous blood (Oh and Lind 1966, Linderkamp et al, 1977b). An explanation might be a sludging of red cells in the venules and small veins from which a major part of the "heel stick blood" is derived, possible due to a lower $\mathrm{pH}$ in these vessels. The ratio between "heel stick blood" and venous blood in newborn infants is $1.09 \pm 0.06$ (Linderkamp et al, 1977b). This ratio is haematocrit dependent; it increases in low haematocrit ranges and decreases in high haematocrit ranges.

It has long been known that infants have higher haematocrit levels than adults (Oski, 1987). Rampling and colleagues (1989) compared blood obtained by venesection from healthy adults with blood obtained from the umbilical vein of healthy neonates. For preterm infants they found a mean haematocrit of $48 \% \pm 8 \%$ (SD), for term infants $50 \% \pm 6 \%$, for male adults $44 \% \pm 3 \%$, and for female adults $41 \% \pm 2 \%$. Reinhart and colleagues (1985) compared haematocrit levels in 10 pairs of mothers and their newborns. They also found higher haematocrit levels in the newborn infants $(47 \% \pm 5 \%)$ than in maternal blood (36\% $\pm 1 \%)$. Buchan (1984) studied haematocrit throughout pregnancy and compared haematocrit levels in non- pregnant and pregnant women, and their full term infants. Haematocrit levels were $45 \% \pm 3 \%, 37 \% \pm 3 \%$ and $49 \%$ $\pm 4 \%$, respectively. The physiological haemodilution of pregnancy is due to the higher increase in plasma volume than the increase in red cell volume with advancing gestation. The differences in haematocrit levels between newborn infants and adults are even more impressive when we take into account that blood from the umbilical vein represents "central venous haematocrit", which is generally lower than peripheral venous haematocrit (Ramamurthy and Brans, 1981).

The higher red cell content in fetal blood contributes to the physiological adaptation of the fetus to maintain sufficient oxygen supply in circumstances of relative hypoxaemia. As discussed in detail previously (subsection 2.2), haematocrit levels vary considerably during the first 24 hours of life due to the amount of plasma shift from the intravascular compartment to the extravascular space. Haematocrit levels increase after birth and reach their maximal level around 3 hours after delivery. 


\subsubsection{Plasma viscosity}

Plasma viscosity is an often neglected determinant of blood flow in vivo. The clinical significance of plasma viscosity has been emphasized by several authors (Harkness, 1971; Dintenfass and Kammer, 1977; Jung et al, 1986). As the diameter of the smaller blood vessels decreases, haematocrit decreases as well, reaching an average value of only 0.10 in the capillaries (Lipowsky et al, 1978). In microvessels with a low haematocrit, changes in plasma viscosity might become an important determinant of flow velocity.

Plasma viscosity depends on the plasma protein profile and the temperature. The viscosity of normal human plasma decreases almost linearly by $2.4 \%$ with each additional degree Celsius within a temperature range of 20 to $40^{\circ}$ Celsius (Philips and Harkness, 1976). The International Committee for Standardisation in Haematology (1984) recommends $37^{\circ}$ Celsius as a standard working temperature.

Because plasma can be considered a Newtonian fluid, plasma viscosity is independent of the shear rate. Due to great individual differences in the protein profile, the correlation between plasma viscosity and the total protein content is rather poor. The effect of a particular protein on plasma viscosity increases with its concentration, its size and its asymmetry (Harkness, 1971). In normal adult plasma albumin contributes for only $36 \%$ to plasma viscosity, although it comprises $60 \%$ of the total protein weight. Serum globulins have a greater effect, especially the larger $\alpha_{2}$-macroglobulins and the heavy-weight, anisometric immunoglobulins. Fibrinogen contributes for $22 \%$, despite the fact that it accounts for only $4 \%$ of plasma protein weight (Mayer et al, 1966). The marked effect of fibrinogen on plasma viscosity is due to its high molecular weight (mol wt 340.000) and elongated shape. Most authors (Philips and Harkness, 1976; Mayer et al, 1966) reported that plasma viscosity is strongly correlated with fibrinogen levels, whereas Dintenfass and Kammer (1977) found that immunoglobulins play a more important role. However, an accurate calculation of plasma viscosity, taking into account the contribution of the different proteins, has not been described. Measurement of plasma viscosity provides an useful, non-specific index of "disease", believed to be superior to that provided by the Erythrocyte Sedimentation Rate. An abnormal plasma viscosity is a strong evidence for the presence of a disease which is accompanied by changes in plasma protein composition (for example infectious diseases).

Measurement of plasma viscosity can be performed in a simple tubeviscometer. When a Newtonian liquid flows steadily through a tube whose diameter and lenght are known, the relationship between driving pressure and flow rate can be used to calculate the liquid's viscosity with the HagenPoiseuille equation:

$$
\mathrm{Q}=\frac{\pi \times \mathrm{r}^{4} \times \Delta \mathrm{P}}{8 \times \eta \times l}
$$

where $Q$ is the volume flow rate, $\Delta P$ is the pressure drop, $\eta$ is the viscosity and $r$ and $l$ are the tube radius and length, respectively. In a simple capillary viscometer the time for the plasma to pass between two markers reflects its viscosity. 
At a given haematocrit and for all shear rates, whole blood viscosity of the human adult is higher than that of the newborn infant. This difference is caused by the plasma viscosity which is more elevated in adults than in neonates (table 2.4.1.).

The wide ranges in plasma viscosity as found in the different studies are probably due to the different methods (rotational vs capillary) and the different apparatus used.

table 2.4. 1. Plasma viscosity levels in healthy adults and normal term infanis obtained with different methods and in different studies.

\begin{tabular}{|c|c|c|c|}
\hline & \multicolumn{3}{|c|}{ Plasma Viscosity (mPa.s) } \\
\hline & Method & Adults & Term newborns \\
\hline Dintenfass and & capillary & & \\
\hline Kammer, 1977 & viscometer & $1.26 \pm 0.12$ & 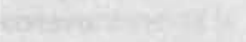 \\
\hline Foley et al & Contraves & 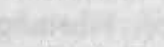 & \\
\hline 1978 & rotational & $1.86 \pm 0.47$ & $1.12 \pm 0.19$ \\
\hline Riopel et al & Wells & & \\
\hline 1982 & rotational & $1.36 \pm 0.10$ & $1.18 \pm 0.17$ \\
\hline Linderkamp & Wells & 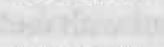 & \\
\hline 1984 & rotational & $1.46 \pm 0.11$ & $1.25 \pm 0.09$ \\
\hline Buchan & Deer & & \\
\hline 1984 & rotational & $1.58 \pm 0.08$ & $1.44 \pm 0.28$ \\
\hline Reinhart et al & Couette & & \\
\hline 1985 & rotational & $1.30 \pm 0.04$ & $1.08 \pm 0.05$ \\
\hline Jung et al & Myrenne & & \\
\hline 1986 & capillary & $1.24 \pm 0.05$ & \\
\hline Rampling et al & Contraves & & \\
\hline $1989^{\circ}$ & rotational & $1.34 \pm 0.08$ & $1.24 \pm 0.13$ \\
\hline
\end{tabular}

Buchan (1984) and Linderkamp and colleagues (1984) studied neonatal plasma viscosity at different gestational ages. In both studies a progressive rise in plasma viscosity was found with advancing gestational age. A positive correlation between plasma viscosity and fibrinogen with advancing pregnancies was described.

Since plasma viscosity is higher in adults than in neonates, especially in preterm infants, transfusions of plasma from adult donors to preterm infants might increase the plasma viscosity of these infants. This could implicate that a higher arteriolar-venular pressure difference will be required to maintain the same capillary perfusion. This might increase the risk of cerebral bleeding or ischaemia in these high risk infants. 


\subsubsection{Red cell aggregation}

Although it has been known for a long time that under certain circumstances red cells attract to one another, Lister (1858) was the first to describe the proces of red cell aggregation. In his description he states "... red corpuscles are seen to become applied to one another by their flat surfaces, so as to form long cylindrical masses like piles of money; and the terminal corpuscles of each 'rouleau' adhering to other rouleaux, a network is produced with intervals of coulerless liquor sanguinis". Făhraeus (1929) observed that the tendency of rouleaux-formation was shear dependent. When stress is applied, the continous network of rouleaux is broken down into smaller rouleaux which gradually become smaller and smaller until, at sufficiently high shear forces, all rouleaux disperse into discrete cells. Under normal circumstances the tendency to aggregate will be minimal in microvessels because of the high shear forces. However, aggregation may become important when the driving pressures become low, for example in shock.

Red cell aggregation results from the capacity of large plasma proteins, especially fibrinogen, to forme bridges between adjacent cells. These bridges overcome the mutual repulsion between cells due to the negative charges on their surfaces. Fibrinogen is generally accepted as the most active red cell aggregating agent (Chien et al, 1970). It is a large, elongated molecule and is therefore quite effective to bridge between cells at a distance where the repulsive effects are small. Rampling and Whittingstall (1986) have shown that only proteins with molecular weights of 150.000 or more show aggregating abilities. Besides fibrinogen, macromolecular proteins like immunoglobulins and $\alpha_{2}$-macro-globulins also have aggregating abilities. As mentioned in subsection 2.4.2, these long molecules also determine plasma viscosity. This dual rheological characteristic of proteins causes the viscosity of whole blood to be greater than the sum of plasma viscosity and red cell number in protein-free saline.

Red cell aggregates disturb the flow streamlines in plasma; hence, red cell aggregation is largely responsible for the increase in whole blood viscosity at low shear rates. Under pathological conditions red cell aggregation may occur in different areas of the circulation. It is assumed that red cell aggregation has a negative effect on flow.

In newborn infants, the rate and final extent of red cell aggregation are lower than in adults (Gaehtgens, 1977). Linderkamp and colleagues (1984) studied red cell aggregation in neonates with gestational ages ranging from 24 to 41 weeks and in adults. They concluded that 1) the rate and final extent of red cell aggregation is markedly lower in preterm infants than in full term infants 2) the extent of red cell aggregation is directly associated with fibrinogen levels 3 ) red cell aggregation of neonatal red cells may be enhanced by adding adult plasma. Thus, it is not the specific properties of neonatal red cells that affect aggregation, but the composition of the plasma. In very small preterm infants, red cell aggregation did not even occur after stasis of the blood, whereas in term neonates aggregates were formed within a few seconds. An explanation might be that fibrinogen in preterm infants contains a sialic acid which inhibits the bridging function.

The data mentioned above indicate that at a given haematocrit whole blood viscosity in preterm infants is lower than in term infants. The latter, in turn have a lower viscosity than adults, as is illustrated in table 2.4.1. 


\subsubsection{Red cell deformability}

Human red cells have an unstressed diameter of approximately $7.5 \mu \mathrm{m}$, whereas nutritive capillaries have diameters ranging from 3 to $5 \mu \mathrm{m}$

(Kiesewetter et al, 1979). The ability of the red cell to undergo deformation is of paramount importance for adequate perfusion of these capillaries. The viscoelasticity of the membrane, the low cytoplasmatic viscosity, the high ratio of surface area to cell volume, and the property of the cell membrane to rotate around the interior (tank treading) contribute to a high intrinsic flexibility and deformability (Schmid-Schönbein, 1988). A multiplicity of techniques and instruments are available to assess red cell deformability. Unfortunately, it is difficult to obtain comparative and reproducible data.

When designing studies for the measurement of red cell deformability it is necessary to be aware of the fact that the properties which may be present in vivo are different from those in vitro.

Although the passage time of individual red cells through a single-pore membrane seems to be the most reliable method for measuring red cell deformability (Kiesewetter et al, 1981b), it is at present not routinely used. With the instruments used today a combination of various measurements is required to provide reliable data. The procedures are time consuming, do not yield reproducible data, require large quantities of blood and are not yet useful for routine clinical purposes in neonatology.

Neonatal red cells are bigger, age faster and have a shorter lifespan than adult cells. It was thought that these characteristics of neonatal red cells might cause less deformability. However, Linderkamp and colleagues (1982) found no differences in deformability between neonatal and adult red cells. A reason for this might be that neonatal red cells have an increased membrane elasticity, resulting in optimal flow conditions in narrow tubes (Zilow and Linderkamp, 1989). 


\section{SURVEY OF METHODS AND ASSESSMENTS USED IN THIS STUDY}

This chapter gives a brict survey of the assessments and methods used in this thesis. For detailed information the reader is referred to the various chapters.

\subsection{Haematocrit}

In all newborn infants admitted to the neonatal ward of the Academic Hospital Mastricht, hacmatocrit was routinely determined at 3 hours after birth from a capillary blood sample obtained by heel stick. Subsequently a venous sample was taken in al] infants with a capillary haematocrit of more than $70 \%$ and in infants with capillary haematocrit of more than $65 \%$ and showing clinical symptoms. These venous blood samples were obtained from a vein in the elbow or on the back of the hand and collected in $50 \mu$ heparinised glass tubes. Venous occlusion or squeezing was avoided. Because haematocrit determined from heel stick samples is rather unreliable, it was only used for screening. Since capillary haematocrit consistently exceeds venous haematocrit (Oh and Lind, 1966; Kuenzel and Wolf, 1970) no potential patients for exchange transfusion were missed.

To assess haematocrit, a blood sample was spinned at $6000 \mathrm{rpm}$ during 4 minutes. Haematocrit values were obtained in duplicate. A Hawksley microhaematocrit reader was used for the actual measurement. When the difference between both haematocrit determinations was 1 vol $\%$ the highest value was chosen to represent venous haematocrit. When the difference was 2 vol\% the mean value was chosen and when the difference was 3 vol\% or more haematocrit determination was repeated. We did not correct for plasma trapped in the packed cell mass. The trapped plasma accounts probably for only about $2 \%$ of total plasma (Linderkamp et al, 1977a). It is always present and can not be considered as a potential source of error.

\subsection{Blood flow velocity and red cell transport}

When ultrasound is reflected from moving structures (for example blood cells), the reflected ultrasound has another frequency than the emitted one. The difference between emitted and reflected ultrasound frequency is called the Doppler shift. The frequency shift depends on the speed of ultrasound in the tissue, the frequency of the emitted ultrasound, and the angle between the emitted ultrasound beam and the direction of flow (see figure 3.2.1.). 


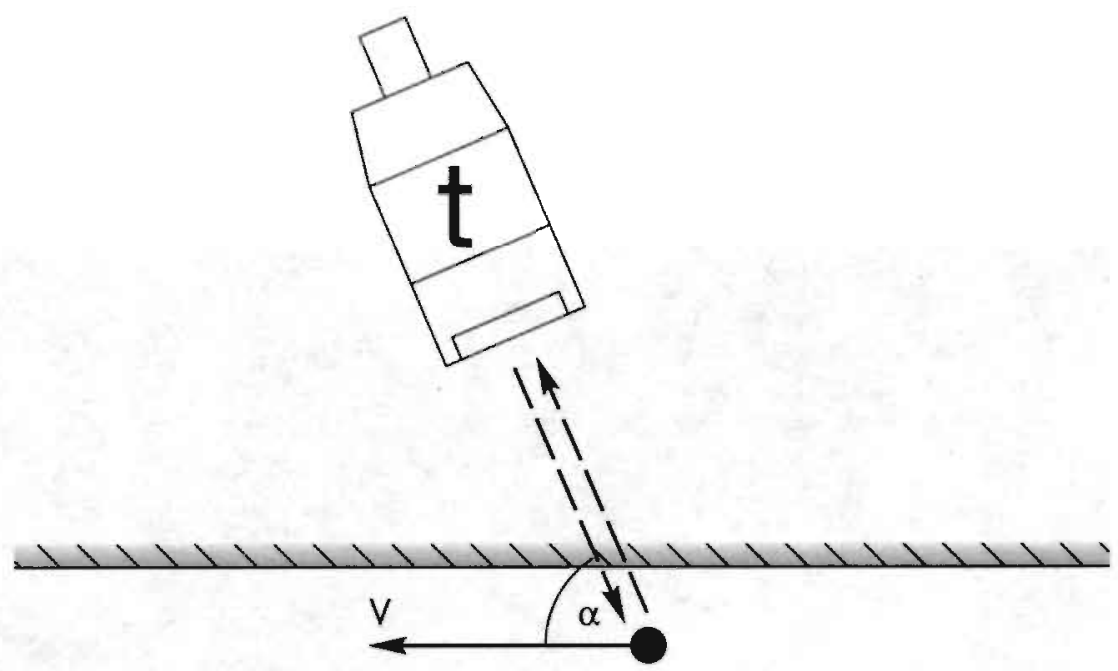

fig. 3.2.1. Schematic cross section of transducer $(t)$ and ultrasound beam for a continuous wave Doppler system.

$v=$ local blood flow velocity

$\alpha=$ insonation angle

Blood flow velocity in a blood vessel may be calculated according to the formula

velocity $=\frac{\text { frequency shift } \times \mathrm{c}}{2 \times \mathrm{f} \times \cos \alpha}$

$c=$ speed of ultrasound in tissue $(1500 \mathrm{~cm} / \mathrm{s})$

$\mathrm{f}=$ frequency of ultrasound

$\alpha=$ angle between ultrasound beam and flow direction (Doppler angle)

The speed of ultrasound in soft human tissues is rather constant. In our study the Doppler angle between the probe and the skin above the vessel was approximately $15^{\circ}$ which means that maximal flow velocities were obtained.

Non-invasive determination of blood flow velocity in newborn infants by means of Continuous Wave Doppler ultrasound (Bada et al, 1979) is a widely employed technique. Although Continuous Wave Doppler may obtain frequency shifts from all vessels within the ultrasound beam and not only from the single vessel of interest, it has proven to be a reliable technique for serial determinations (Volpe et al, 1982).

In the present study blood flow velocity was obtained using a bidirectional Continuous Wave Doppler instrument (Medasonics D-10). A $5 \mathrm{MHz}$ pencilprobe transducer was used. The transducer contained two piezo- 
electrical crystals, one for continuous emission of utrasound and one for reception of backscattered signals. A zero-crossings detector was employed to assess shifts in Doppler frequency between emitted and received ultrasound frequency. Doppler frequency shifts were determined relative to a known internal calibration of $1 \mathrm{KHz}$. A built-in $200 \mathrm{~Hz}$ high-pass filter was used to remove vessel wall movements.

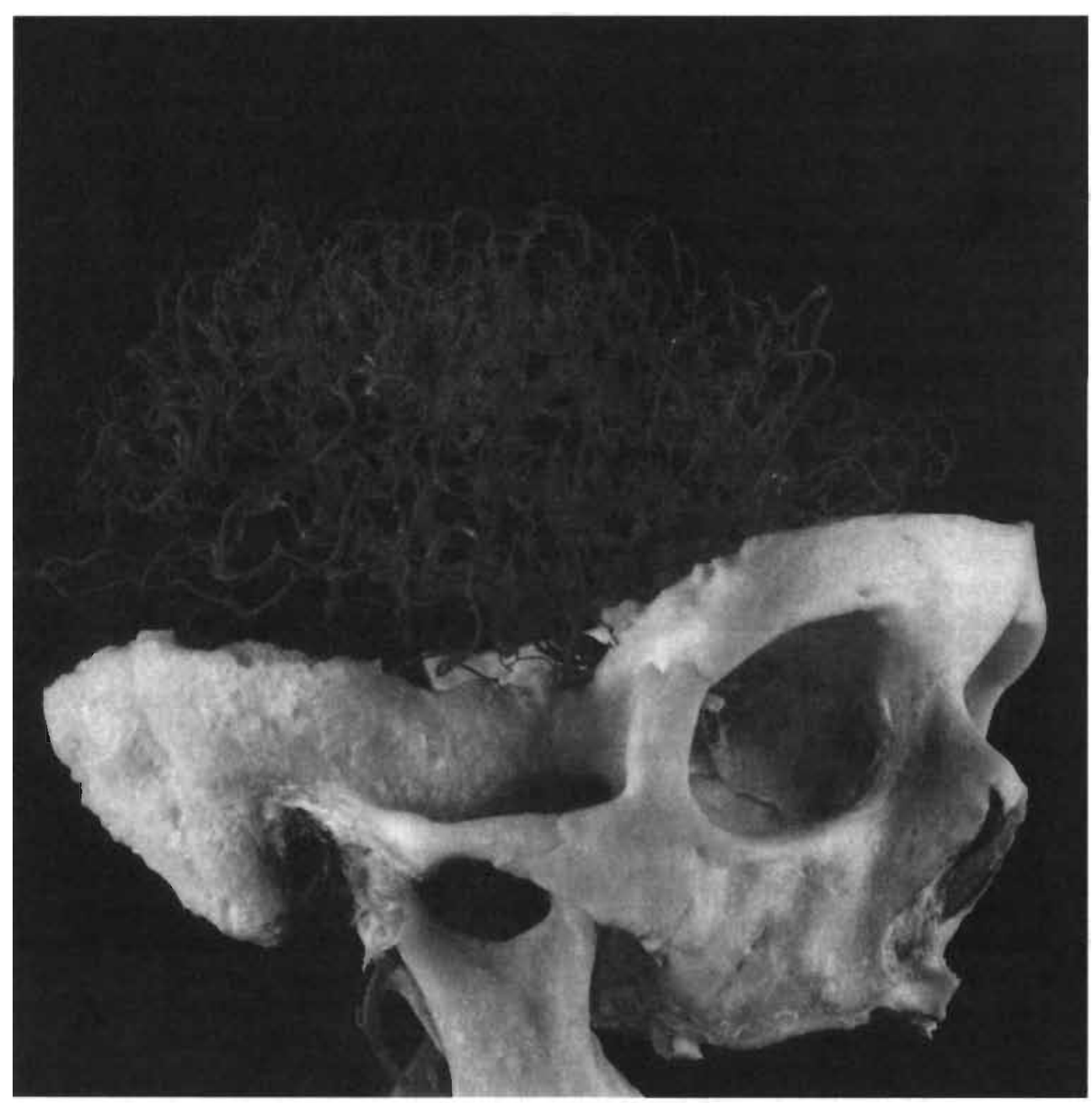

fig. 3.2.2. Schematic model of cerebral arterial vascular tree. (With permission of the Department of Anatomy/Embryology, RL) 
Velocity signals were recorded from both anterior cerebral arteries, the left mid cerebral artery, the left brachial artery, and the left femoral artery. The anterior cerebral arteries were insonated by placing the transducer near the midline of the anterior fontanel and by adjusting the position slightly into the direction of the ipsilateral artery. The mid cerebral artery was insonated through the coronal suture by placing the probe at the level of the helix of the ear and adjusting it slightly in upward direction. When using the Continuous Wave Doppler technique, signals will be obtained from all vesse]s within the penetration depth of the emitted ultrasound, and therefore it is possible that more cerebral vessels were insonated by the ultrasound beam. However, from a replica of the cerebral arterial system (see figure 3.2.2.) we could exclude that no other major vessels contributed to the signals.

Subsequently Doppler signals were optimized through auditory and visual judgment and the velocity waveforms were recorded on a strip-chart recorder. An example obtained from the anterior cerebral artery is shown in figure 3.2.3..

Eight consecutive waveforms in a recording were analysed to obtain peaksystolic flow velocity (PSFV), end-diastolic flow velocity (EDFV), mean flow velocity (expressed as area under the curve per minute (AUC)), the Pulsatility Index (expressed as (PSFV-EDFV) / AUC) and the Pulsatility Index (PI-Pourc) according to Pourcelot [ PI = (PSFV-EDFV) / PSFV ] (1974). As an index of red cell transport capacity the product of mean flow velocity and haematocrit (AUC $\times$ Hct/100) was calculated.

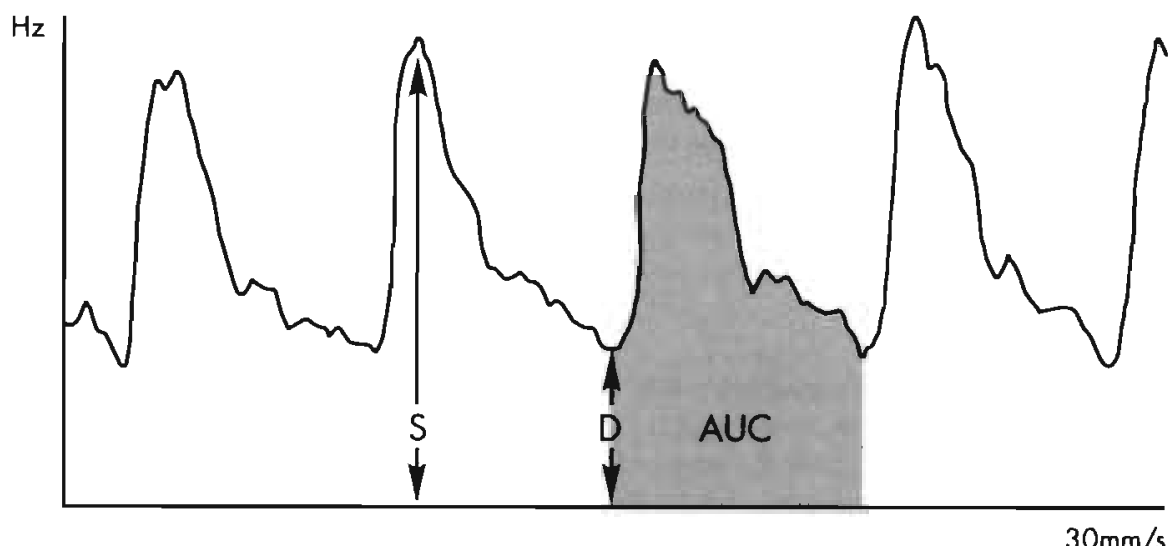

Fig.3.2.3. Example of Doppler flow velocity pattern in the anterior cerebral artery of o normocythaemic term infont.

$\mathrm{S} \quad=$ peak-systolic flow velocity (PSFV)

$\mathrm{D}=$ end-diastolic Flow velocity (EDFV)

$A \cup C=$ area under the curve, representing mean flow velocity 


\subsection{Partial plasma exchange transfusion}

A partial plasma exchange transfusion was performed in all newborn infants with peripheral venous haematocrit values $\geq 70 \%$, or when infants with haematocrit values between $65 \%$ and $70 \%$ had clinical symptoms probably due to impaired blood perfusion. The procedure was performed under sterile conditions. The attending physician wore sterile gloves, gown, a mask and a cap. The umbilical region was cleaned with iodine and chlorhexidine and the infant was covered with sterile clothes. Partial plasma exchange transfusion is a routine procedure and for the purpose of the present study no additional proceedings were necessary. A $5 \mathrm{~mm}$ Argyle catheter was placed in the umbilical vein and advanced into the inferior vena cava. Plasma containing 5\% albumin (Dutch Blood Transfusion Service) was chosen as exchange solution. The exchange volume was determined from the equation Vexch $=\mathrm{CV} \times[$ Hct obs - Hct des] $/$ Hct obs as mentioned in chapter 2 at the end of subsection 2.1. Circulating volume was calculated assuming a relative CV of $85 \mathrm{ml} / \mathrm{kg}$ body weight (Shohat et al, 1984). In the second part of the study a relative CV of $106 \mathrm{ml} / \mathrm{kg}$ was chosen for SGA infants (see chapter 6). The desired haematocrit level was $58 \%$.

In infants with a birth weight $<2000 \mathrm{~g}$ the procedure was performed using syringes of $5 \mathrm{ml}$, and in infants $>2000 \mathrm{~g}$ with syringes of $10 \mathrm{ml}$. Due to the dead space of $0.7 \mathrm{ml}$ in the exchange assembly the effective exchange volume for every step was $4.3 \mathrm{ml}$ and $9.3 \mathrm{ml}$, respectively. Withdrawal of blood and injection of plasma was done slowly to prevent abrupt changes in blood volume and blood pressure. After injection of plasma 1 minute was allowed for mixing before the next withdrawal was started. A central venous blood sample was taken immediately prior to the exchange procedure and after each exchange step in order to assess the central venous haematocrit and evaluate the exchange procedure. 


\subsection{Circulating blood volume}

Circulating blood volume can be determined by means of several methods. All these methods are based on the indicator dilution technique. Dilution techniques are fairly accurate, but are invasive. The Evans blue dye dilution method (Senn and Karlson, 1958) includes extraction procedures which are time consuming and require large amounts of blood. Tagging of autologous red cells with ${ }^{51} \mathrm{Cr}$ (Linderkamp et al, 1977a) is an accurate method, but it is time consuming and yields relatively high doses of absorbed radiation. The use of radioionidated human serum albumin is an easy and rapid method to determine the circulating blood volume, but with possible risks due to radiation exposure. Methods based on indicator dilution techniques are not applicable in routine clinical practice. In our method for determination of circulating volume in polycythaemic newborn infants the blood withdrawn during the exchange procedure was used. The routine clinical procedure was not changed for the purpose of the present study.

When a partial exchange transfusion has to be performed it is necessary to know the circulating blood volume in order to calculate the exchange volume in polycythaemic newborn infants. By assessing the haematocrit at the end of the exchange procedure and comparing this value with the initial haematocrit, one obtains a measure of the actual circulating blood volume. Subsequently, the procedure may be extended to actually reach the desired haematocrit of $58 \%$. For each exchange step the circulating blood volume can, in principle, be calculated from the equation

$$
\operatorname{Hct}(\mathrm{end})=\frac{(\mathrm{CV}-\mathrm{EV}) \times \mathrm{Hct}(0)}{\mathrm{CV}} \quad \text { or } \quad \mathrm{CV}=\frac{\mathrm{EV} \times \mathrm{Hct}(0)}{\operatorname{Hct}(0)-\operatorname{Hct}(\mathrm{end})}
$$

$$
\begin{aligned}
& \operatorname{Hct}(\text { end })=\text { haematocrit after the exchange step } \\
& \mathrm{Hct}(0)=\text { the initial haematocrit } \\
& \mathrm{CV} \quad=\text { circulating blood volume } \\
& \mathrm{EV}
\end{aligned}
$$

By measuring the haematocrit after every exchange step during the exchange procedure (see section 3.3 ) and taking into account the true exchange volume, the circulating blood volume can be recalculated over and over. Applying regression to this set of data provides a more accurate value for the circulating blood volume. A detailed description of the determination of circulating blood volume is presented in chapter 6 . 


\subsection{Plasma viscosity}

Plasma viscosity was determined with a capillary tube viscometer. The principle of measurement is based on well known rheological properties of Newtonian fluids. Viscosity is assessed using the time required for the fluid to pass two markers. If a Newtonian fluid flows with a constant pressure drop $(\Delta \mathrm{P})$ through a tube of known length and diameter, and if the volume flow rate is known, the viscosity of the fluid is determined by the Hagen-Poiseuille equation, as mentioned in chapter 2 , subsection 2.4.2. A capillary tube plasma viscometer has the advantage that it requires only small volumes of test fluid. In addition, it has an acceptable degree of accuracy (Jung et al, 1985), is relatively cheap and the assessments require a short period of time. Figure 3.5.1. shows the capillary viscometer used for plasma viscosity determinations in the present study.

A disposible polyurethane tube with constant inner diameter of $0.8 \mathrm{~mm}$ is connected to a plastic syringe filled with the test fluid. The test fluid is then automatically injected into the tube to the level of a photo electric detection mark. Subsequently, the test fluid is thermostatically warmed to $37^{\circ} \mathrm{C}$. The tube is then automatically cut after which the fluid starts to flow by gravity. The time that it takes the fluid to pass 2 other detection markers is measured and used to calculate its viscosity. The procedure is controlled by a microprocessor. Prior to the experiments the apparatus is calibrated by means of standard solutions with known viscosity. Plasma viscosity values obtained by this method are similar to values obtained by Dintenfass and Kammer (1977) and Heilman and colleagues (1981).

In the present study plasma was frozen at $-30^{\circ} \mathrm{C}$ and stored for a period of 2-3 months prior to measurements. In a pilot study we compared plasma viscosity values measured immediately after taking the sample and after freezing and thawing. No differences were found in viscosity values and we concluded that freezing had no appreciable influence on plasma viscosity. 


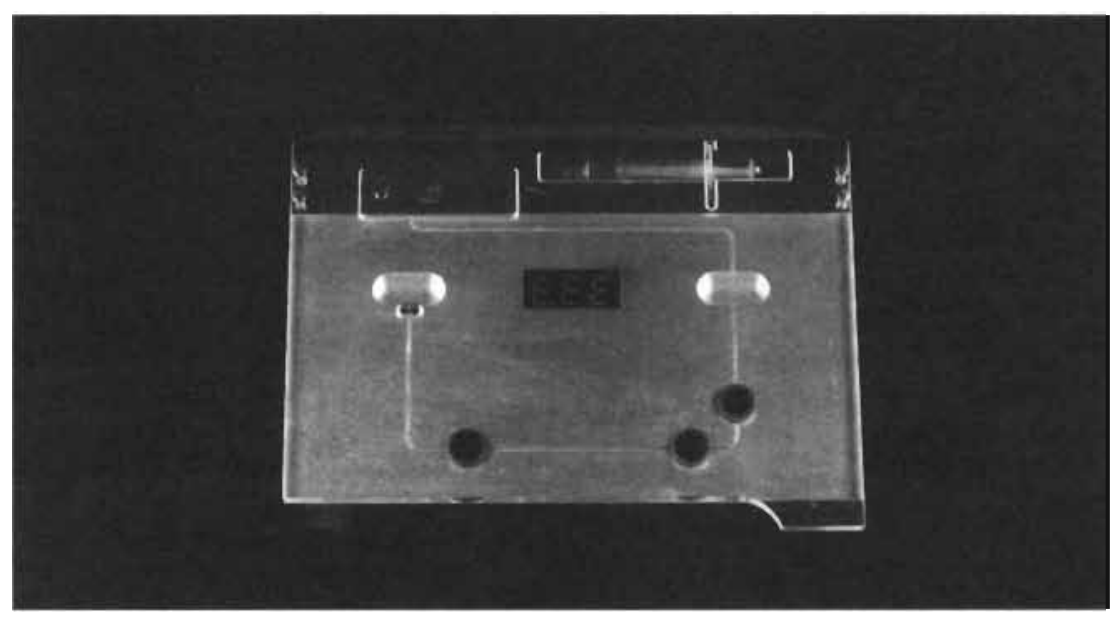

fig. 3.5.1. Capillary plasma viscometer (type Myrenne) 


\section{EFFECTS OF PARTIAL PLASMA EXCHANGE TRANSFUSION ON CEREBRAL BLOOD FLOW VELOCITY IN POLYCYTHAEMIC PRETERM, TERM AND SMALL-FOR-DATE NEWBORN INFANTS}

W.J. Maertzdorf (1), G.J. Tangelder (2), D.W. Slaaf (3), and C.E. Blanco (1)

Academic Hospital Maastricht, Departments of Neonatology (1), Physiology (2), and Biophysics (3), University of Limburg, Maastricht, The Netherlands

Eur. J. Pediatr. (1989) 148: 774-778 
Isovolemic haemodilution with plasma was performed in 36 newborn infants with polycythaemia at 3 hours after birth. Continuous Wave Doppler ultrasonography was used to study the short and longer term influence of partial plasma exchange transfusion on cerebral blood flow velocity in both the anterior cerebral and mid cerebral arterial system up to 24 hours after haemodilution. The study group consisted of 11 preterm infants, 13 small-forgestational age term infants, and 12 appropiate-for-gestational age term infants. After exchange transfusion peripheral venous haematocrit decreased from $72.5 \%$ (range $67-80 \%$ ) to $59.4 \%$ (range $53-68 \%$ ). In all experimental groups cerebral blood flow velocity before exchange transfusion was significantly lower (18-44\%) than in 15 matched controls and increased to control levels after exchange transfusion. Cerebral blood flow velocity improved most in preterm infants. After the transfusion the values were not different from the age-, weight-, sex- and parity-matched control groups and they remained at this level during the next 24 hours. No differences could be found between the anterior and mid-cerebral arterial system. When clinical symptoms were present, they subsided in all infants. In conclusion, partial plasma exchange transfusion has a favourable effect for at least 24 hours on cerebral blood flow velocity in newborn infants with polycythaemia.

\section{INTRODUCTION}

Polycythaemia occurs in $2-5 \%$ of all newborn infants. The groups at risk are small-for-gestational age infants, infants of diabetic mothers, and infants in whom cord clamping has been delayed. During the first hours after birth plasma shifts from the intravascular to the extravascular spaces. This causes an increase in haematocrit (Hct), reaching its maximum level around 3 hours after birth (Ramamurthy and Berlanga, 1987). At Hct levels above 65\%, blood viscosity increases exponentially (Shohat et al, 1984a). Polycythaemia and increased blood viscosity have been shown to decrease cerebral blood flow velocity (Humphrey et al, 1979; Humphrey, 1981; Younkin et al, 1987). However, it is still inconclusive whether or not partial plasma exchange transfusion (PPET) is indicated to improve cerebral blood flow velocity (van der Elst et al, 1980; Goldberg et al, 1982; Hest and Ulrich, 1982; Black ett al, 1985).

At present, it is possible to obtain information on cerebral blood flow velocity through non-invasive Doppler ultrasonography (Volpe et al, 1982; Gray et al, 1983; Hansen et al, 1983). Rosenkrantz and colleagues (1986) studied blood flow velocities in the anterior cerebral arteries in a group of term polycythaemic newborn infants and showed that the reduction in Het by PPET resulted in an increase in cerebral blood flow velocity (CBFV). However, the postnatal ages when the infants were studied varied and CBFV after haemodiluton was measured only once at four to six hours after the exchange procedure. The aims of our study were 1) to study the effects of PPET on CBFV up to 24 hours after the procedure in newborn infants who were diagnosed as having polycythaemia at three hours after birth,2) to compare the effects on CBFV in both the anterior and mid-cerebral artery and 3 ) to compare in this respect appropriate-for-gestational age (AGA) term infants with preterm infants and small-for-gestational age (SGA) term infants. 


\section{PATIENTS AND METHODS.}

Thirty-six newborn infants ( 17 boys and 19 girls; $2.6 \%$ of total number of deliveries) admitted to our neonatal unit were subjected to partial plasma exchange transfusion (PPET group). Table 4.1. summarises the gestational ages, birth weights and peripheral venous haematocrits of 11 polycythaemic preterm infants, 13 small-for-gestational age term infants, and 12 appropriatefor-gestational age term infants. None of these infants were born from a mother with diabetes mellitus.

table 4.1. Gestational age, birth weight and peripheral venous haematocrit in polycythaemic preterm, small-for-gestational age (SGA) and appropriate-forgestational age (AGA) term infants. Values are presented as mean $\pm S D$. Number after the period in gestational age refer to the day in a week.

$\begin{array}{llll} & \begin{array}{l}\text { Gestational age } \\ \text { (weeks) }\end{array} & \begin{array}{l}\text { Birth weight } \\ (\mathrm{g})\end{array} & \begin{array}{l}\text { Haematocrit } \\ (\%)\end{array} \\ \text { preterm }(\mathrm{n}=11) & 34.6 \pm 1.6 & 2210 \pm 550 & 72.5 \pm 2.6 \\ \mathrm{SGA}(\mathrm{n}=13) & 38.6 \pm 1.2 & 2290 \pm 190 & 74.1 \pm 3.9 \\ \mathrm{AGA}(\mathrm{n}=12) & 40.1 \pm 1.4 & 3370 \pm 640 & 71.0 \pm 3.3\end{array}$

As a control group 15 newborn infants, 5 for each experimental group, were matched for sex, gestational age, birth weight, apgar score and parity. Umbilical cords were clamped within one minute after birth in all newborn infants.

Routinely, in all newborn infants born in our hospital and admitted to the neonatal unit capillary Hct was measured three hours after birth. When the capillary Hct was $\geq 70 \%$, a peripheral venous blood sample was taken. In the control group peripheral venous Hct was also measured at three hours after birth. Haematocrits were determined in duplicate with a micro-haematocrit centrifuge at $6000 \mathrm{rpm}$ for four minutes.

When the peripheral venous $\mathrm{Hct}$ was $\geq 70 \%$, a PPET was performed regardless of the presence of clinical symptoms. When the peripheral venous Hct ranged between $65-70 \%$, an exchange transfusion was performed only in those children with clinical symptoms. The exchange procedure was always performed between three and four hours after birth. The exchange volume (Vexch) was determined from the following equation:

$$
\text { Vexch }=\text { Circulating Volume } x \frac{\text { [observed } \mathrm{Hct} \text { - desired Hct }]}{\text { observed Hct }}
$$

A value of $58 \%$ was chosen as desired Hct (Shohat et al, 1984). The relative circulating volume was assumed to be $85 \mathrm{ml} / \mathrm{kg}$ body weight (Rawlings et al, 1982). 
The exchange transfusion was performed through a $5.0 \mathrm{~mm}$ Argyle catheter placed into the umbilical vein at the level of the inferior vena cava. At this level samples were taken for measuring central venous Hct. Volume exchange was performed in increments of $10 \mathrm{ml}$ in infants of more than $2000 \mathrm{~g}$ and in increments of $5 \mathrm{ml}$ in infants of less than $2000 \mathrm{~g}$. Plasma containing $5 \%$ albumin was used as exchange solution (Central Laboratory of the Dutch Blood Transfusion Service, Amsterdam). Doppler velocity recordings were performed in the PPET group before and at 3,12 and 24 hours after partial exchange transfusion. In the control group Doppler velocity recordings were measured at 3,12 and 24 hours after birth. Recordings from the left and right anterior cerebral artery were made through the open fontanel and from the midcerebral artery through the left coronal suture. We used a bidirectional Continuous Wave Doppler velocimeter (Medasonic D 10) with a $5 \mathrm{MHz}$ pencil probe. Low frequencies due to vessel wall movements were filtered out using a $200 \mathrm{~Hz}$ high-pas filter. Shifts in Doppler frequency were assessed by a zerocrossings detector and recorded as an instantaneous function of time. The anterior cerebral arteries were insonated by placing the pencil probe in the midline of the fontanel, slightly directing towards the eye. The mid-cerebral artery was insonated by placing the probe at the level of the helix of the left ear on the coronal suture and subsequently adjusting it slightly in upward direction (Drayton and Skidmore, 1987). To exclude the possibility of insonating in this way vessels branching from other cerebral arteries, we examined a three dimensional replica of the cerebral arterial system. Given the beam width and penetration depth of our continuous wave Doppler system, no other major vessels will be present within the sampling volume. Therefore, the contribution, if any, of signals derived from small blood vessels of other origin must be small. When Doppler signals were considered optimal through auditory and visual judgment, they were recorded on a strip chart at $30 \mathrm{~mm} / \mathrm{s}$.

Eight consecutive wave forms were analysed to obtain peak-systolic flow velocity (PSFV), end-diastolic flow velocity (EDFV), mean flow velocity (expressed as area under the curve per minute (AUC)) and Pulsatility Index (PI-Pourc) as defined by Pourcelot (Pourcelot, 1974):

PI-Pourc $=($ PSFV-EDFV $) / P S F V$. As an index of red cell transport $(\mathrm{RCT})$ the product of mean flow velocity and peripheral venous Hct (AUC x Hct/100) was calculated. Coefficient of variation (expressed as SD/mean $\times 100$ ) was used to quantitate the fluctuations of the wave forms. If the coefficient of variation was less than 10 per cent the Doppler tracing was defined as stable.

Data are presented as mean \pm SD. Differences between groups were statistically tested for significance by Student's T-test. Differences within groups were tested by paired Student's T-test. Level of significance: $\mathrm{p}<0.05$. 


\section{RESULTS}

As is shown in table 4.2., peripheral venous Hct decreased significantly after the exchange transfusion and final Hct was not different from that of the control group.

Central venous $\mathrm{Hct}$ was on the average approximately $90 \%$ of the peripheral venous Hct. Hct values at 12 and 24 hours after exchange transfusion were not different from values at 3 hours. Twenty-six $(72 \%)$ of the polycythaemic infants showed one or more clinical symptoms and 12 infants $(28 \%)$ had no clincial symptoms.

Heart rate (range 104-156 bpm), inean blood pressure (range $35-61 \mathrm{~mm}$ $\mathrm{Hg}$ ) and $\mathrm{PCo} 2$ levels (range 4.1-6.5 kPa) did not change significantly after exchange transfusion and were not diffcrent from the values of the control group. No differences were found in Doppler frequency shifts between left and right anterior cerebral artery. Therefore the values from both sides were combined for analysis. Changes in flow velocity in the anterior cerebral arteries were not different from those in the mi.1-cerebral artery.

Blood flow velocity values and RCT in the control group and in the total PPET group before and after exchange rre shown in table 4.2. Values of PSFV, EDFV and mean flow velocity (AUC) before PPET were significantly lower as compared to control, and increased to control levels after PPET. Pourcelot index (PI-Pourc) was not affected by PI'ET and did not differ from control. RCT (AUC $x$ Hct/100) increased slightly but significantly after PPET. However, values before and after PPET did not differ significantly from control. 
table 4.2. Influence of partial plasma exchange transfusion (PPET) on peripheral venous haematocrit and perfusion data of anterior cerebral arteries and mid cerebral artery, respectively. Data of matched controls are shown for comparison.

Velocity values are expressed in $\mathrm{Hz}$. Data are presented as mean $+\mathrm{SD}$.

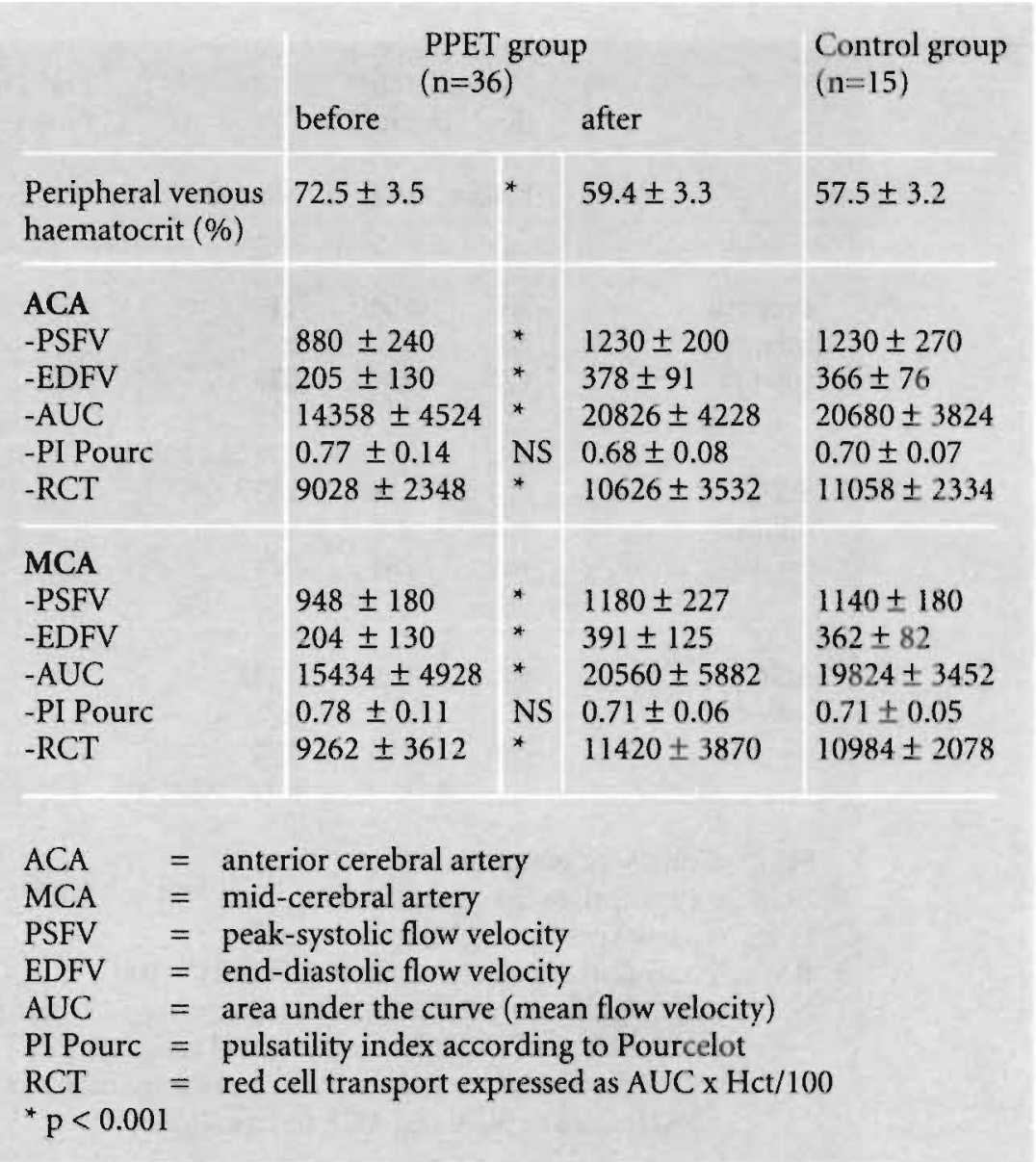


table 4.3. Cerebral blood flow velocity parameters and red cell transport in polycythaemic preterm, small-for-gestational age and appropriate-forgestational age newborn infants before and after partial plasma exchange transfusion and in matched control groups $(n=15)$. Data are presented as mean $\pm S D$.

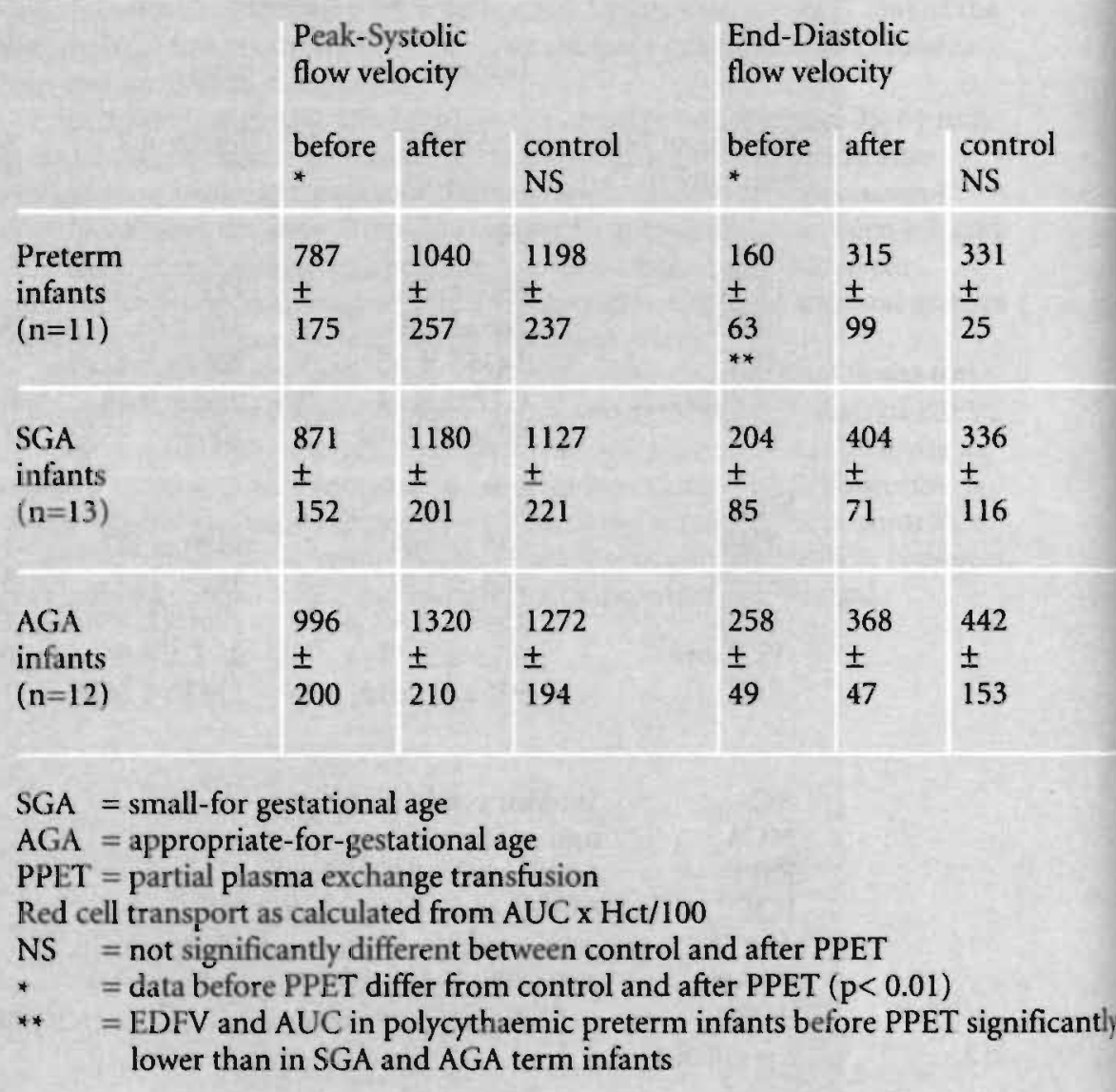

The differences in CBFV and RCT before and after exchange transfusion in preterm, SGA and AGA infants and in matched controls are shown in table 4.3.. Initially, polycythaemic preterm, SGA and AGA infants had significantly lower PSFV, EDFV and mean flow velocity than matched controls. After PPET these values did not differ anymore from control. The three matched control groups did not differ significantly from each other. Polycythaemic preterm infants before PPET had significantly lower values of EDFV and mean flow velocity as compared to the polycythaemic term (SGA and AGA) infants. In the control groups cerebral blood flow velocities remained constant during the period of observation. Also in the three different PPET groups the 


\begin{tabular}{|c|c|c|c|c|c|c|c|c|}
\hline \multicolumn{3}{|c|}{$\begin{array}{l}\text { Mean flow } \\
\text { velocity (AUC) }\end{array}$} & \multicolumn{3}{|c|}{$\begin{array}{l}\text { Pulsatility Index } \\
\text { (Pourcelot) }\end{array}$} & \multicolumn{3}{|c|}{ Red cell transport } \\
\hline $\begin{array}{l}\text { before } \\
\text { * }\end{array}$ & after & $\begin{array}{l}\text { control } \\
\text { NS }\end{array}$ & before & after & control & $\begin{array}{l}\text { before } \\
*\end{array}$ & after & $\begin{array}{l}\text { control } \\
\text { NS }\end{array}$ \\
\hline $\begin{array}{l}12212 \\
\pm \\
4496\end{array}$ & $\begin{array}{l}16336 \\
\pm \\
4462\end{array}$ & $\begin{array}{l}21746 \\
\pm \\
6048\end{array}$ & $\begin{array}{l}0.78 \\
\pm \\
0.12\end{array}$ & $\begin{array}{l}0.69 \\
\pm \\
0.08\end{array}$ & $\begin{array}{l}0.70 \\
\pm \\
0.12\end{array}$ & $\begin{array}{l}7998 \\
\pm \\
2458\end{array}$ & $\begin{array}{l}10418 \\
\pm \\
2286\end{array}$ & $\begin{array}{l}11868 \\
\pm \\
2710\end{array}$ \\
\hline $\begin{array}{l}15298 \\
\pm \\
3845\end{array}$ & $\begin{array}{l}22816 \\
\pm \\
3861\end{array}$ & $\begin{array}{l}18209 \\
\pm \\
4032\end{array}$ & $\begin{array}{l}0.81 \\
\pm \\
0.13\end{array}$ & $\begin{array}{l}0.72 \\
\pm \\
0.10\end{array}$ & $\begin{array}{l}0.73 \\
\pm \\
0.10\end{array}$ & $\begin{array}{l}9292 \\
\pm \\
2686\end{array}$ & $\begin{array}{l}10788 \\
\pm \\
2265\end{array}$ & $\begin{array}{l}11022 \\
\pm \\
1935\end{array}$ \\
\hline $\begin{array}{l}17176 \\
\pm \\
5288\end{array}$ & $\begin{array}{l}21824 \\
\pm \\
5499\end{array}$ & $\begin{array}{l}21353 \\
\pm \\
3472\end{array}$ & $\begin{array}{l}0.73 \\
\pm \\
0.04\end{array}$ & $\begin{array}{l}0.72 \\
\pm \\
0.07\end{array}$ & $\begin{array}{l}0.66 \\
\pm \\
0.07\end{array}$ & $\begin{array}{l}10028 \\
\pm \\
3048\end{array}$ & $\begin{array}{l}11849 \\
\pm \\
2425\end{array}$ & $\begin{array}{l}11468 \\
\pm \\
1617\end{array}$ \\
\hline
\end{tabular}

improved flow velocities found at 3 hours following exchange remained at this level at 12 and 24 hours. 


\section{DISCUSSION}

In the present study, PPET was used as a method to decrease Hct in polycythaemic preterm, SGA and AGA term newborn infants. Mean cerebral blood flow velocity improved in all three groups, the improvement being most pronounced in the preterm group. Cerebral blood flow velocities improved to levels of the control group in both the anterior and mid-cerebral arterial system and remained constant during the observation period of 24 hours.

Haematocrit is an important factor contributing to blood viscosity (Pearson et al, 1981). Increased blood viscosity is present in polycythaemic newborns causing a variety of clinical symptoms due to impaired organ perfusion (Rosenkrantz and Oh, 1982). Shohat and colleagues (1984a) demonstrated an increase in Hct during the first hours of life; peak Hct is reached between two and four hours after birth. Therefore, it is advisable to identify polycythaemic newborn infants shortly after birth. In most of the previous studies performed in polycythaemic newborn infants, however, blood sampling was delayed and not standardized. In the present study, the effects of PPET as performed at 3 hours after birth in polycythaemic newborn infants, were studied up to 24 hours after exchange transfusion. Isovolemic haemodilution resulted in a considerable decrease in peripheral venous and central venous $\mathrm{Hct}$ in polycythaemic preterm, SGA and AGA term infants.

Capillary Hct generally exceeds the venous Hct (Ramamurthy and Brans, 1981), but the difference is variable. This also holds for peripheral venous Hct and central venous Hct. In our study we observed a significant decrease in both peripheral venous and central venous Hct after the PPET. The peripheral venous Hct remained constant in the period from 3 to 24 hours after birth in the control group. In the PPET group it remained constant up to 24 hours after the exchange transfusion. This means that after the postnatal age of 3 hours no plasma shifts occurred and that PPET did not introduce plasma shifts.

Continuous Wave Doppler ultrasonography provides good information concerning flow velocity changes under different circumstances. If the probe is adjusted for maximal signals by visual or by audio control, optimal recordings can be obtained. We were aware of the fact that the built-in $200 \mathrm{~Hz}$ filter in our instrument not only filtered out low frequencies due to vessel wall movements, but very low diastolic velocities as well. In only two of the infants studied, the EDFV before PPET showed zero-flow recordings. Theoretically, Doppler frequencies could have been filtered out in these infants. However, this can not be an explanation for the differences in cerebral blood flow velocities obtained before and after PPET. The reduction of Hct resulted in a significant increase in cerebral blood flow velocities in all 3 groups up to values not different from matched controls. As other authors (Rosenkrantz and Oh, 1986) we found an increase in PSFV, EDFV, and mean flow velocity when lowering the Hct. In our study the PI-Pourc did not change significantly. This confirms the more recent supposition that this index is not correlated with flow velocity.

Doppler effects may be affected by heart rate, blood pressure, cerebral vascular resistance and blood viscosity. However, heart rate and blood pressure in the 3 groups of polycythaemic infants were not affected by the PPET. Therefore, it is likely that effects of PPET on cerebral blood flow velocity represent changes in vascular resistance or blood viscosity. 
It is still a controversial issue whether increases in flow velocities are a result of haemodilution. An increase in blood flow velocity can in part be explained by the concomitant decrease in blood viscosity (Humphrey, 1981). A decrease in oxygen delivery might also play a role, as was suggested by Rosenkrantz and colleagues (1984). However, Massik and colleagues (1987) observed a fall in CBFV following an infusion of red cells containing methaemoglobin, which suggests that the decrease in flow velocity is due to an increase in Hct and not to a change in oxygen delivery. From our data it is clear that after PPET red cell transport increased rather than decreased. This suggests that a decrease in blood viscosity rather than a decrease in oxygen delivery plays a role in the increase in cerebral blood flow velocity following PPET.

The effects of PPET on CBFV in polycythaemic newborn infants remained constant up to 24 hours and flow velocities were not different from the control group. This is at variance with the short lasting effects of haemodilution on placental blood flow velocity in women with pregnancy induced hypertension (Huisman, 1986).

The mean flow velocity in preterm infants before PPET was significantly lower $(p<0.001)$ than in SGA and AGA infants. After PPET the mean flow velocity in preterm infants was within the same range as in the other groups and not different from matched controls. The higher increase in mean flow velocity in preterm infants is mainly caused by a higher increase in EDFV (see table 4.3).

EDFV in polycythaemic preterm infants was significantly lower than in polycythaemic SGA and AGA infants. This has also been reported for nonpolycythaemic newborn infants (Strasburg et al, 1982). The latter could be due to factors such as impaired autoregulation, left to right shunting via the ductus arteriosus or increased blood viscosity. Because low diastolic flow velocity might predispose to cerebral ischaemia or intraventricular haemorrhage, haemodilution in polycythaemic newborns is especially important in preterm infants.

Whether cerebral hypoperfusion due to polycythaemia could cause cerebral damage is not clear (Høst and Ulrich, 1982; Black et al, 1985). Our patients with extreme polycythaemia showed clinical symptoms such as jittering, cyanosis and tachypnoea (respiratory rate $>60 / \mathrm{min}$ ). No other aetiologies, as neurological, metabolic, pulmonary or cardiovascular, were found to explain these clinical symptoms. Three hours after exchange tranfusion and, hence, after improvement of cerebral blood flow velocity, the clinical symptoms had disappeared in all infants and did not return for the next 24 hours. Therefore, we may conclude that PPET has a favourable and sustained effect on CBFV in newborn infants with extreme polycythaemia. The measurement of CBFV in polycythaemic infants might add a criterion to indicate PPET and it might be also considered as a screening test. 


\section{EFFECTS OF PARTIAL PLASMA EXCHANGE TRANSFUSION ON BLOOD FLOW VELOCITY IN LARGE ARTERIES OF ARM AND LEG, AND IN CEREBRAL ARTERIES IN POLYCYTHAEMIC NEWBORN INFANTS}

W.J. Maertzdorf (1), G.J. Tangelder (2), D.W. Slaaf (3) and C.F. Blanco (1)

Academic Hospital Maastricht, Departments of Neonatology (1), Physiology (2) and Biophysics (3), University of Limburg, Maastricht, The Netherlands

Acta Paediatr. Scand.: accepted for publication 


\section{ABSTRACT}

Continuous Wave Doppler velocimetry was performed in brachial, femoral, and cerebral arteries in four preterm, four small-for-gestational age. (SGA), and eight appropriate-for-gestational age (AGA) polycythaemic newborns before and at 3 and 24 hours after partial plasma exchange transfusion (PPET) and in 18 matched controls at 3 and 24 hours after birth. In peripheral arteries, end-diastolic flow velocity was zero in all eight AGA controls, but only in two of the other infants. Consequently, mean flow velocity and red cell transport (RCT) in AGA controls were significantly lower than in the other 5 groups, which did not differ. PPET did not influence flow velocities and RCT in peripheral arteries, but normalized the flow velocities in cerebral arteries in all three subgroups of polycythaemic infants, which were lower than in control infants. Cerebral RCT in controls increased significantly between 3 and 24 hours after birth and in polycythaemic infants between 0 and 3 hours after PPET. In conclusion, reduction in haematocrit had different effects on blood flow velocity and RCT in peripheral and cerebral vessels, which suggests that the increased cerebral blood flow velocity after PPET is not simply due to a reduction in viscosity or oxygen content of the blood. The lower peripheral blood flow velocities in normocythaemic AGA infants as compared to all other groups suggest that the level of maturity is an important determinant for the capacity to regulate blood flow.

\section{INTRODUCTION}

Neonatal polycythaemia may lead to clinical symptoms such as lethargy, jitterness or seizures (Goldberg et al, 1982; Black et al, 1982), cyanosis and respiratory distress (Gatti et al, 1966; Gross et al, 1973; Wiswell et al, 1986), renal failure (Aperia et al, 1974), necrotizing enterocolitis (Leake et al, 1975) and plethora (Saigal and Usher, 1977), probably due to impaired blood flow to different organs. In polycythaemic newborn infants partial plasma exchange transfusion (PPET) is used routinely to normalize the haematocrit with the aim of improving organ perfusion.

Cerebral blood flow is directly related to haematocrit (Humphrey et al, 1979). We have shown that in polycythaemic newborn infants cerebral blood flow velocity (CBFV) is lower than in normal newborns and can be normalized after a PPET (Maertzdorf et al, 1989). Whether this improvement in CBFV is due to a decrease in blood viscosity caused by the reduction in red cell mass or to a decrease in oxygen transport capacity is still a matter of debate. Rosenkrantz and colleagues (1984) hypothesized, based on studies in newborn lambs, that a reduction of cerebral blood flow in neonatal polycythaemia is a physiological response to an increase in oxygen content and not a result of impaired fluidity of the blood. Massik and colleagues (1987), however, reported data suggesting that the decrease in cerebral blood flow observed in polycythaemia was actually caused by an increase in blood viscosity. If the changes in CBFV after haemodilution were indeed primarily dependent on changes in blood viscosity, it might be expected that haemodilution will have a similar influence on flow velocities to other organ systems. 
Except for the cerebral circulation no data are available on blood flow velocity in major arteries of polycythaemic newborn infants. The few studies reporting observations on the influence of haematocrit on blood flow to the skin or to the carcass had different results: after haemodilution an increase in cutaneous blood flow (Waffarn et al, 1984; Swetnam et al, 1987) was found, but no changes in flow to the calf or to the carcass were demonstrated (Bergquist and Zetterström, 1974; Holzman et al, 1986). The aim of the present study was to observe the effects of a PPET in polycythaemic preterm, small-(SGA) and appropriate-(AGA) for-gestational age newborn infants on blood flow velocity in arteries of arms and legs and in cerebral arteries at 3 and 24 hours after the procedure and to compare these data to a matched control group.

\section{PATIENTS AND METHODS}

Sixteen inborn polycythaemic infants formed the study group. Table 5.1 summarises gestational age, birth weight and the peripheral venous haematocrit (Hct) values of 4 preterm infants, 4 SGA and 8 AGA term infants and 18 controls. Polycythaemia was defined as a peripheral venous $\mathrm{Het}$ exceeding $65 \%$.

A capillary Hct was determined at 3 hours after birth in all infants admitted to our nursery. When this $\mathrm{Hct}$ was $>65 \%$, a peripheral venous blood sample was taken from an antecubital vein or from a vein on the back of the hand. No tourniquet or squeezing was used.

PPET was performed when the peripheral venous Hct was more than $70 \%$, or when the peripheral venous Hct was between $65 \%$ and $70 \%$ and associated with clinical symptoms probably due to hyperviscosity of the blood. Fourteen infants had a peripheral venous Hct of more than $70 \%$. Of these 14 infants, 10 had associated symptoms at 3 hours after birth. Two infants showed clinical symptoms at a peripheral venous Hct of $68 \%$. Plethora ( 8 infants) and jitterness ( 7 infants) were the most frequently observed symptoms. Other aetiologies for clinical symptoms, such as hypoglycaemia, were screened.

The control group consisted of 18 normocythaemic (Hct median 59\%; range 49\%-64\%) newborn infants without clinical symptoms, matched for gestational age and birth weight (see table 5.1). The mode of delivery did not differ between control and polycythaemic infants. Umbilical cords were always clamped within 1 minute after birth.

Hct was determined in duplicate with a Hawskley micro-haematocrit reader after 4 minutes centrifugation at 6000 rpm.

Blood gases were determined in a blood sample obtained by heel-stick and measured with a blood-gas analyzer at $37^{\circ} \mathrm{C}$ ( $\mathrm{ABL} 3$ Radiometer, Copenhagen, Denmark).

The electrocardiogram was used to determine heart rate; blood pressure was measured using a Dinamap 847 device (Critikon, Irvine, Ca, USA).

PPET was always performed at 3-4 hours after birth with plasma containing $5 \%$ albumin (Central Laboratory of the Dutch Blood Transfusion Service, Amsterdam, The Netherlands). The total exchange volume (Vexch) was determined from the equation:

$$
\text { Vexch }=\text { Circulating Volume } x \frac{\text { [observed Hct - desired Hct }]}{\text { observed Hct }}
$$


A desired Hct value of $58 \%$ was chosen. The relative circulating volume was assumed to be $85 \mathrm{ml} / \mathrm{kg}$ body weight. We used a $5.0 \mathrm{~mm}$ Argyle catheter placed in the umbilical vein at the level of the inferior vena cava. In infants weighing more or less than $2000 \mathrm{~g}$ increments were $9.3 \mathrm{ml}$ or $4.3 \mathrm{ml}$, respectively, with correction for the dead space of $0.7 \mathrm{ml}$ in the assembly. In the first part of the study we did not take into account this dead space when calculating the exchange volume. This resulted in a slightly smaller exchange volume than the one calculated from the equation.

The study was approved by the Ethics Committee of the Hospital. The PPET procedure is common practice and has not been changed for the purpose of this work.

Procedures were performed at room temperature $\left(23 \pm 0.5^{\circ} \mathrm{C}\right)$ or in an incubator with neutral environmental temperature (Hey, 1971).

Blood flow velocity was measured prior to and at 3 and 24 hours after PPET in the polycythaemic infants (about 3,6, and 27 hours after birth, respectively). In the control group, blood flow velocity was measured at about 3 and 24 hours after birth.

Blood flow velocity was measured using a Continuous Wave bidirectional Doppler velocimeter (Medasonic D10, Medasonics, Mountain View, Ca, USA). A $5 \mathrm{MHz}$ pencil probe was used and Doppler frequency shifts were assessed by zero-crossing technique and expressed in $\mathrm{Hertz}(\mathrm{Hz})$. Doppler signals were judged by auditory and visual inspection and recorded as an instantaneous function of time and documented on a strip-chart recorder at 3 $\mathrm{cm} / \mathrm{s}$.

Peripheral blood flow velocity measurements were performed on the left brachial and femoral artery, by means of placing the transducer in the bicipital groove halfway down the upper arm and $2 \mathrm{~cm}$ below the Pouparts' ligament, respectively. Optimal recordings could be obtained when the angle between the ultrasound beam and the surface of the skin above the insonated artery was between 15 and $30^{\circ}$. CBFV measurements were performed on the left and right anterior cerebral arteries and on the left mid cerebral artery, as described previously (Maertzdorf et al, 1989).

Eight consecutive wave forms were analysed to obtain peak-systolic flow velocity (PSFV), end-diastolic flow velocity (EDFV), mean flow velocity (expressed as area under the curve per minute (AUC)), Pulsatility Index (PI), i.e. (PSFV-EDFV)/AUC, and Pulsatility Index as defined by Pourcelot (PIPourc), i.e. (PSFV - EDFV)/PSFV (Pourcelot, 1974). As an index of red cell transport (RCT) the product of mean flow velocity and peripheral venous $\mathrm{Hct}$ (AUC x Hct/100) was calculated. When beat-to-beat coefficient of variation was less than $10 \%$ Doppler recordings were defined as stable.

Flow data in the tables are presented as means \pm SD. Student's paired $t$-test was used to test for changes in Hct values before and after PPET.

Differences in flow velocities prior to and at 3 and 24 hours after the exchange in polycythaemic infants, and at 3 and 24 hours after birth in the control group were tested with the Wilcoxon matched-pairs ranks test; differences between polycythaemic and control infants were assessed with the Mann-Whitney ranks sum test. As a level of significance we used: $p<0.05$.

Box plots in the figures represent median values, interquartile ranges (i.e., the interval between the two values below which $25 \%$ and $75 \%$ of the data falls, respectively) and ranges (Mc Gill, 1978). 


\section{RESULTS}

Table 5.1 shows the peripheral venous Hct values in the various groups at different times. Hct values decreased significantly after PPET and did not change in the following period of 21 hours. In control infants, Hct values at 24 hours after birth were not different from those at 3 hours.

table 5.1. Gestational age, birth weight and peripheral venous haematocrit (Hct) in polycythaemic preterm, and small- (SGA) and appropriate- (AGA) forgestational age term infants, and in age and weight matched controls. Values represent median and range (within parentheses). Numbers after the period in gestational age refer to the day in a week.

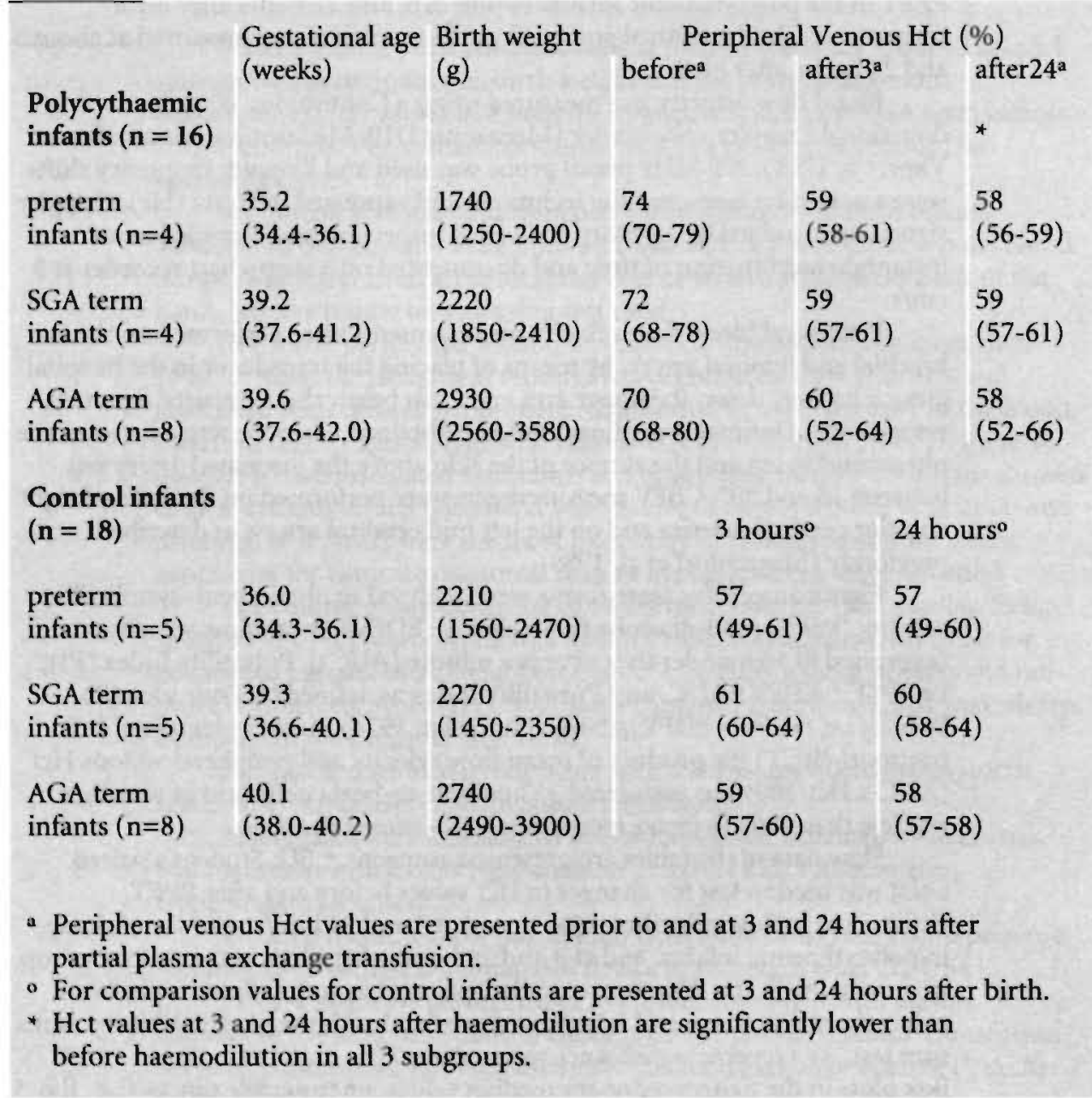


Heart rate (median 126; range $96-144 \mathrm{bpm}$ ) and mean arterial blood pressure (51;37-62 $\mathrm{mm} \mathrm{Hg}$ ) before PPET did not differ from heart rate values (132;102-152 bpm) and mean arterial blood pressure $(52 ; 32-61 \mathrm{~mm} \mathrm{Hg}$ ) after the procedure. Heart rate $(128 ; 112-156 \mathrm{bpm})$ and mean arterial blood pressure $(42 ; 38-52 \mathrm{~mm} \mathrm{Hg})$ in controls did not differ from values in polycythaemic infants.

Blood PCO2 levels $(5.2 ; 4.1-6.5 \mathrm{kPa})$ in polycythaemic infants were not different from controls $(5.0 ; 4.3-6.2 \mathrm{kPa})$, and did not change significantly after PPET (4.9;4.2-5.9 kPa). No differences were found in PCO2 levels between the three subgroups of polycythaemic and control infants.

\section{Velocity parameters in control infants}

In the control group there was a difference in brachial and femoral artery flow velocity between AGA infants on the one hand and preterm and SGA infants on the other. At 3 and 24 hours after birth control preterm and SGA infants had a significantly higher AUC and EDFV, and therefore a significantly lower PI-Pourc, than control AGA infants (first and last column of tables 5.2. and 5.3.). All AGA control infants had a zero EDFV in both peripheral arteries, while a zero EDFV was found only in two of the five SGA infants and in none of the preterms. PSFV and PI did not differ between the three subgroups of control infants. Hence, pooled values are presented in tables 5.2. and 5.3. 
table 5.2. Blood flow velocity parameters in the brachial artery before and at 3 and 24 hours after partial plasma exchange transfusion in polycythaemic preterm, and small- (SGA) and appropriale-(AGA) for- gestational age term infants. Values for matched control infants are presented as well. For definition of the flow parameters see methods section. Data for PSFV and PI were pooled because the three subgroups did not differ. Data are presented as mean \pm SD.

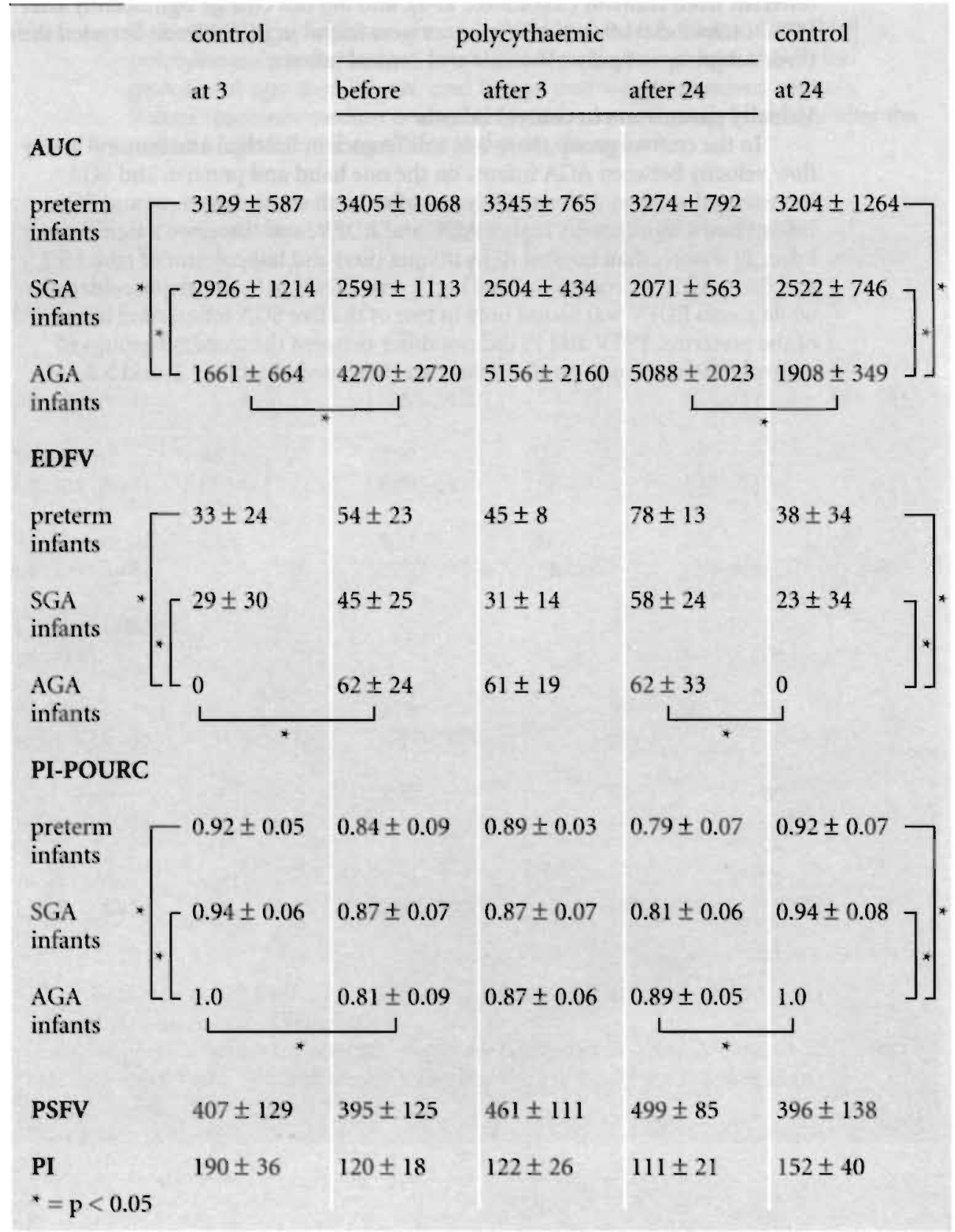


table 5.3. Blood flow velocity parameters in the femoral artery before and at 3 and 24 hours after partial plasma exchange transfusion in polycythaemic preterm, and small- (SGA) and appropriate- (AGA) for-gestational age term infants. Values for matched control infants are presented as well. For definition of the flow parameters see methods section. Data for PSFV and PI were pooled because. the three subgroups did not differ. Data are presented as mean $\pm S D$.

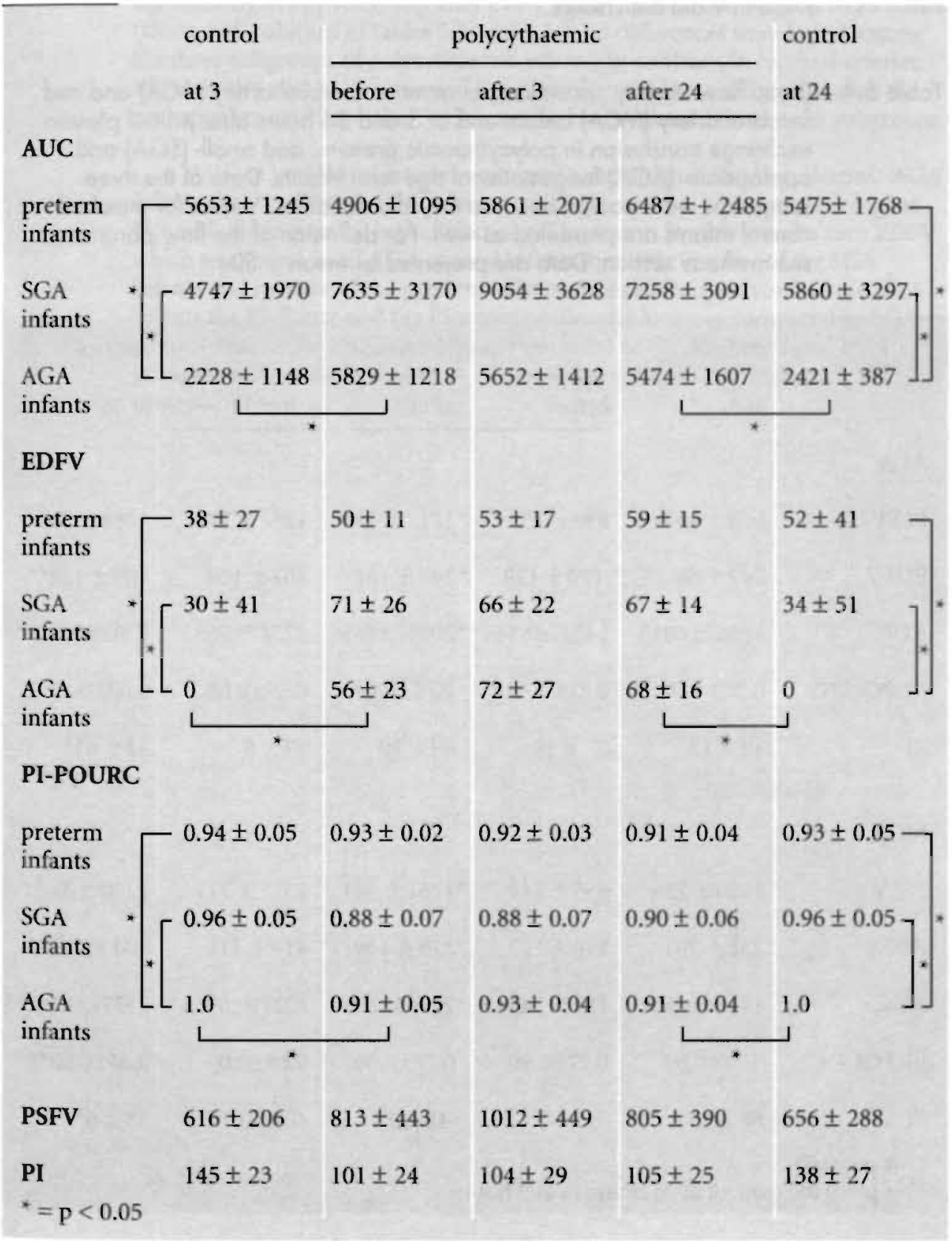


In cerebral arteries (table 5.4.) there were no differences in flow parameters among the three groups of control infants.

In control preterm, SGA and AGA infants no significant changes in peripheral blood flow velocities were found over the period of 3 to 24 hours after birth (first and last columns in tables 5.2. and 5.3.). In cerebral arteries, however, EDFV and AUC in control infants increased significantly over this period, whereas PI-Pourc and PI decreased significantly, as is shown in table 5.4.. PSFV did not change.

Table 5.4. Blood flow velocity parameters in anterior cerebral artery (ACA) and mid cerebral artery (MCA) before and at 3 and 24 hours after partial plasma exchange transtusion in polycythaemic preterm, and small- (SGA) and appropriate (AGA) for-gestational age term infants. Data of the three subgroups were pooled because they did not differ. Values for matched control infants are presented as well. For definition of the flow parameters see methods section. Data are presented as mean \pm SD.

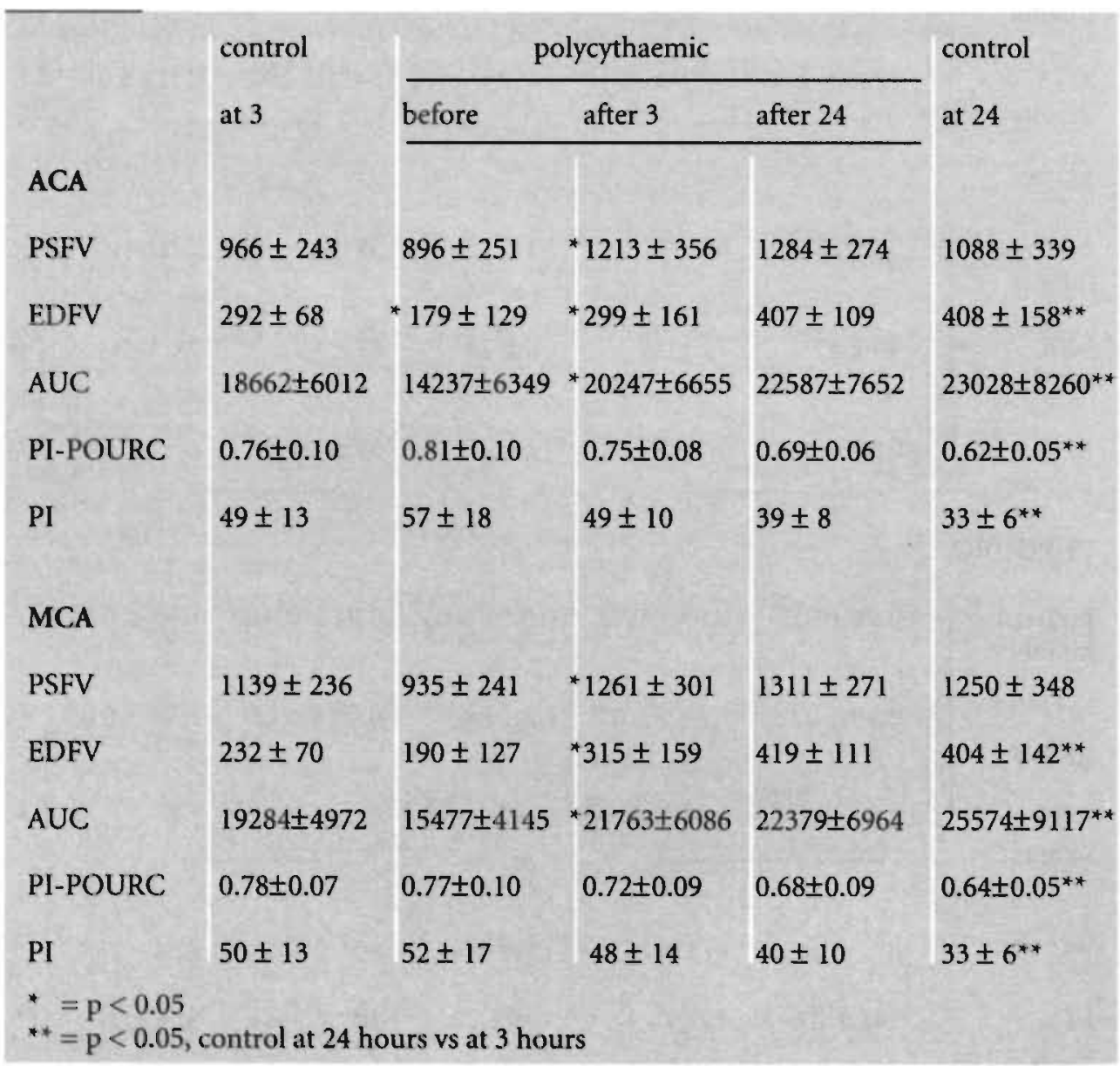




\section{Velocity parameters in polycythaemic infants}

Figure 5.l. shows an example of Doppler tracings of blood flow velocities in a polycythaemic SGA infant before and 3 hours after PPET. It can be seen that brachial and femoral blood flow velocities did not change, whereas cerebral blood flow velocities increased; cerebral EDFV and AUC were most affected.

In peripheral arteries, blood flow velocity parameters did not change significantly in any subgroup after PPET and remained constant up to 24 hours (three mid-columns of tables 5.2. and 5.3.); no differences were found among the three subgroups of polycythaemic infants. In contrast, in cerebral arteries, PSFV, EDFV and AUC increased significantly in all three subgroups after the exchange transfusion (table 5.4.); no differences existed between the subgroups.

AUC in peripheral arteries was significantly higher in polycythaemic AGA infants than in control AGA infants (tables 5.2. and 5.3.), despite their higher $\mathrm{Hct}$ and, consequently, higher viscosity. The reason for this was the zero EDFV which was found in all AGA control infants, but only in a few of the SGA infants and in none of the preterm infants. As a result, in polycythaemic AGA infants the PI-Pourc and the PI were significantly lower as compared to AGA control infants (tables 5.2. and 5.3.). Peripheral EDFV, PI-Pourc and PI in polycythaemic preterm and SGA infants did not differ from their matched controls. 

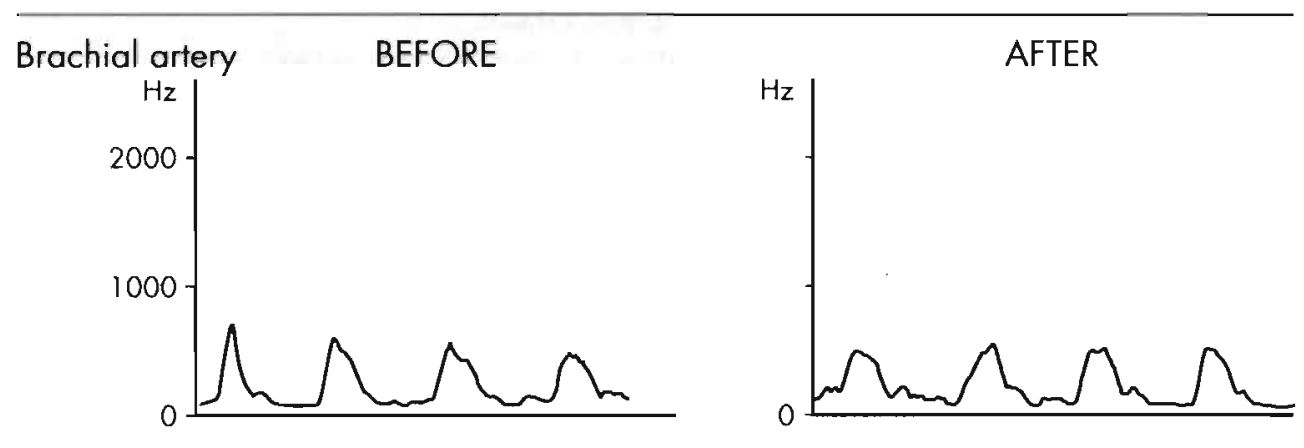

Femoral artery
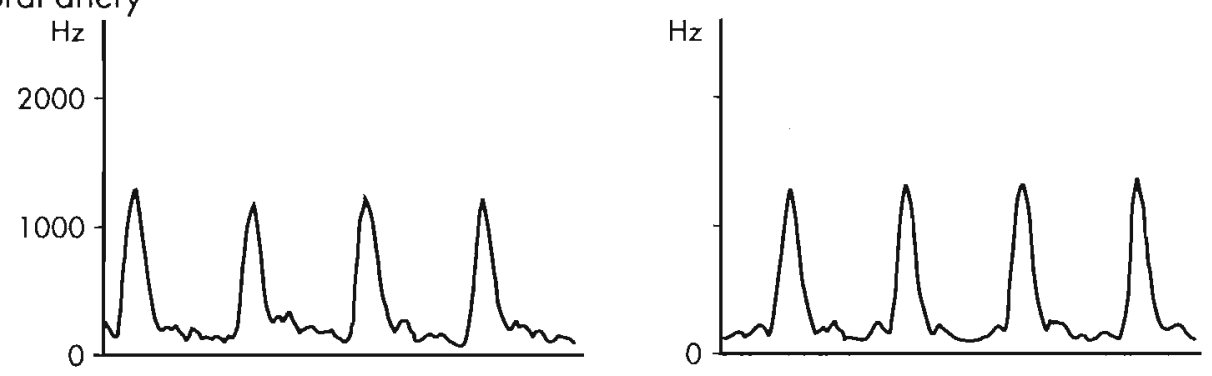

Anterior cerebral artery
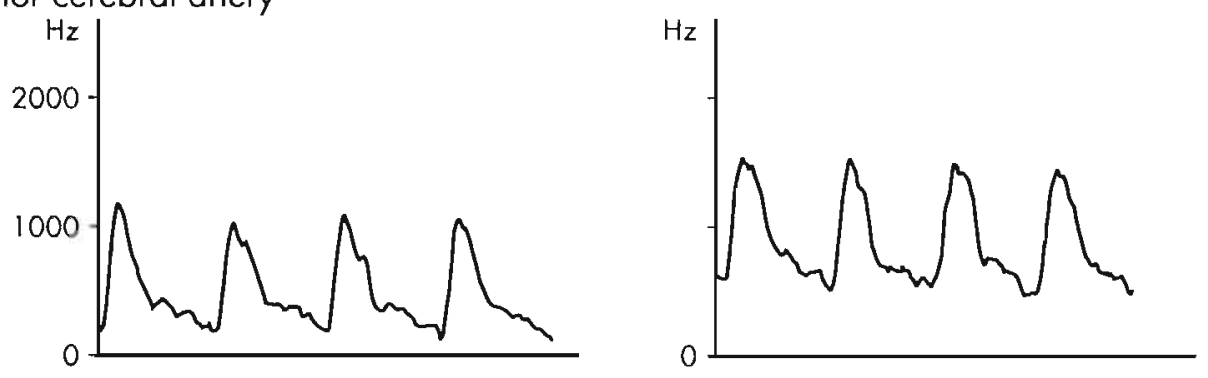

Mid cerebral artery
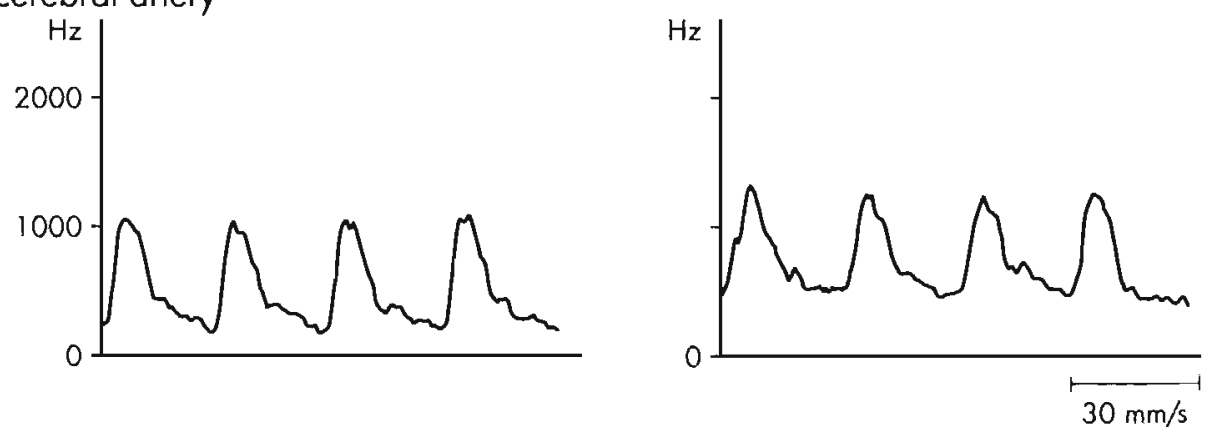

fig 5.1. Tracings of blood flow velocities in the brachial artery, femoral artery, and anterior and mid-cerebral artery before and at 3 hours after partial plasma exchange transfusion in a small-for-gestational age polycythaemic newborn infant (gestational age 40.2 weeks, birth weight $2490 \mathrm{~g}$, haemalocrit $72 \%$ ). 


\section{Red cell transport}

Red cell transport $(\mathrm{AUC} \times \mathrm{Hct} / 100)$ data are presented in figures 5.2. and 5.3. The hatched boxes represent polycythaemic infants and the open boxes control infants. In the brachial and femoral arteries (figure 5.2.), RCT was significantly higher in polycythaemic AGA infants than in control AGA infants. The difference was still present at 24 hours and was not influenced by PPET. In preterm and SGA infants (pooled in figure 5.2.), the peripheral RCT values did not differ between control and polycythaemic infants.

In none of the three subgroups of polycythaemic infants did PPET change RCT in the peripheral arteries. RCT in the cerebral arteries (all subgroups pooled in figure 5.3.), however, increased significantly after the exchange.

Peripheral RCT in controls did not change significantly over the period of 3 to 24 hours after birth, whereas it increased significantly in cerebral arteries over that period; this was the case for all three subgroups. 


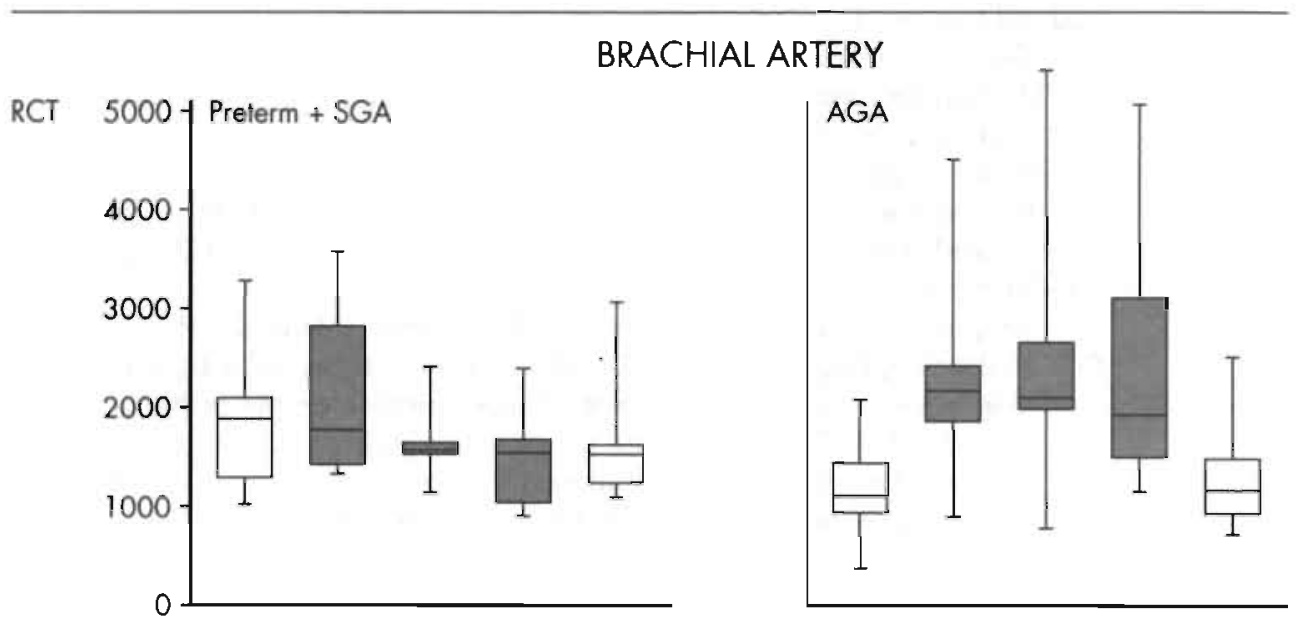

FEMORAL ARTERY
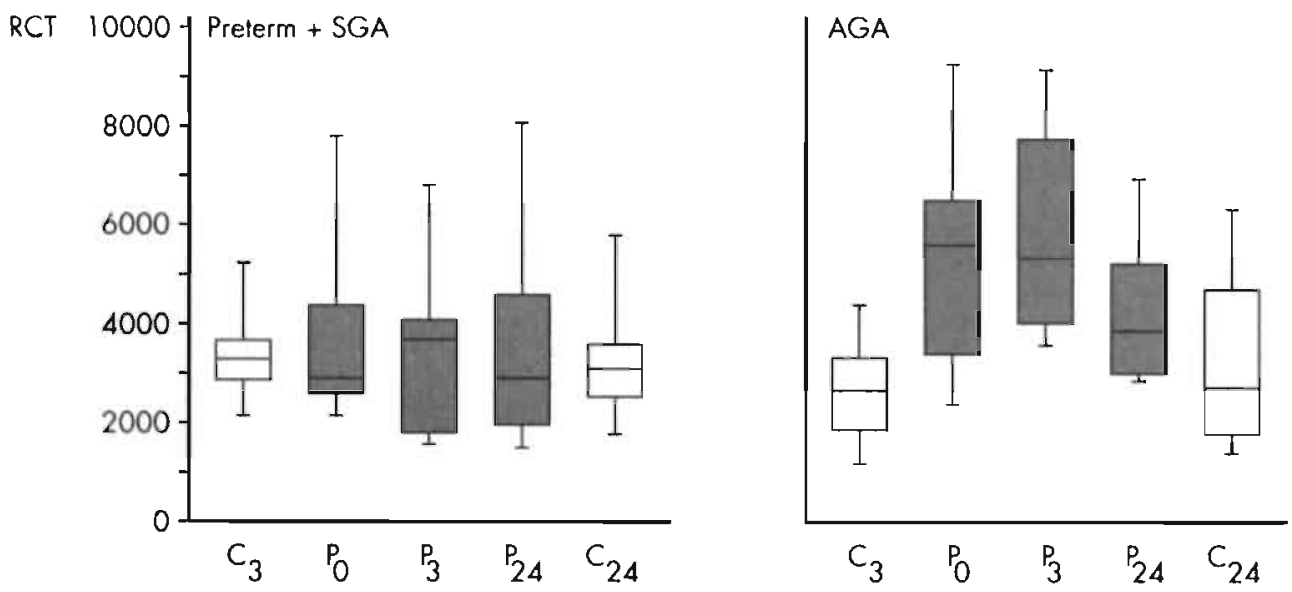

fig 5.2. Red cell transport (AUC $\times \mathrm{Hct} / 100$ ) in brachial (upper panel) and femoral (lower panel) arteries before (PO) and of 3 (P3) and 24 (P24) hours after partial plasma exchange transfusion in polycythaemic newborn infants. Red cell transport in control infants is presented at 3 (C3) and 24 (C24) hours after birth. Data are presented as box-plots. Note differences in scale between upper and lower panel. C3 and C24 in AGA infants are significantly lower than in PO, P3 and P24. No significant differences between PO, P3 and P24. 
ANTERIOR

CEREBRAL ARTERY

$\mathrm{RCT}$

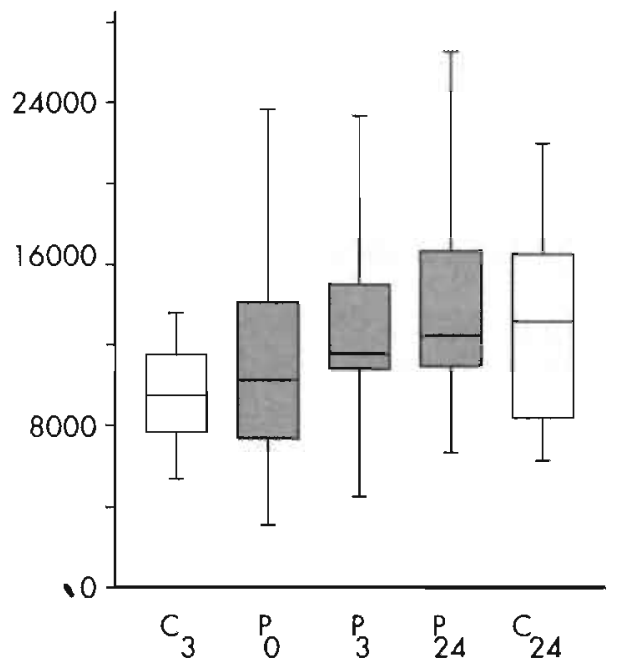

MID

CEREBRAL ARTERY

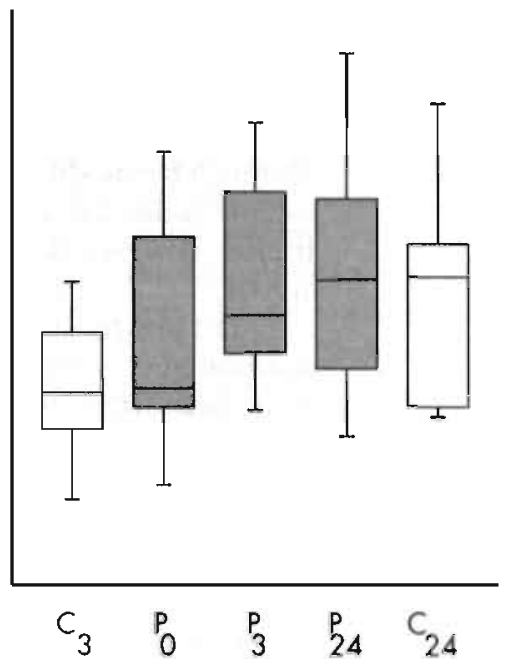

fig 5.3. Red cell transport (AUC $x$ Hct/100) in anterior (ACA) cerebral arteries and mid (MCA) cerebral arteries before (PO) and of 3 (P3) and 24 (P24) hours after partial plasma exchange transfusion in polycythaemic newborn infants. Red cell transport in control infants is presented of 3 (C3) and 24 (C24) hours after birth. Data are presented as box-plots. C24 is significantly higher than $\mathrm{C} 3$; PO is significantly lower than P3 and p24. 


\section{DISCUSSION}

Partial plasma exchange transfusion in polycythaemic preterm, SGA, and AGA infants had no influence on blood flow velocity in the brachial and femoral artery, but it did increase CBFV. In peripheral arteries, polycythaemic AGA infants had a higher AUC than control AGA infants. This finding was mainly caused by the zero EDFV found in all normocythaemic AGA infants. Although haemodilution in polycythaemic newborns decreased red cell volume, it did not significantly change RCT in peripheral arteries. In cerebral arteries, however, RCT even increased after haemodilution, due to an increase in AUC.

The present study showed that the influence of haemodilution and of the concomitant decrease in blood viscosity and oxygen content on flow velocities in the large arteries of the arm and leg was negligible. In the same infants, however, blood flow velocities in cerebral arteries increased significantly. An increase in cerebral artery flow was also found in other studies (Humphrey et al, 1979; Rosenkrantz and Oh, 1982; Maertzdorf et al, 1989). In addition, we found that polycythaemic AGA infants had a significantly higher AUC in the brachial and femoral arteries than matched controls, despite their higher Hct, and consequently higher blood viscosity. This finding suggests that the change in flow to different organ systems after haemodilution is not simply caused by the change in $\mathrm{Hct}$, viscosity, red cell mass and $\mathrm{O} 2$ transport, but that vasomotor-activity may also cause changes in flow to different organ systems.

The notion that vasomotor activities in different vascular systems may react differently to changes in $\mathrm{Hct}$, as suggested by this and other studies (Mott and Walker, 1983), is supported by reports on the influence of Hct on flow to the skin (Waffarn et al, 1984; Swetnam et al, 1987) or to the carcass (Bergqvist and Zetterström, 1974; Holzman et al, 1986; Norman et al, 1988). Increases in cutaneous blood flow of $80 \%$ and $38 \%$ after PPET in polycythaemic newborn infants have been reported using laser Doppler velocimetry (Swetnam et al, 1987) or heat clearance and transcutaneous PO2 and PCO2 techniques (Waffarn et al, 1984), respectively. In addition, a highly negative correlation was found between Hct and capillary perfusion of the skin using videophotometric capillary microscopy (Norman et al, 1988). However, in calf and foot no differences in blood flow were found after isovolemic haemodilution in polycythaemic newborn infants using plethysmography (Bergqvist and Zetterström, 1974). In newborn lambs it was found that the blood flow in the carcass was only minimally influenced by the Hct using radionuclide microspheres technique (Holzman et al, 1986).

Arms and legs are composed of various tissues. Flow velocity in large peripheral arteries predominantly represents flow to muscle and bone. Hence, the results obtained in this study seem to be in agreement with the above mentioned studies that in normal infants carcass flow is not influenced by changes in Hct. Zetterström and colleagues (1989) found no relationship between blood flow in calf and foot and Hct in infants with Hct levels below $70 \%$. Since in nailfold capillaries a relation was found between Hct and blood flow, he concluded that the majority of the blood supplied by the peripheral arteries bypasses the superficial skin capillaries. Various studies, using plethysmography, have shown that limb flow decreases with gestational age and during the first day of live (Kidd et al, 1966; Berg and Celander, 1971; Wu et al, 
1980 ), probably as a result of changes in vascular tone. These findings are in agreement with our results of a decreased flow velocity in control AGA infants. Takenaka and colleagues (1988) suggest that an acute increase in flow velocity in the aorta and pulmonary artery after haemodilution might be due to a decrease in left to right shunting via the ductus. If this is the explanation, we would expect that changes in blood flow velocity would be comparable in all large arteries. However, we found that flow velocity in cerebral arteries increased after PPET, but that it did not change in peripheral arteries in the same infants in our study. This finding could be an argument for the differences found in vasomotor action in different vascular systems.

In our study, RCT in cerebral arteries of polycythaemic infants was in the same range as that in control infants. In peripheral arteries the same was found for preterm and SGA infants, but not for ful]-term AGA infants. The reason for this might be that only healthy infants, such as normocythaemic full-term AGA infants, are capable of regulating peripheral blood flow velocity. All AGA control infants showed a zero EDFV in peripheral arteries, while none of the preterm and only $40 \%$ of the SGA infants showed this. Adults also have a zero EDFV in peripheral arteries, and, hence, the presence of a zero EDFV in peripheral arteries may reflect the level of maturity.

In all three groups of control infants, RC.T in cerebral arteries, in contrast to peripheral arteries, increased significantly up to a period of 24 hours after birth. This finding is in agreement with the gradual increase in cerebral blood flow as measured during the first 16 hours of life in normocythaemic preterm newborn infants (Calvert et al, 1988). After haemodilution, no change in CBFV with time was noted in polycythaemic infants. This might be explained by the fact that after the exchange transfusion, RCT in cerebral arteries was already at its upper limit.

In conclusion, the present study indicates that the increase in CBFV after partial plasma exchange transfusion in polycythaemic newborn infants is not simply due to a reduction in viscosity or oxygen content of the blood. In addition, we found that normocythaemic AGA term infants have a lower flow velocity in peripheral arteries than normocythaemic preterm and SGA infants or than the different groups of polycythaemic infants. This finding indicates that the level of maturity is an important determinant for the capacity to regulate blood flow. 


\section{CIRCULATING BLOOD VOLUME IN APPROPRIATE- AND SMALL-FOR- GESTATIONAL AGE FULLTERM AND PRETERM POLYCYTHAEMIC INFANTS}

W.J. Maertzdorf (1), W. Aldenhuijsen-Dorland (1), D.W. Slaaf (2), G.J. Tangelder (3) and C.E. Blanco (1)

Academic Hospital Maastricht, Departments of Neonatology (1), Biophysics (2) and Physiology (3), University of Limburg, Maastricht, The Netherlands

Acta Paediatr. Scand. (1991) 80: 620-627 
Relative circulating volume was determined in 31 polycythaemic newborn infants who underwent a partial plasma exchange transfusion. The infants were divided in four subgroups: appropriate-for-gestational age (AGA) term and preterm infants, and small-for-gestational age (SGA) term and preterm infants. The circulating volume was calculated using a regression line between the number of exchange steps and central venous haematocrit values obtained before the procedure and after every exchange step. The median relative circulating volume in all polycythaemic newborn infants was 94.0 (range 69143) $\mathrm{ml} / \mathrm{kg}$. Irrespective of gestational age and birth weight the median relative circulating volume in AGA infants was 86.5 (range 69-107) $\mathrm{ml} / \mathrm{kg}$, which differed significantly from the value of 106 (range $85-143$ ) $\mathrm{ml} / \mathrm{kg}$ found in SGA infants. If a partial plasma exchange transfusion is indicated we recommend to calculate the exchange volume in AGA infants using a relative circulating volume of $86 \mathrm{ml} / \mathrm{kg}$ and in SGA infants using a relative circulating volume of $106 \mathrm{ml} / \mathrm{kg}$.

\section{INTRODUCTION}

Neonatal polycythaemia defined as peripheral venous haematocrit $(\mathrm{Hct})$ $>65 \%$, occurs in $2-5 \%$ of all newborn infants (Wirth et al, 1979; Ramamurthy and Brans, 1981). Polycythaemia may be associated with a variety of symptoms and possible sequelae as a consequence of impaired blood flow probably due to hyperviscosity of the blood (Gatti et al, 1966; Mentzer, 1978; Aperia et al, 1974; Leake et al, 1975). This clinical situation can be corrected by normalizing the haematocrit by means of a partial plasma exchange transfusion (PPET), during which blood is replaced by a plasma-substitute.

The required exchange volume is generally (Rawlings et al, 1982) calculated assuming one single exchange step: Total exchange volume $=$

\section{Circulating volume $\mathrm{x} \frac{\text { (Hct observed - Hct desired) }}{\text { Hct observed }}$}

(equation 1)

The circulating volume is estimated from body weight and a fixed relative circulating volume of $85 \mathrm{ml} / \mathrm{kg}$ body weight. The use of a fixed relative circulating volume is a potential source of error, since circulating volume is strongly correlated with the cord clamping time (Usher and Lind, 1965) and seems negatively correlated with birth weight (Rawlings et al, 1982).

In clinical practice the exchange procedure is performed in steps with 5 or $10 \mathrm{ml}$ syringes, depending on birth weight. By neglecting the dead space in the exchange-assembly, a systematical overestimation is made of the actual exchange volume or amount of blood cells removed from the circulation and, hence, a smaller than expected reduction in haematocrit is obtained.

Theoretically, the circulating volume of a polycythaemic newborn infant can be estimated from the total exchange volume used and the haematocrits before and after the partial plasma exchange transfusion. However, a better accuracy might be obtained if the repetitive nature of the exchange procedure is 
used to obtain more data points by measuring the central venous haematocrit not only before and after exchange transfusion, but also after each step during the exchange procedure. In addition, we took into account the influence of the dead space in the exchange system. The method was applied to polycythaemic newborn infants to relate circulating volume not only to birth weight, but also to gestational age. It was found that for proper calculation of the exchange volume different values of circulating volume have to be assumed in appropriate-(AGA) and small-for-gestational age (SGA) newborn infants.

\section{PATIENTS AND METHODS}

\section{Patients}

In a 3-years period 31 newborn patients ( 16 girls, 15 boys) met the criteria for a partial plasma exchange transfusion. All infants were delivered

table 6.1. Central venous haematocrit values before and after partial plasma exchange transfusion in polycythaemic newborn infants distributed by sex, gestational age and birth weight. Initial peripheral venous haematocrit values are given for comparison. Numbers after the period in gestational age refer to the day in a week.

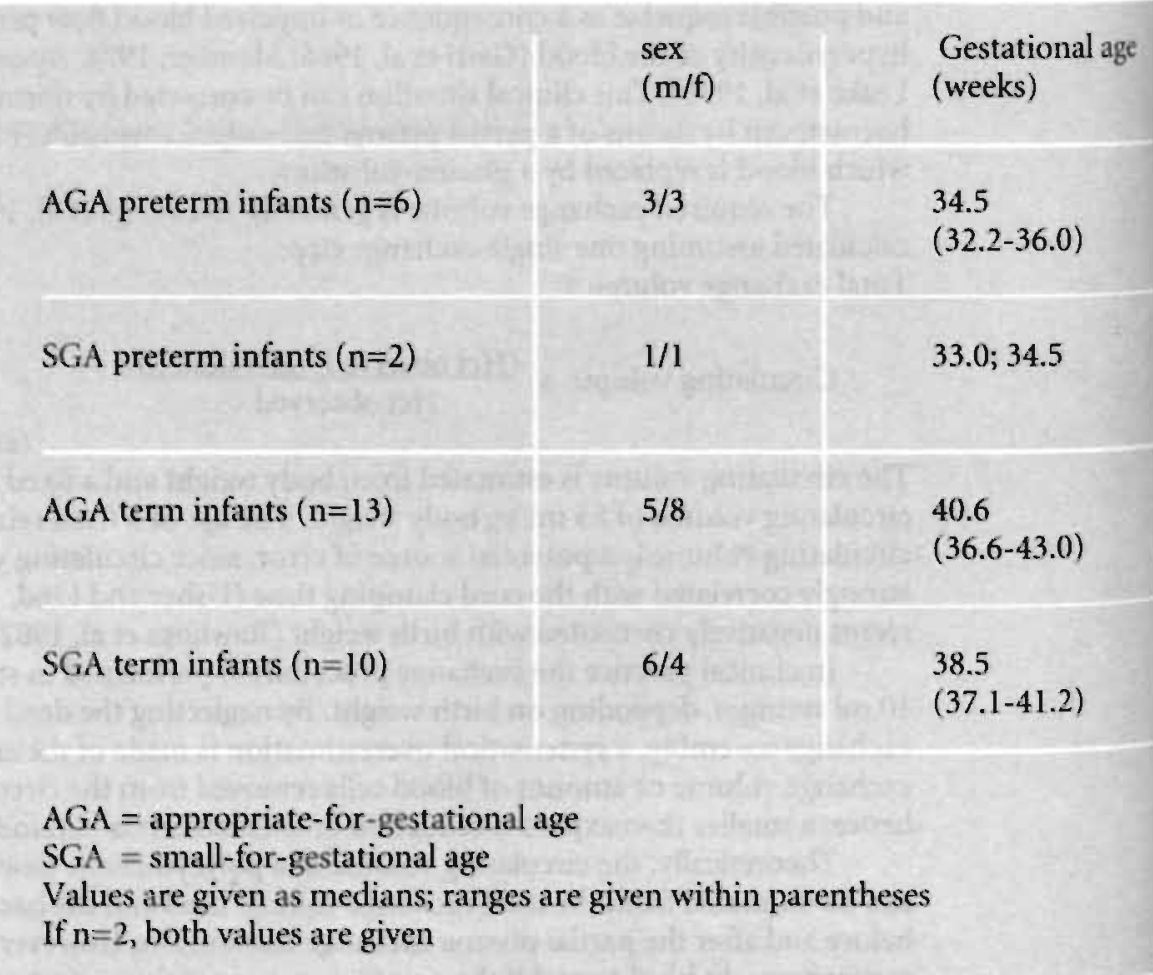


spontaneously. Umbilical cords were always clamped within one minute after birth. No patients suffered from asphyxia (defined as umbilical arterial $\mathrm{pH}<7.24$ or Apgar-score less than 7 at one minute after birth). The study group was divided into four subgroups, based on gestational age and whether they were appropriate-or small-for-gestational age (table 6.1.). Newborn infants were defined as small-for-gestational age if their birth weights were below the 3 rd centile. Capillary Hct was determined in all infants admitted to the nursery as a routine at three hours after birth. When the capillary Hct exceeded a level of $65 \%$, a peripheral venous blood sample was taken from an antecubital vein or from a vein on the back of the hand. PPET was indicated in all infants with a peripheral venous Hct exceeding $70 \%$, or in those infants with a peripheral venous Hct between $65-70 \%$ and presenting clinical symptoms probably due to hyperviscosity, like plethora, jitteriness and respiratory distress. As desired peripheral venous Hct after PPET a value of $58 \%$ was chosen.

Infants were weighed at admission and gestational age was determined from mother's history, fetal biparietal diameter and the criteria described by Dubowitz and colleagues (1970). The electrocardiogram was used to determine the heart rate; blood pressure was measured using a Dinamap 847 device, which is based on the oscillometric principle.

Birth weight

(g)

Central venous $\mathrm{Hct}(\%)$

before after

56.0

1940

(1255-2760)

64.5

$1250 ; 1430$

(2540-4640)

2280

(1205-2530)
65.0

(59.0-71.0)
(51.0-71.0)

$62.0 ; 71.0$

(45.0-59.0)

$54.0 ; 55.0$

65.0

(56.0-75.0)

56.0

(47.0-62.0)

56.0

(47.0-60.0)
Peripheral venous $\mathrm{Hct}(\%)$ initial

73.0

(67.0-78.0)

$74.0 ; 76.0$

70.0

(68.0-80.0)

71.5

(65.0-79.0) 


\section{Methods}

\section{Determination of haematocrit}

Haematocrits were measured in duplicate. Blood was sampled in heparinised $55 \mathrm{~mm}$ glass-tubes and spinned at $6000 \mathrm{rpm}$ for four minutes. Haematocrits were determined with a Hawksley micro-haematocrit reader.

\section{Procedure of partial plasma exchange transfusion}

Plasma containing 5\% albumin (Plasmanate) was used as exchange solution. The exchange transfusion was performed through a $5 \mathrm{~mm}$ catheter (Argyle) placed in the umbilical vein and advanced into the inferior vena cava. The catheter was connected to a three-way stopcock. A $5 \mathrm{ml}$ or $10 \mathrm{ml}$ syringe was used to withdraw within about 2 minutes, $4 \mathrm{ml}$ or $9 \mathrm{ml}$ of blood, respectively. Subsequently, $1 \mathrm{ml}$ of blood was withdrawn for Hct measurement. with another syringe after switching off the three-way stopcock to the other position. This was done to ensure minimal mixing of the blood sample taken for Hct determination with the remaining of plasmanate after a previous exchange injection. Then $5 \mathrm{ml}$, or $10 \mathrm{ml}$ (see below) plasmanate was given in about 2 minutes to replace the withdrawn blood. A period of one minute was allowed for recirculation of the injected exchange solution before the next withdrawal started. Each exchange cycle lasted for about 5 minutes.

The dead space of the system (catheter + three-way stopcock) was $0.7 \mathrm{ml}$. The exchange was performed using a $5 \mathrm{ml}$ syringe in infants with birth weights of less than $2000 \mathrm{~g}$ and a $10 \mathrm{ml}$ syringe when birth weights exceeded $2000 \mathrm{~g}$. The effective exchange volume was $4.3 \mathrm{ml}$ and $9.3 \mathrm{ml}$, respectively.

\section{Determination of circulating volume}

A central venous blood sample was taken immediately prior to the exchange procedure and as the last part of every exchange step for assessment of the central venous Hct.

For each exchange step, the circulating volume can be calculated if the Hct before and after exchange as well as the exchange volume are known. Rearranging equation (1) yields:

$$
\frac{\operatorname{Hct}(\mathrm{end})}{\operatorname{Hct}(0)}=\frac{\mathrm{CV}-\mathrm{EV}}{\mathrm{CV}}
$$

$$
\begin{aligned}
& \text { Hct(end) = Hct after the exchange step } \\
& \begin{array}{ll}
\mathrm{Hct}(0) & =\text { the initial Hct } \\
\mathrm{CV} & =\text { circulating blood volume } \\
\mathrm{EV} & =\text { the exchange volume (corrected for the dead space) }
\end{array}
\end{aligned}
$$

Since the procedure is performed in steps this relation should be applied repetitively. After $n$ steps of exchange the equation becomes

$$
\operatorname{Hct}(n) / \operatorname{Hct}(0)=[(\mathrm{CV}-\mathrm{EV}) / \mathrm{CV}]^{n}=[1-\mathrm{EV} / \mathrm{CV}]^{n}
$$


In principle, equation 3 can be used to calculate the circulating volume, if the number of steps, the true exchange volume, and initial and final haematocrit are known. However, a higher accuracy might be obtained if Hct is assessed after each exchange step and a regression is applied. Equation 3 can be rearranged:

$$
\log [\operatorname{Hct}(n) / \operatorname{Hct}(0)]=n \log [1-\mathrm{EV} / \mathrm{CV}]
$$

(equation 4)

The slope of the linear relation between $\log [\mathrm{Hct}(n) / \mathrm{Hct}(0)]$ and $n$ will yield $\log [1-\mathrm{EV} / \mathrm{CV}]$. Circulating volume may then be derived with sufficient accuracy from the point of intercept of the regresssion line with the $n=5$-axis. To this end one should plot CV / EV along this axis. Substitution of $n=5$ in equation 3 and rearranging yields the formula used:

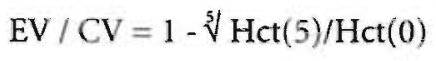

(equation 5)

By inter or extrapolation one finds CV / EV and, hence, CV.

\section{Statistical analysis}

Statistical analyses were performed using the Wilcoxon rank sum test and linear regression analysis. Data are presented as medians and ranges.

Twenty-four out of 31 polycythaemic newborn infants showed clinical symptoms and seven were asymptomatic. No major differences existed in the incidence of clinical symptoms between the four groups.

In polycythaemic preterm infants mean blood pressure was lower ( $44 \pm 6$ $\mathrm{mm} \mathrm{Hg}$ ) than in polycythaemic term infants $(52 \pm 6 \mathrm{~mm} \mathrm{Hg})$; heart rate in polycythaemic preterm infants was higher ( $138 \pm 12 \mathrm{bpm}$ ) than in polycythaemic term infants ( $120 \pm 8 \mathrm{bpm})$. Blood pressure and heart rate did not change after PPET. Median peripheral venous pre-exchange $\mathrm{Hct}$ was $72 \%$ (range 65\%-80\%) and median central venous pre-exchange $\mathrm{Hct}$ was $65.5 \%$ (range 51\%-75\%). Central venous $\mathrm{Hct}$ values before and after PPET and the initial peripheral venous $H c t$ values in the different subgroups of polycythaemic newborn infants are presented in table 6.1.. Pre-exchange levels in all subgroups were similar. No complications occurred during or after partial plasma exchange transfusion and clinical symptoms probably due to hyperviscosity disappeared after the procedure. 


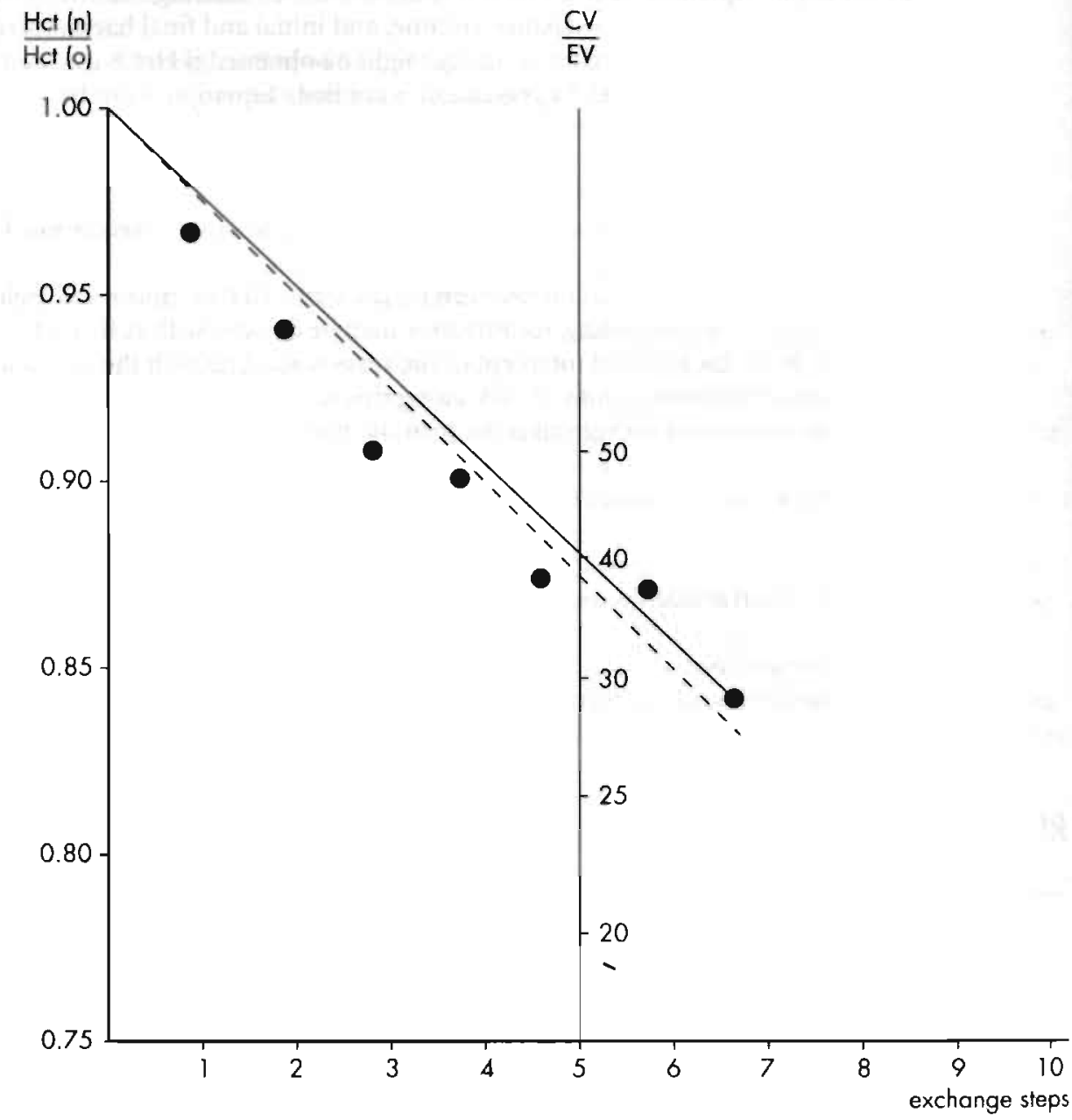

fig 6.1. Example of relative haematocrit after every exchange step as a function of the number of exchange steps in an appropriate-for-gestational age preterm female infant ( 34.4 weeks; $2760 \mathrm{~g})$. The scale of the ordinate is logarithmic. The slope of the dashed regression line represents $\log [1-\mathrm{EV} / \mathrm{CV}]$. Along the axis $n=5$ is given $C V / E V$, calculated using the formula $\mathrm{EV} / \mathrm{CV}=1 \cdot 5 \mathrm{Hct}(5) / \mathrm{Hct}(0)$. The solid line represents the slope between the initial and last Hct.

\section{Comparison of methods for determination of circulating volume}

Figure 6.1. illustrates the regression method used to determine circulating volume in one patient (gestational age $344 / 7$ weeks, birth weight $2760 \mathrm{~g}$ ). The central venous Hct measured after every exchange step was plotted against the central venous haematocrit before exchange and the linear regression was calculated (dashed line). Total circulating volume was determined from the 
intercept of this regression line at $n=5$. In the example presented in figure 6.1. the intersection point was 39.2 and the circulating volume in this patient was: calculated as $9.3 \times 39.2=365 \mathrm{ml}$. The intersection point of the solid line, presenting the decline from the initial $\mathrm{Hct}$ to the last $\mathrm{Hct}$, was 40.6 , yielding a circulating volume of $378 \mathrm{ml}$.

By using the regression line method in all polycythaemic newborn infants we found a median relative circulating volume of $94.0 \mathrm{ml} / \mathrm{kg}$ (range $69-143$ ). By using the decline from the initial Hct to the last Hct method we found a median relative circulating volume of $91.0 \mathrm{ml} / \mathrm{kg}$ (range 66-134). As it can be seen in the scatterplot (fig 6.2.), no systematic differences in circulating volume could be found when assessed by both methods. The data on circulating volume presented in this study were calculated using the linear regression method.

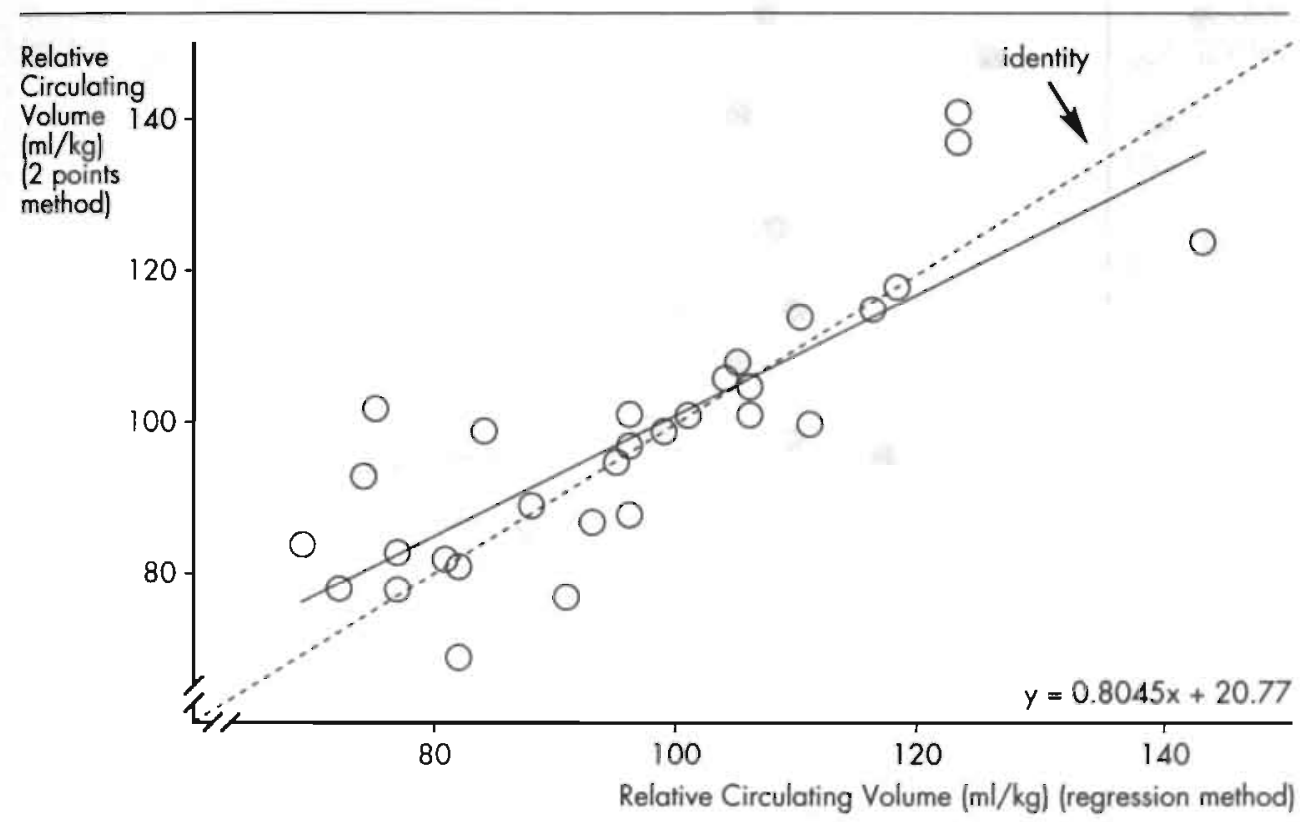

fig.6.2. Scatterplot of relative circulating volumes determined by the slope between initial and last Hct (two points method) and by the slope of the regression line (regression method). The dashed line presents the line of identity and the solid line presents the regression line. 
Circulating volume in appropriate- and small-for-gestational age polycythaemic newborn infants

Relative circulating volume as a function of birth weight for all polycythaemic newborn infants is presented in fig 6.3.. A negative, but not significant $(p=0.08)$ correlation was found between relative circulating volume and birth weight, when data of all infants were pooled. As indicated by the slope of the regression line, the influence of birth weight, if any, is limited. However, within the AGA or SGA subgroups no correlation existed between relative circulating volume and birth weight or gestational age.

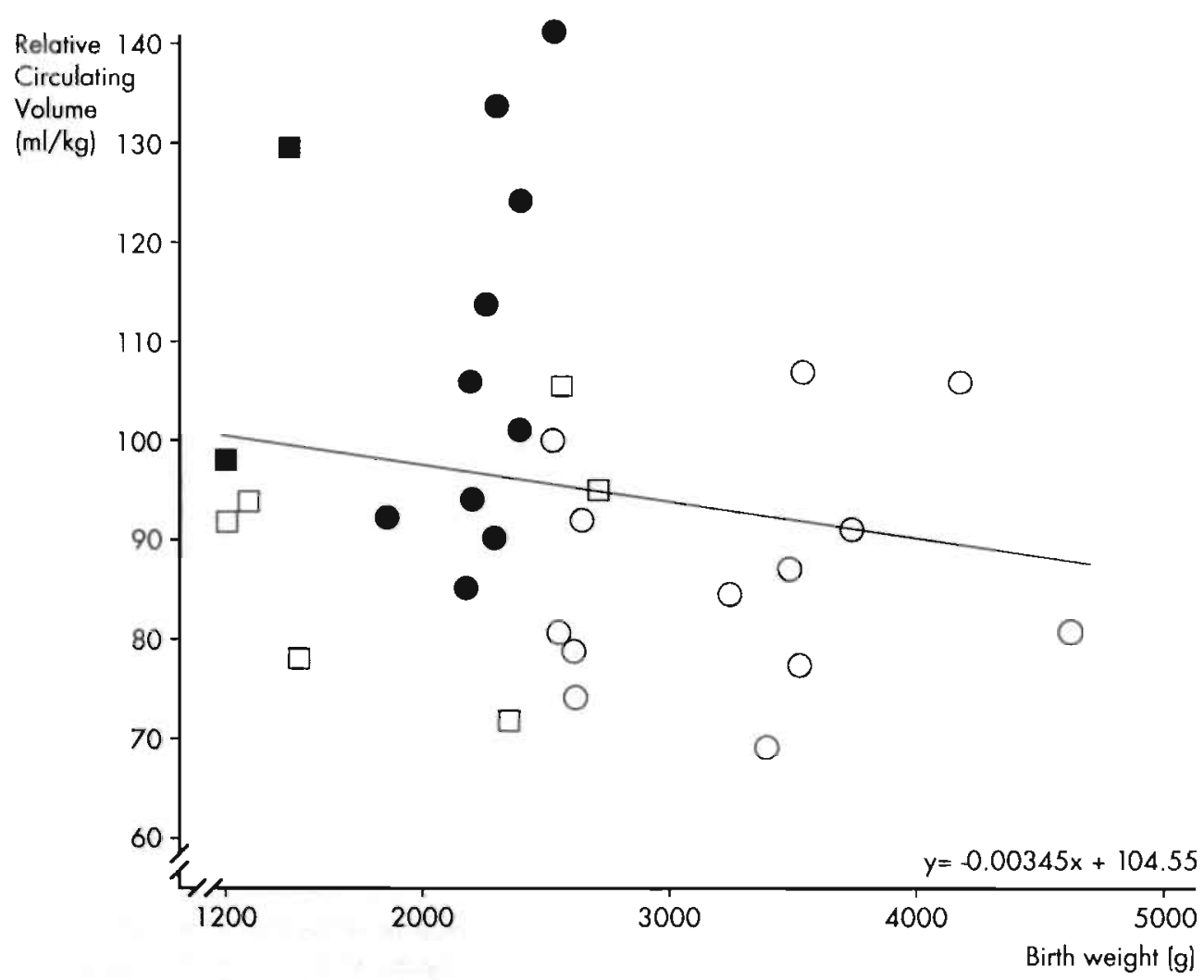

fig 6.3. Birth weight and relative circulating volume in polycythaemic newborn infants.

[ appropriate-for-gestational age preterm infants

$O$ appropriate-for-gestational age term infants

- small-for-gestational age prelerm infants

small-for-gestational age term infants 
Figure 6.4. depicts the relative circulating volumes in AGA term and preterm infants and in SGA term and preterm infants. As it can be seen in the figure, SGA polycythaemic newborn infants had a significantly higher relative circulating volume than AGA polycythaemic newborn infants ( $p<0.001$ ), irrespective of gestational age or birth weight. For AGA polycythaemic newborn infants the median relative circulating volume was 86.5 (range 69107 ) $\mathrm{ml} / \mathrm{kg}$ and for SGA it was 106 (range $85-143$ ) $\mathrm{ml} / \mathrm{kg}$ (term and preterm infants pooled in both groups).

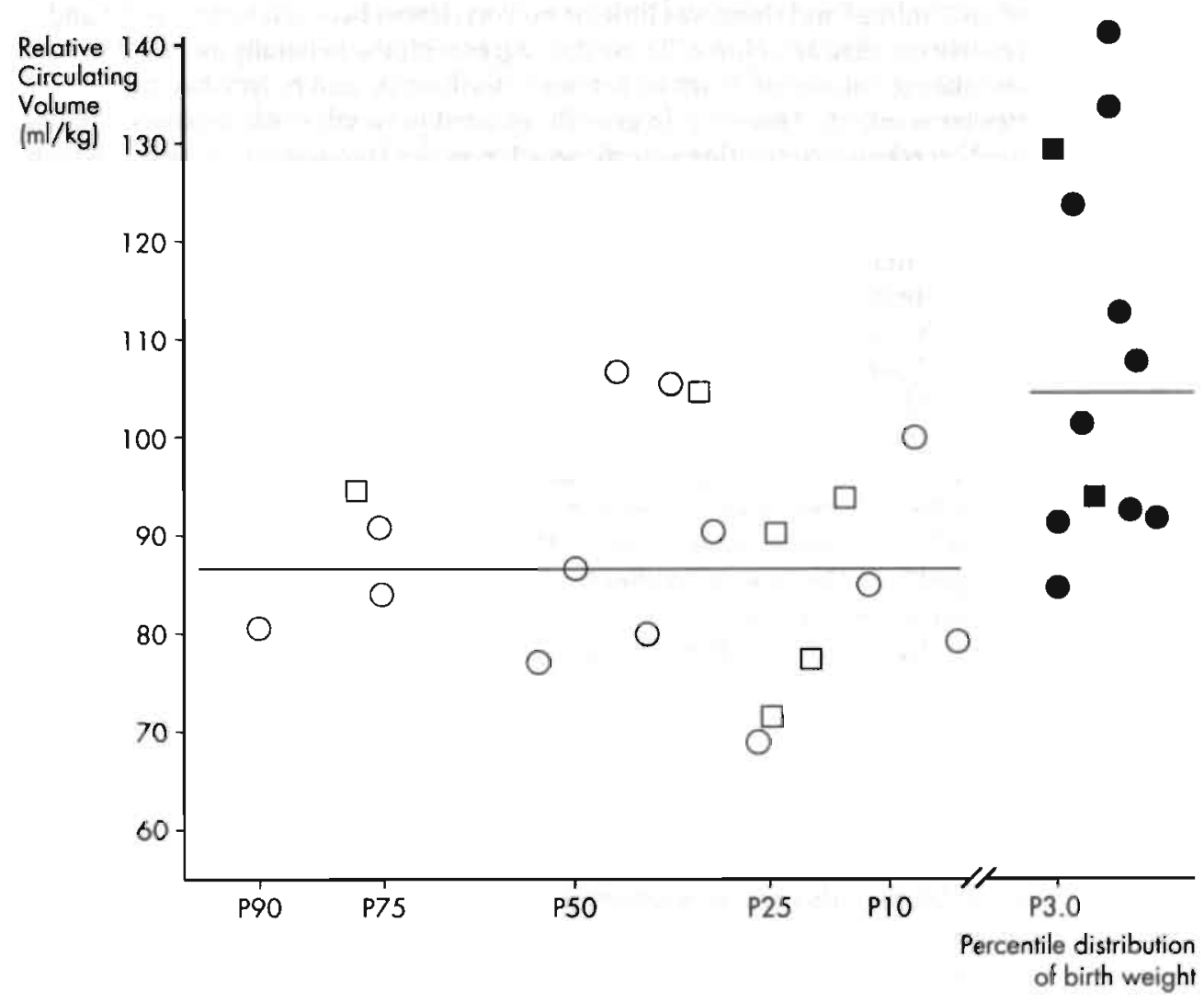

fig 6.4. Relative circulating volume as a function of intrauterine growth quality in polycythaemic newborn infants. Growth quality is expressed according to the percentile curve of growth.

$\square$ appropriate-for-gestational age preterm infants

$\bigcirc$ appropriate-for-gestational age term infants

small-for-gestational age preterm infants

small-for-gestational age term infants

Horizontal lines represent the median relative circulating volume in polycythaemic AGA and SGA infants. 


\section{DISCUSSION}

In 31 polycythaemic newborn infants relative circulating blood volume was assessed from the initial haematocrit and the haematocrits during and after PPET. Median relative circulating volume was $94 \mathrm{ml} / \mathrm{kg}$ but individual values varied considerably. Growth retardation was associated with a higher relative circulating volume whereas birth weight per se had a less clear influence.

The study group was divided by gestational age and birth weight. No differences in relative circulating volume between appropriate-for-gestational age preterm and term polycythaemic newborn infants were found. In these groups relative circulating volumes varied widely (median $86.5 \mathrm{ml} / \mathrm{kg}$, range 69-107 ml/kg) and there was little or no correlation between birth weight and relative circulating volume. These data agree with the generally assumed circulating volume of $85 \mathrm{ml} / \mathrm{kg}$ for normocythaemic and polycythaemic newborn infants. However, in growth retarded polycythaemic newborn infants, median relative circulating volume was $106 \mathrm{ml} / \mathrm{kg}$ (range $85-143 \mathrm{ml} / \mathrm{kg}$ ), which is significantly higher than in appropriate-for-gestational age preterm and term infants. This might be due to increased erythropoiesis or to a redistribution of the placental-fetal blood volume which result in an increased relative blood volume in infants with placental insufficiency and chronic fetal distress. (Cassady, 1970). The negative correlation between relative circulating volume and birth weight in all polycythaemic newborn infants was largely attributable to the influence of the subgroup of growth retarded infants.

Circulating volumes can differ widely due to perinatal redistributions of blood and the extent of placental transfusion (Usher et al, 1963; Yao and Lind, 1974). In normocythaemic newborn infants the circulating volume largely depends on the cord clamping time. The relative circulating volume in early clamped (less than 1 minute after birth) normocythaemic newborn infants at 4 hours after birth is about $78 \mathrm{ml} / \mathrm{kg}$, increasing to $99 \mathrm{ml} / \mathrm{kg}$ in late clamped (more than 5 minutes after birth) infants (Usher et al, 1963; Usher and Lind, 1965). In our study cords were clamped within 1 minute after birth and PPET and determination of circulating volume was standardised at three to four hours after birth when plasma shifts have been completed (Yao and Lind, 1974). In our study the median relative circulating volume was $94 \mathrm{ml} / \mathrm{kg}$ for the whole group, which is considerably higher than the average value of $78 \mathrm{ml} / \mathrm{kg}$ reported for normocythaemic newborn infants (Usher et al, 1963; Usher and Lind, 1965). Other workers reported an average value of relative circulating blood volume of $100 \mathrm{ml} / \mathrm{kg}$ (range $76-141 \mathrm{ml} / \mathrm{kg}$ ) (Brans et al, 1981) and 88.4 $\mathrm{ml} / \mathrm{kg}$ (range 44-176 ml/kg) (Rawlings et al, 1982) in polycythaemic newborn infants, which complies better with our study. However, in these studies no differentiation was made between data of different subgroups of polycythaemic newborn infants (Rawlings et al, 1982) and no correlation was found between relative circulating blood volume and the quality of intrauterine growth (Brans et al, 1981).

PPET is usually performed through a catheter placed in the inferior vena cava. After isovolaemic haemodilution with a plasma equivalent the haematocrit was found higher than expected (Brans et al, 1981). In our study we took into account the dead space in the assembly and the stepwise nature of the exchange procedure. The influence of stepwise removal and infusion, rather than one single exchange, on the final haematocrit is limited and leads to a 
small underestimation of the circulating volume. However, a considerable underestimation occurs, if the dead space is neglected, especially in low birth weight infants in whom PPET is performed in small aliquots. Some authors (Campbell and Stewart, 1979; Scarcella and Gambardella, 1986) recommend to use two peripheral vessels for PPET in order to avoid the problems of the dead space and the potential risk of catheterisation of the umbilical vein.

A disadvantage of the two-vessel method is that two operators are necessary and that a peripheral artery has to be cannulated. Although there are poteritial risks in the catheterisation of the umbilical vein, in our hands no complications occurred.

Differences in haematocrits values between capillary blood obtained by heel stick and simultaneously obtained peripheral venous blood, and between peripheral venous blood and central venous blood were considerable and unpredictable. These findings are in agreement with some other studies (Oh and Lind, 1966; Linderkamp et al, 1977b; Ramamurthy and Berlanga, 1987). Higher haematocrits in capillary blood and in venous blood obtained from small peripheral vessels with low shear rate are probably due to sludging of red cells. In clinical practice haematocrits obtained from large peripheral vessels may be a better selection criterion for PPET.

Infants with low birth weight are at risk for disturbances in blood flow. We recommend to use for the calculation of exchange volume in growth retarded infants a larger relative circulating volume than in appropriate-forgestational age infants. When a PPET is indicated the desired haematocrit will be better approximated if the exchange volume is calculated based on a circulating volume of $86 \mathrm{ml} / \mathrm{kg}$ for appropriate-for-gestational age infants and of $106 \mathrm{ml} / \mathrm{kg}$ in growth retarded infants. Determination of a central venous haematocrit after the last exchange step is sufficient to calculate with enough accuracy the exchange volume necessary to reach the desired haematocrit. 


\section{PLASMA VISCOSITY IN POLYCYTHAEMIC NEWBORN INFANTS}

W.J. Maertzdorf (1), D.W. Slaaf (2), G.J. Tangelder (3) and C.E. Blanco (1)

Academic Hospital Maastricht, Departments of Neonatology (1),

Biophysics (2), and Physiology (3), University of Limburg, Maastricht, The Netherlands

Eur. J. Pediatr. : accepted for publication 
Plasma viscosity was determined in 46 polycythaemic newborn infants and in 42 matched normocythaemic infants. The infants were divided in preterm, small-for-gestational age and appropriate-for-gestational age term infants. In normocythaemic preterm infants plasma viscosity (median 1.055 $\mathrm{mPa}$.s) was significantly lower than in small-for-gestational age infants (median $1.155 \mathrm{mPa} . \mathrm{s}$ ) and in appropriate-for-gestational age infants (median 1.135 $\mathrm{mPa} . \mathrm{s}$ ). In the polycythaemic study group preterm infants also had significantly lower plasma viscosity levels (median $1.009 \mathrm{mPa} . \mathrm{s}$ ) than small-(median 1.090 $\mathrm{mPa} . \mathrm{s}$ ) and appropriate- (median $1.073 \mathrm{mPa} . \mathrm{s}$ ) for-gestational age term infants. Polycythaemic newborn infants had significantly lower plasma viscosity levels than normocythaemic newborn infants in all 3 subgroups.

There was no correlation between plasma viscosity values and haematocrit. Polycythaemic low birth weight infants with clinical symptoms had significantly higher plasma viscosity values than infants without clinical symptoms. We suggest that the presence of clinical symptoms in polycythaemic newborn infants might be related to factors which are reflected by an increase in plasma viscosity.

\section{INTRODUCTION}

Polycythdemia in newborn infants (defined as a peripheral venous haematocrit exceeding 65\%) may lead to a variety of clinical symptoms as: lethargy, jitteriness (Gross et al, 1973), cyanosis and respiratory distress (Gatti et al, 1966), plethora (Saigal and Usher, 1977), renal failure (Aperia et al, 1974) and feeding problems (Wiswell et al, 1986). These clinical symptoms are probably the result of impaired blood flow due to a rectuced fluidity of the blood and they disappear after haemodilution (Maertzdorf et al, 1991). Haemodilution not only decreases haematocrit $(\mathrm{Hct})$, but may also influence other factors which contribute to whole blood viscosity.

Resistance to flow is determined by geometrical factors of the vasculature and the properties of the circulating blood. Under physiological conditions whole blood viscosity is mainly determined by the red cell mass (Pearson et al, 1980). However, parameters like plasma viscosity, red cell aggregation and red cell deformability also have an influence on whole blood viscosity. Whether or not and to what extent these factors contribute to clinical symptomatology in polycythaemic newborn infants is still unknown.

Plasma viscosity plays a major role in blood fluidity in small nutritive capillaries, where the Hct may be low, due to the Făhraeus-Lindqvist effect. At the microcirculation level viscous forces dominate perfusion, and fluidity of blood approximately equals that of plasma (Rosenblum, 1972). The clinical significance of plasma viscosity as a factor for circulatory problems in adults has been emphasized by several authors. A deviating plasma viscosity is caused by changes in plasma protein composition as it is seen in some clinical disorders such as infectious diseases, neoplasms, rheumatic diseases and cardiovascular disorders (Harkness, 1971; Dintenfass and Kammer, 1977; Jung et al, 1986). A deviating plasma viscosity might have a direct pathophysiological effect by decreasing blood fluidity. At present it is not 
known, however, whether still unknown factors are the cause of the primary disease and whether plasma viscosity is only a reflection of these abnormalities. Plasma viscosity rises progressively with advancing gestational age but it is still lower in term newborn infants than in adults (Buchan, 1984; Linderkamp et al, 1984; Rampling et al, 1989). These differences are due to low concentrations of large protein molecules in newborn infants, and to fetal variants of fibrinogen, characterized by increased sialic acid residues, which result in lower plasma viscosity (Rampling et al, 1989).

In order to study the possible effects of plasma viscosity in polycythaemic newborn infants we measured plasma viscosity in polycythaemic preterm and small-(SGA) and appropriate-(AGA) for-gestational age term infants and in matched controls, and investigated the possible relation between the level of plasma viscosity and the occurrence of clinical symptoms in polycythaemic newborn infants.

\section{PATIENTS AND METHODS}

Plasma viscosity was measured in 46 polycythaemic newborn infants and in 42 matched controls. Table 7.1. summarises gestational age, birth weight and peripheral venous Hct of the three subgroups of polycythaemic infants, as well as of the three control groups consisting of normocythaemic newborn infants, matched for sex, gestational age and birth weight. Preterm infants were defined as birth before 37 weeks of gestation and term infants as birth between 37 and 42. weeks of gestation. Infants were defined as small- for-gestational age if birth weight was less than the 3 rd percentile of the intrauterine growth curve (Lubchenco et al, 1963).

Capillary Hct was determined in all infants admitted to the neonatal unit as a routine at three hours after birth. When the capillary Hct was $\geq 70 \%$, a peripheral venous blood sample was taken from an antecubital vein or from a vein on the back of the hand. All infants with a venous $\mathrm{Hct} \geq 70 \%$, or between $65-70 \%$ with clinical symptoms were included in this study. Plethora, cyanosis, respiratory distress, lethargy or jitteriness were considered clinical symptoms due to impaired blood flow if no other reasons for those symptoms could be found. The maternal history was reviewed and nicotin abuse was defined as smoking $>5$ cigarettes per day. To obtain plasma, the blood was spinned at $6000 \mathrm{rpm}$ for 8 minutes. The supernatant plasma was gently aspirated and stored at $-30^{\circ} \mathrm{C}$. Plasma from control infants was collected and handled in the same way. In a pilot study we found that freezing and thawing the plasma of newborn infants had no influence on plasma viscosity (unpublished observations).

Plasma viscosity was measured using a capillary tube viscometer (type KSPV 3, Myrenne GmbH, Roetgen, Germany). According to the recommendations of the International Committe for Standardisation in Haematology (1984) measurements were performed at $37^{\circ} \mathrm{C}$ standard working temperature. The instrument was calibrated by means of standard solutions with known viscosity. Plasma viscosity was determined from the time the fluid needed to pass two graduation points, and it was expressed in mPa.s. 
table 7.1. Gestational age, birth weight and peripheral venous haematocrit in polycythaemic preterm, small-for-gestational age (SGA) and appropriate-forgestational age (AGA) term newborn infants and in matched controls. Numbers after the period in gestational age refer to the day in a week.

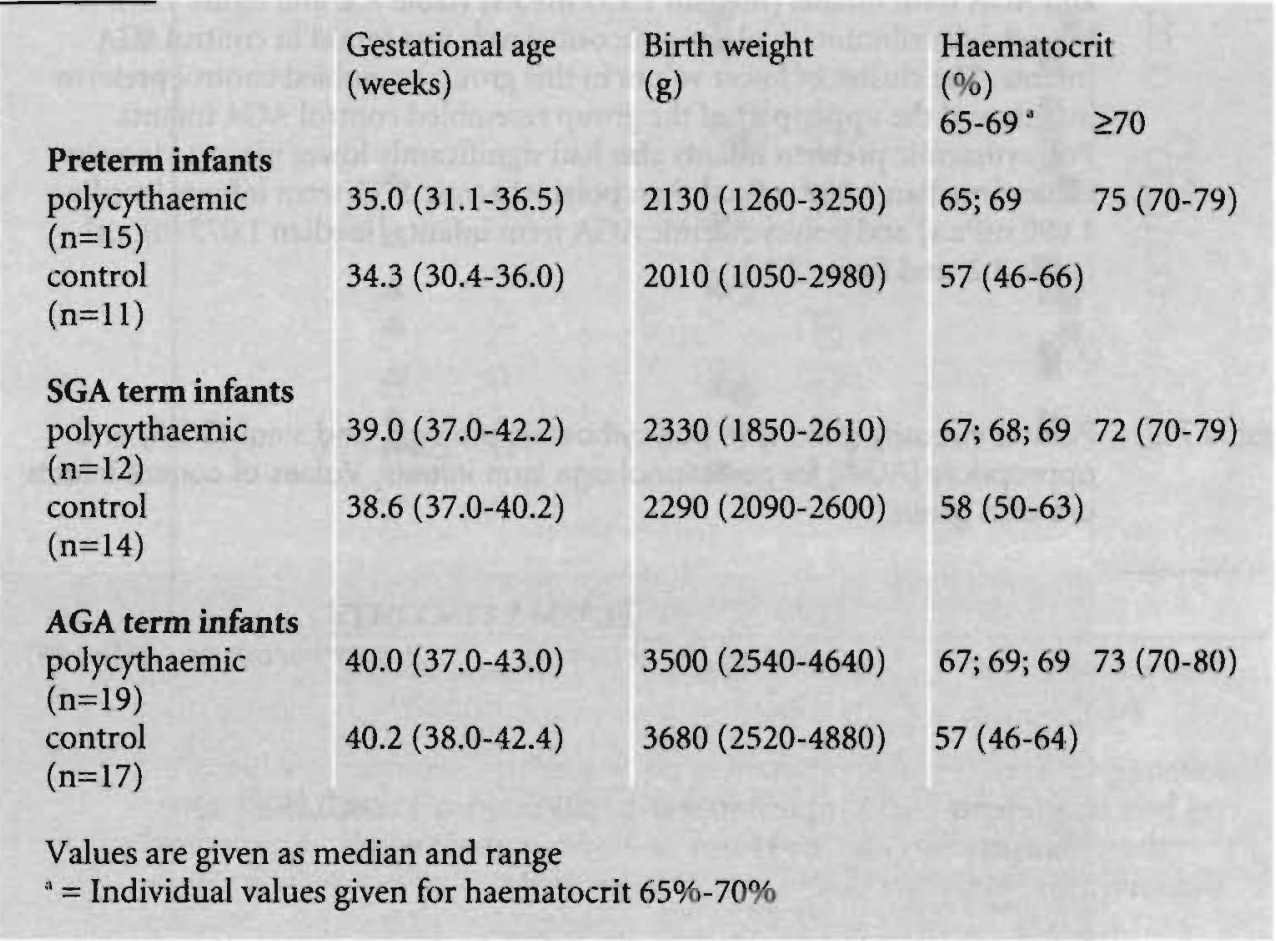

Data are presented as median and range. Differences between groups and between polycythaemic infants and control infants were tested with the Kruskall-Wallis test. The coefficient of correlation was used to express the correlation between two variables. A difference was considered to be statistically significant when $\mathrm{p}<0.05$. 


\section{RESUITS}

In normocythaemic control infants plasma viscosity values increased with gestational age. In preterm infants plasma viscosity [median $1.055 \mathrm{mPa} . \mathrm{s}$ ] was significantly $(\mathrm{p}<0.05)$ lower than in SGA term infants [median $1.155 \mathrm{mPa} . \mathrm{s}$ ] and AGA term infants [median $1.135 \mathrm{mPa} . \mathrm{s}$ ] (table 7.2. and figure 7.1.). A bimodal distribution in plasma viscosity levels was found in control SGA infants. The cluster of lower values in this group resembled control preterm infants and the upper part of the group resembled control AGA infants. Polycythaemic preterm infants also had significantly lower plasma viscosity values [median $1.009 \mathrm{mPa} . \mathrm{s}$ ] than polycythaemic SGA term infants [median $1.090 \mathrm{mPa} . \mathrm{s}$ ] and polycythaemic AGA term infants [median $1.073 \mathrm{mPa} . \mathrm{s}$ ] (table 7.2. and figure 7.1.).

table 7.2. Plasma viscosity (mPa.s) in polycythaemic preterm, and small-(SGA) and appropriate-(AGA) for-gestational age term infants. Values of control infants are also given.

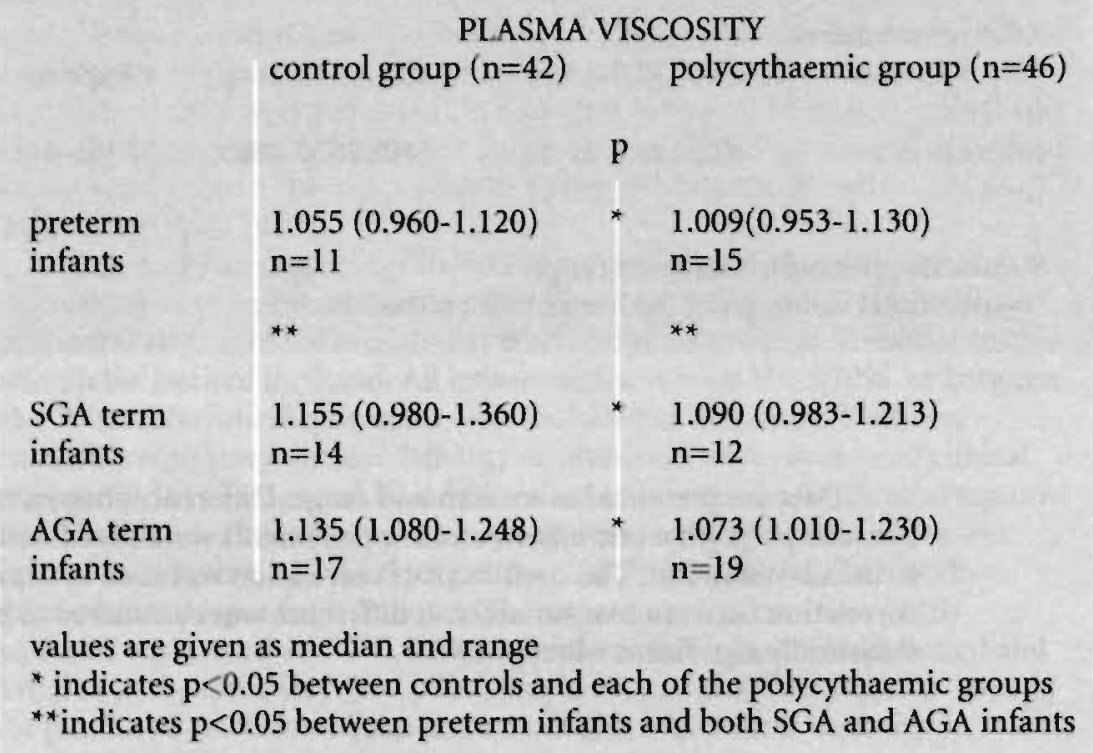




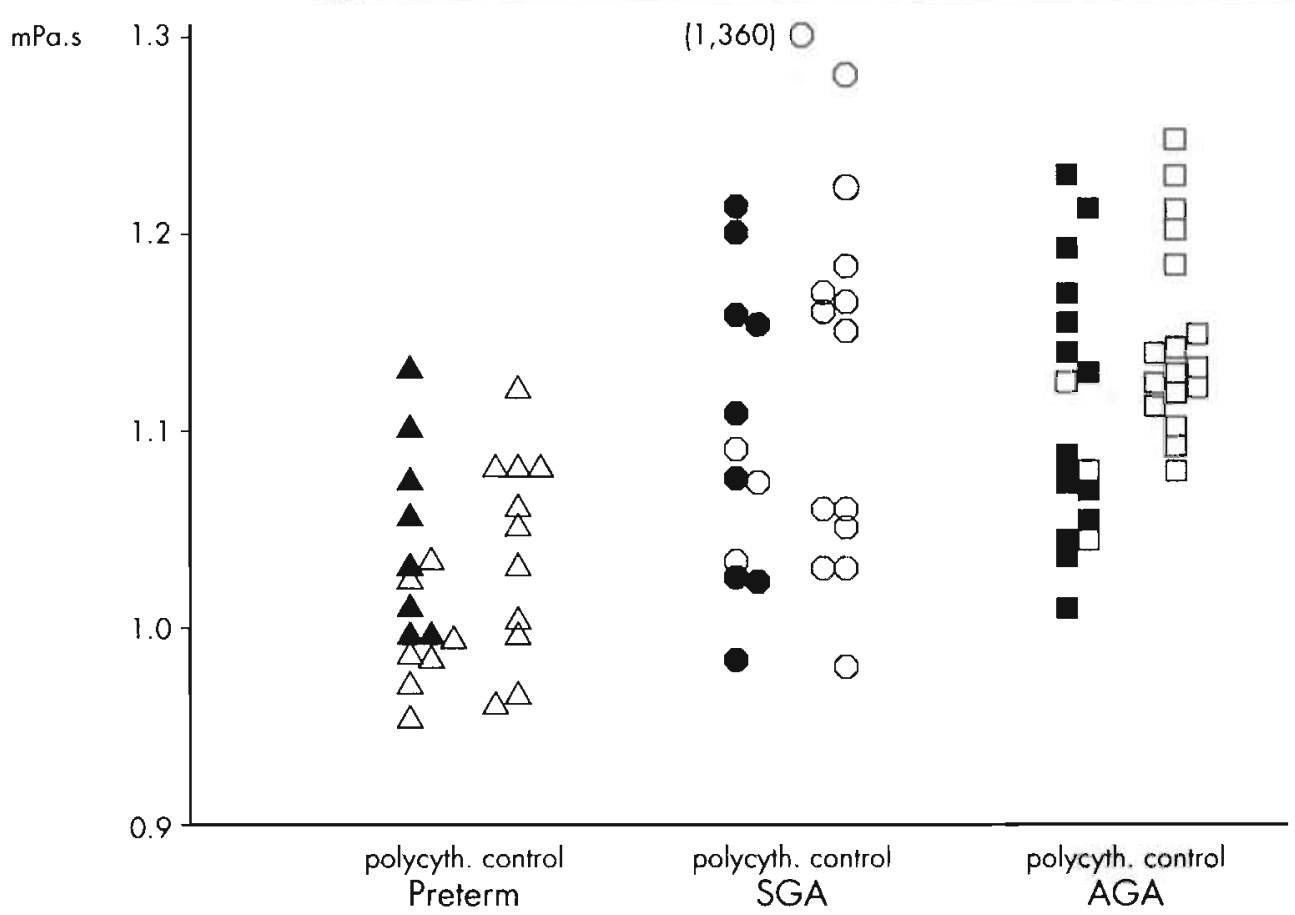

fig 7.1. Plasma viscosity levels (mPa.s) in polycythaemic preterm, small-for-gestational age [SGA] and appropriale-for-gestational age (AGA) term infants and in matched controls. Open symbols represent controls and polycythaemic infants without clinical symptoms. Closed symbols represent polycythaemic infants with clinical symptoms.

Plasma viscosity in each of the 3 subgroups of polycythaemic infants was significantly lower than in the corresponding control group. In preterm infants it was lower by $4.6 \%$, in SGA infants by $5.8 \%$ and in AGA term infants by $5.6 \%$. In each of the corresponding subgroups, however, there was a considerable overlap.

Twenty-five of the 38 newborn infants with a $\mathrm{Hct} \geq 70 \%$ had clinical symptoms (66\%), and 13 infants ( $34 \%$ ) had no clinical symptoms (figure 7.1 ). The incidence of clinical symptoms in preterm infants with Hct values $\geq 70 \%$ was $46 \%$, in SGA infants $67 \%$, and in AGA term infants $81 \%$. The incidence of clinical symptoms in polycythaemic preterm infants was significantly less $(p<0.05)$ than in polycythaemic SGA + AGA term infants. Plasma viscosity levels in polycythaemic newborn infants as related to the presence or abscence of clinical symptoms are presented in figure 7.2.. 


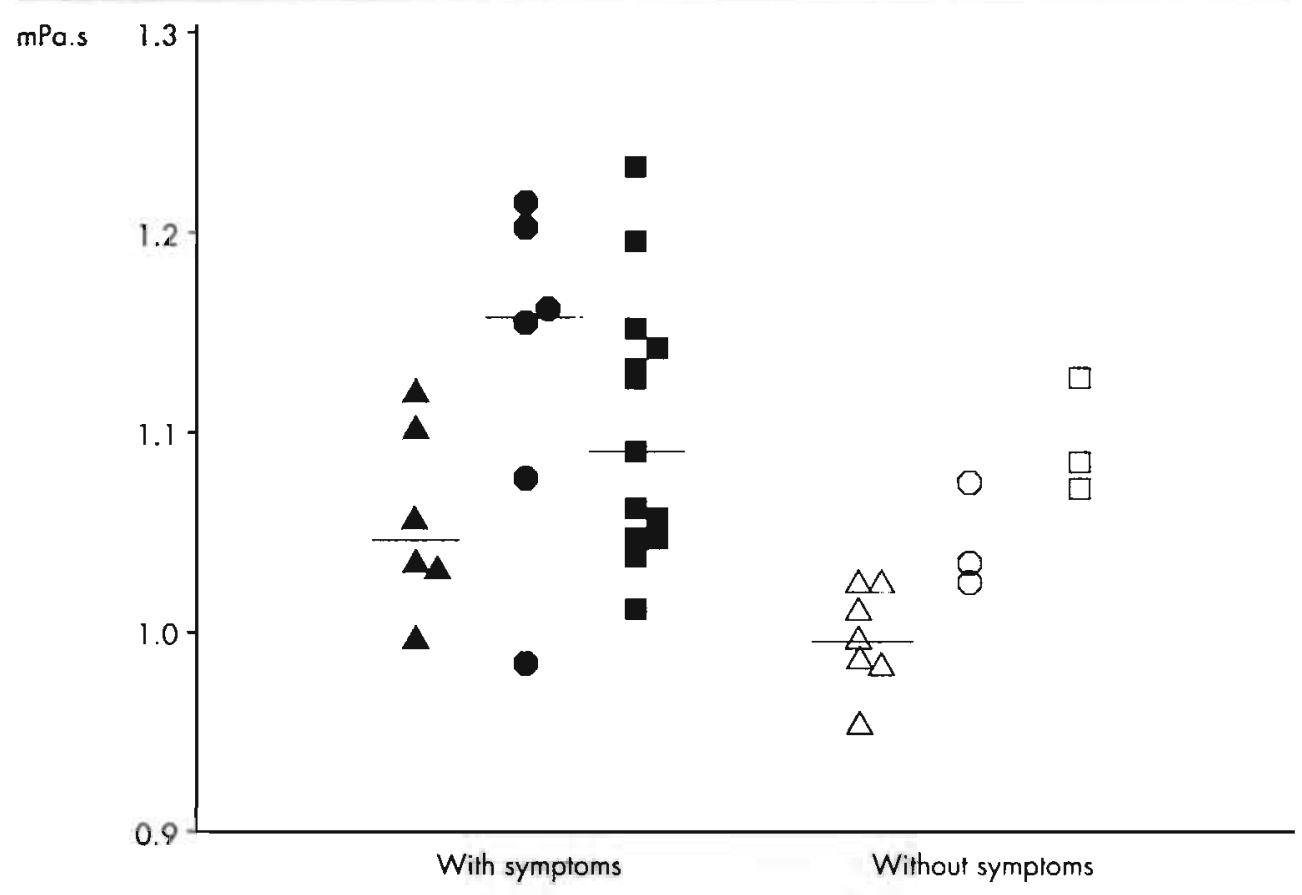

fig 7.2. Plasma viscosity levels (mPa.s) in preterm, small-(SGA) and appropriate(AGA) for-gestational age infants with haematocrit values $\geq 70 \%$. Closed symbols represent infants with clinical symptoms and open symbols represent infants without clinical symptoms. Preterm infants are indicated by triangles, SGA infants by circles and AGA infants by squares. Median is given as horizontal bars.

It can be seen that symptomatic preterm infants had significantly $(\mathrm{p}<0.05)$ higher plasma viscosity levels (median $1.045 \mathrm{mPa} . \mathrm{s})$ than preterm infants without symptoms (median $0.995 \mathrm{mPa} . \mathrm{s}$ ). The 3 polycythaemic SGA infants without clinical symptoms had significantly lower $(\mathrm{p}<0.05)$ plasma viscosity values $[1.023,1.030$, and $1.073 \mathrm{mPa} . \mathrm{s}]$ than $\mathrm{SGA}$ infants with clinical symptoms [median 1.133 (range 0.983-1.213) $\mathrm{mPa} . \mathrm{s}$ ], and those levels were similar to the level in the low part of the bimodal distribution of control SGA infants (fig. 7.1.). In polycythaemic AGA infants no differences in plasma viscosity levels were found between infants with and without clinical symptoms. It has to be emphasized, however, that the number $(n=6)$ of polycythaemic term infants ( $S G A+A G A$ ) without clinical symptoms was small. 
Figure 7.3. shows the scatterplot of plasma viscosity versus $\mathrm{Hct}$ in polycythaemic infants with and without clinical symptoms. There was no correlation between plasma viscosity levels and Hct values in both infants with clinical symptoms $(\mathrm{p}=0.64)$ and infants without clinical symptoms $(\mathrm{p}=0.66)$. The plot also shows that Hct did not differ between infants with and without clinical symptoms.

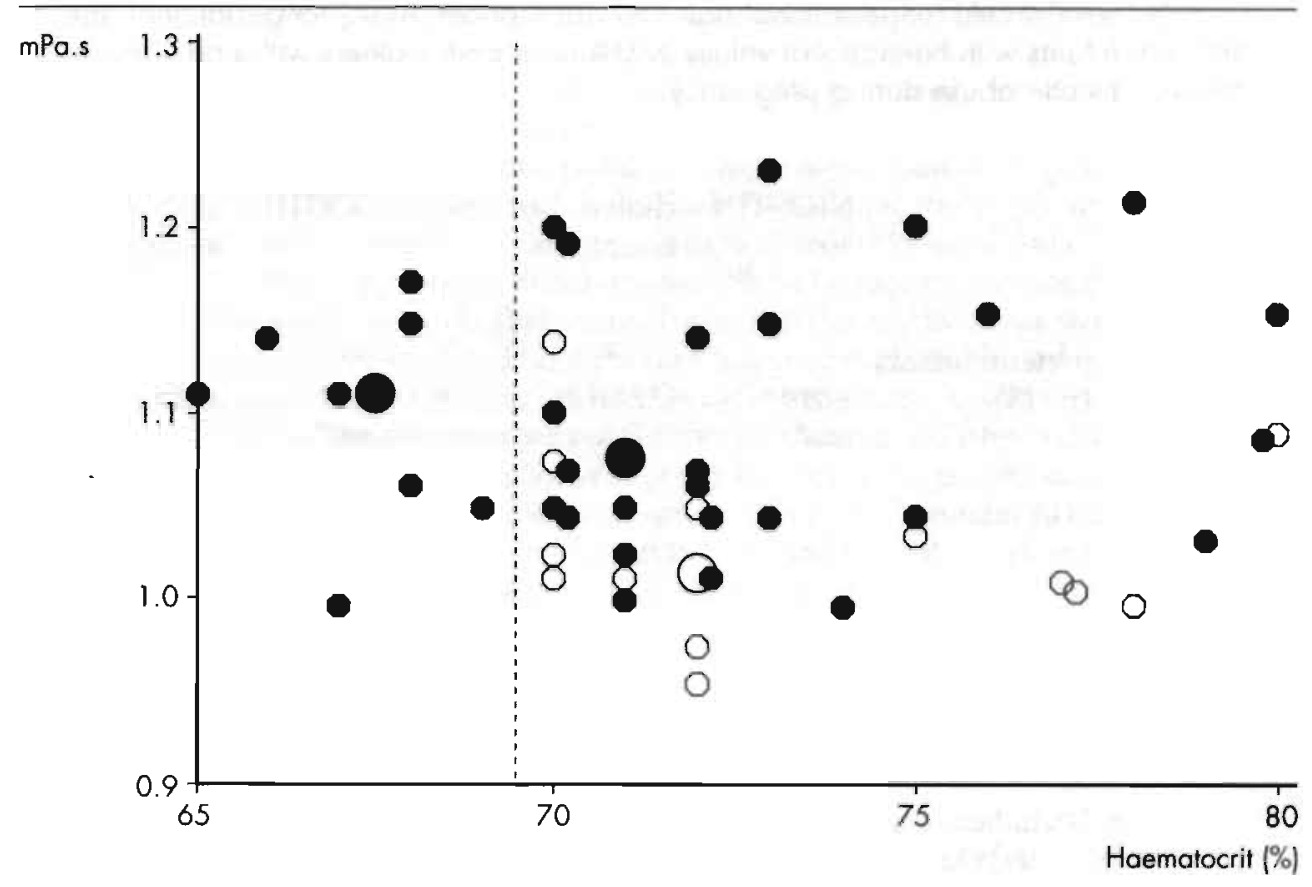

fig 7.3. Scatterplot of plasma viscosity levels (mPa.s) versus haemalocril (\%) in polycythaemic newborn infants (all subgroups pooled) with (closed circles) and without (open circles) clinical symptoms. The large open circle represents the median in haematocrit/viscosity values for infants without clinical symptoms, and the large closed circles for infants with clinical symptoms in the haematocrit range $65-69 \%$ and haematocrit values $\geq 70 \%$, respectively. 
In polycythaemic preterm and SGA infants maternal smoking was strongly correlated with the presence of clinical symptoms (table 7.3.).

Maternal smoking was not correlated with higher Hct or plasma viscosity levels (table 7.3.).

rable 7.3. Plasma viscosity levels (mPa.s) and percentage of clinical signs in preterm, small-(SGA) for-gestational age and appropriate-(AGA) for-gestational age infants with haematocrit values $\geq 70 \%$ born from mothers with and without nicotin abuse during pregnancy.

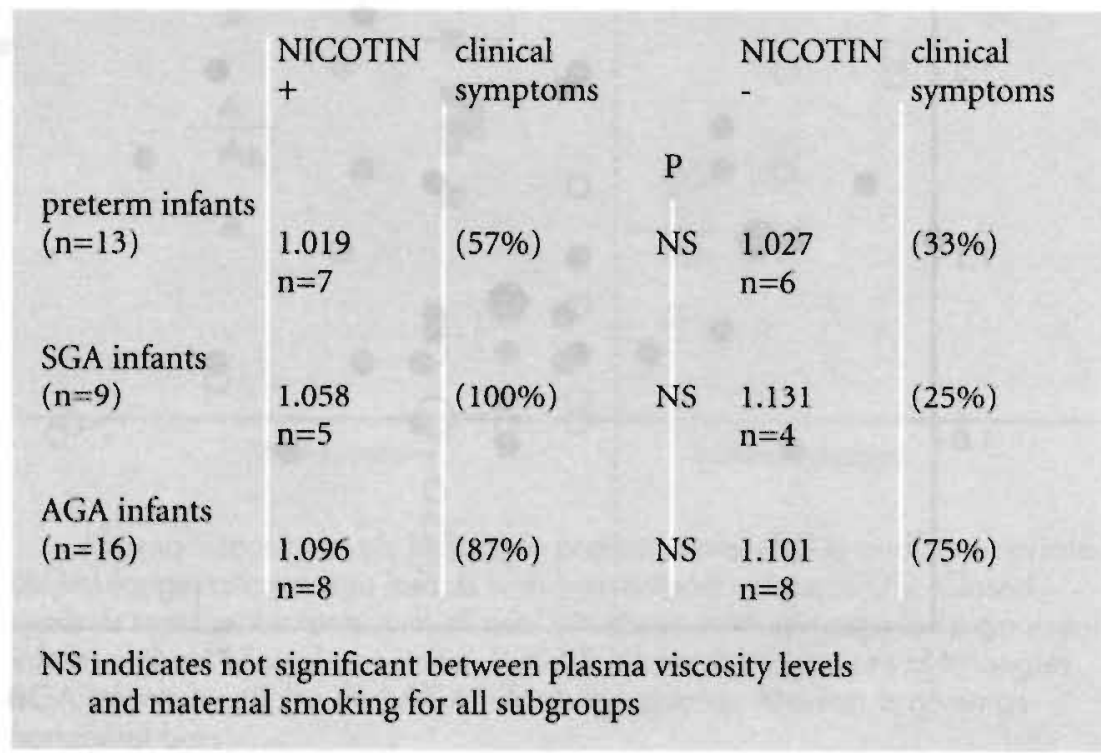




\section{DISCUSSION}

The present study shows that in normal infants plasma viscosity increased with gestational age. Plasma viscosity in polycythaemic preterm, SGA and AGA term infants was lower than in matched controls. As in normocythaemic infants, also polycythaemic preterm infants had lower plasma viscosity values than polycythaemic SGA or AGA term infants. In polycythaemic preterm and SGA newborns, infants with clinical symptoms had a significantly higher plasma viscosity than infants without clinical symptoms. Maternal smoking was in polycythaemic preterm and SGA infants strongly correlated with the presence of clinical symptoms.

Polycythaemic infants did not always show clinical symptoms. Sixty-six percent of the infants with Hct values $\geq 70 \%$ in our study presented clinical symptoms, which is similar to values reported by $W$ iswell and colleagues (1986). Analyzing the distribution of clinical symptoms among the various subgroups we found that its incidence in preterm infants was significantly less than in term infants. This difference might be explained by a difference in plasma composition, as reflected in the lower plasma viscosity in preterm infants. This points to the possibility that rheological factors related to plasma composition, such as plasma viscosity and red cell aggregation, play a role in the development of flow disturbances. Whether other, not yet known plasma factors also play a role in blood flow regulation is still an open question.

Maternal blood and cord blood do not differ in whole blood viscosity (Reinhart et al, 1985). This is surprising, since $\mathrm{Hct}$ in cord blood is much higher than in maternal blood. However, the plasma composition in newborn infants has favourable effects on the flow properties of blood. Therefore, any condition that might alter plasma composition in polycythaemic infants may have an impact on blood flow. If plasma protein composition changes in such a way that plasma viscosity and red cell aggregation increase, flow velocity in the microcirculation will decrease, resulting in an impaired organ perfusion. Rivers and colleagues (1984) suggest that monomerfibrinogen complexes play a role in compromising the microcirculation by increasing the red cell aggregation. Another negative factor which might play a role is the abscence of fetal fibrinogen and an excess of adult fibrinogen not containing sialic acids which improve fluidity of blood (Rampling et al, 1984).

Hyperviscosity is a clinical entity associated to symptoms due to decreased fluidity of blood. It is caused by friction between fluid layers, which results in impaired organ perfusion in the newborn infant. The incidence of the hyperviscosity syndrome is higher than that of neonatal polycythaemia (Rosenkrantz and Oh, 1986). Therefore, factors other than red blood cell mass might also contribute to blood flow disturbances in newborn infants suffering of the hyperviscosity syndrome. The blood viscosity of these infants is elevated because of increased concentration of macroglobulins or decreased red cell deformability. Pearson and colleagues (1980) found that the Hct alone is not a good predictor of whole blood viscosity and that plasma viscosity is an important additional factor. Riopel and colleagues (1982) suggest that the neonatal hyperviscosity syndrome is most likely caused by the combination of an increased Hct and an elevation of plasma viscosity. However, these latter findings could not be confirmed by our data. We found no differences in plasma viscosity levels between symptomatic infants with moderate 
polycythaemia (Hct 65\%-70\%) and symptomatic infants with high Hct levels $(\mathrm{Hct} \geq 70 \%)$. Moreover, plasma viscosity levels in symptomatic infants with moderate polycythaemia were still lower than in control infants.

Although it is recommended to perform a haemodilution in all newborn infants with a venous Hct exceeding 65\% (Black et al, 1982; Walker, 1988), the need for this treatment was doubted by others (van der Elst et al, 1980; Høst and Ulrich, 1982). Rosenkrantz and Oh (1986) conclude that all infants with a venous Hct exceeding $65 \%$ are hyperviscous and that in those infants a partial plasma exchange transfusion is indicated. With such a procedure the Hct and plasma viscosity are lowered and simultaneously constituents which can be held responsible for the impairment of blood fluidity can be removed.

Regarding the different effects of polycythaemia in different subgroups of newborn infants observed in this study, we suggest that in the decision to perform a haemodilution the maturation of the infant and the presence of clinical manifestations are also to be taken into account.

Clinical symptoms in polycythaemic low birth weight infants were more often present in infants born from mothers who smoked during pregnancy, but this finding could not be explained by a difference in Hct or plasma viscosity. One explanation for this finding might be that nicotin decreases the red cell deformability but has no influence on plasma viscosity (Buchan, 1984). Another possibility is that tissue functioning becomes more susceptible to flow disturbances due to direct effects of nicotin. Moreover, withdrawal of nicotin resulting in clinical symptoms can not be excluded.

Manipulation of blood composition such as exchange transfusion, red cell transfusion and infusion of fresh frozen plasma is an accepted form of therapy for some fairly common clinical conditions in neonatology. Adult blood products differ from neonatal blood in haemorheological properties. The use of those products which may contain constituents abnormal for newborn infants, may disturb neonatal blood composition. Newborn infants, especially preterms, have a lower plasma viscosity than older infants or adults (Foley et al, 1978; Riopel et al, 1982; Buchan, 1984; Linderkamp et al, 1984; Reinhart et al, 1985; Rampling et al, 1989). Our study showed that polycythaemic infants also had a low plasma viscosity. Therefore, when a partial plasma exchange tranfusion in a newborn infant is indicated, it is recommended to use a 5\% albumin solution (viscosity $0.868 \mathrm{mPa} . \mathrm{s}$ ) to avoid a possible increase in plasma viscosity.

The difference in plasma viscusity between polycythaemic and control infants was relatively small. Such a small difference can hardly serve as a physiological compensatory mechanism to guarantee an acceptable blood fluidity in the presence of a high Hct. Differences in plasma shift and fluid redistributions after birth between polycythaemic and normocythaemic infants seem to be a logical explanation for these differences in plasma viscosity. Differences in plasma viscosity are more likely to be the result of a change in composition of the plasma as a result of the underlying problems than to be the cause of impaired organ perfusion. 
We conclude that in normocythaemic as well as in polycythaemic newborn infants plasma viscosity increased with increasing gestational age and that polycythaemic newborn infants had lower plasma viscosity levels than their corresponding controls. The maturation in development was also expressed by a higher plasma viscosity level. The presence of clinical symptoms in polycythaemic newborn infants seemed to be related to an increase in factors with are reflected by an increase in plasma viscosity. 


\section{CLINICAL SYMPTOMS IN POLYCYTHAEMIC NEWBORN INFANTS}

\section{ABSTRACT}

The incidence of clinical symptoms in newborn infants with polycythaemia was studied in 13 preterm, 9 small-for-gestational age (SGA) and 16 appropriate-for-gestational age (AGA) term infants with peripheral venous haematocrit values $\geq 70 \%$. In addition, the underlying mechanisms which might be responsible for the occurrence of clinical symptoms were studied.

The occurrence of symptomatic polycythaemia was in preterm infants significantly lower (46\%) than in SGA infants (67\%) and AGA infants (81\%). Clinical symptoms always disappeared after haemodilution performed by a partial plasma exchange transfusion.

Oxygen supply, reflected by measurements of mean blood flow velocity and red cell transport, did not correlate with the presence of clinical symptoms. Polycythaemic infants with clinical symptoms had significantly $(p<0.05)$ higher plasma viscosity values than infants without clinical symptoms. This finding was true for all subgroups. Plasma viscosity and red cell aggregation are possible contributors to flow disturbances in the microcirculation. We suppose that the presence of clinical symptoms in polycythaemic newborn infants might be related to areas of hypoperfusion at the level of the microcirculation, resulting in a decreased oxygen delivery, despite an increased oxygen carrying capacity. 


\section{INTRODUCTION}

Neonatal polycythaemia defined as a peripheral venous haematocrit (Hct) $>65 \%$ occurs in 2 to $5 \%$ of all newborn infants (Wirth et al, 1979; Ramamurthy and Brans, 1981; Reisner et al, 1983). Impaired organ perfusion due to decreased fluidity of the blood in polycythaemic newborn infants is a problem that may affect multiple organs in varying degrees of severity (Rosenkrantz and $\mathrm{Oh}, 1986)$. The most frequently reported clinical symptoms attributed to polycythaemia are plethora, cyanosis, jitteriness, lethargy, feeding difficulties and respiratory distress. Clinical symptoms in polycythaemic newborn infants usually disappear after a partial plasma exchange transfusion (PPET) (Black et al, 1985; Walker, 1988). However, polycythaemic newborn infants do not always show clinical symptoms (Høst and Ulrich, 1982; Wiswell et al, 1986).

The mechanisms responsible for the presence of clinical symptoms are still obscure. In the present study polycythaemic newborn infants were investigated as to the possible relationship between clinical symptoms and circulating volume, blood flow velocity and red cell transport in cerebral and peripheral arteries and plasma viscosity. The objective of this study was to determine whether one or more of these parameters would have predictive value with respect to specific clinical symptoms. The study population was divided into 3 subgroups: preterm infants, small-for-gestational age (SGA) term infants and appropriate-for-gestational age (AGA) term infants, since it can be expected that these 3 subgroups respond differently to polycythaemic related hypoperfusion.

\section{PATIENTS AND METHODS}

In a 4.5 years period we studied 46 polycythaemic newborn infants who were managed by haemodilution. All infants were inborn and admitted to the maternity ward or the neonatal ward. A PPET was performed in 38 infants with Hct values $\geq 70 \%$ regardless clinical symptoms and in 8 infants with clinical symptoms and $\mathrm{Hct}$ values between $65-70 \%$. Only infants with $\mathrm{Hct}$ values equal or over $70 \%$ were used for the evaluation of clinical symptomatology.

Gestational age, birth weight and peripheral venous Hct in these 38 infants and in the 8 infants with Hct values below $70 \%$ are summarised in table 8.1 . In all infants the 1 minute Apgar score was 7 or higher. None of the infants had a history of perinatal distress or showed signs of perinatal asphyxia. All infants born preterm or small-for-gestational age were admitted to our nursery; appropriate-for-gestational age term infants were only admitted if they had clinical manifestations or if there was another reason for clinical surveillance. In all infants admitted to our nursery a Hct was determined at 3 hours after birth, as described in chapters 4 and 5 . 
table 8.1. Gestational age, birth weight and haematocrit in preterm, small- (SGA) and appropriate (AGA) for-gestational age term infants with venous haematocrit values $\geq 70 \%$ and with haematocrit values between $65 \%-70 \%$. Numbers after the period in gestational age refer to the day in a week.

\begin{tabular}{|c|c|c|c|}
\hline & $\begin{array}{l}\text { Gestational age } \\
\text { (weeks) }\end{array}$ & $\begin{array}{l}\text { Birth weight } \\
\text { (g) }\end{array}$ & $\begin{array}{l}\text { Haematocrit } \\
(\%)\end{array}$ \\
\hline $\begin{array}{l}\text { preterm } \\
\mathrm{Hct} \geq 70 \% \\
(\mathrm{n}=13)\end{array}$ & $\begin{array}{l}33.3 \\
(31.1-36.5)\end{array}$ & $\begin{array}{l}2210 \\
(1430-3250)\end{array}$ & $\begin{array}{l}72 \\
(70-79)\end{array}$ \\
\hline $\begin{array}{l}\text { Het } 65 \%-70 \% \\
(n=2)\end{array}$ & $35.5 ; 37.2$ & $1530 ; 2180$ & $65 ; 67$ \\
\hline $\begin{array}{l}\text { SGA } \\
\mathrm{Hct} \geq 70 \% \\
(n=9)\end{array}$ & $\begin{array}{l}39.0 \\
(37.6-42.2)\end{array}$ & $\begin{array}{l}2330 \\
(1850-2610)\end{array}$ & $\begin{array}{l}73 \\
(70-79)\end{array}$ \\
\hline $\begin{array}{l}\text { Het } 65 \%-70 \% \\
(n=3)\end{array}$ & $\begin{array}{l}37.1 \\
39.1 \\
41.2\end{array}$ & $\begin{array}{l}2170 \\
2500 \\
2400\end{array}$ & $\begin{array}{l}68 \\
68 \\
69\end{array}$ \\
\hline $\begin{array}{l}\text { AGA } \\
\text { Het } \geq 70 \% \\
(n=16)\end{array}$ & $\begin{array}{l}39.5 \\
(37.0-43.0)\end{array}$ & $\begin{array}{l}3460 \\
(2540-4640)\end{array}$ & $\begin{array}{l}72 \\
(70-80)\end{array}$ \\
\hline $\begin{array}{l}\text { Hct } 65 \%-70 \% \\
(n=3)\end{array}$ & $\begin{array}{l}39.0 \\
40.6 \\
41.4\end{array}$ & $\begin{array}{l}3980 \\
3500 \\
3400\end{array}$ & $\begin{array}{l}68 \\
69 \\
68\end{array}$ \\
\hline
\end{tabular}

Values are given as mean and range.

For infants with $\mathrm{Hct}$ values between $65 \%-70 \%$ the individual values are given.

\section{Symptoms}

Clinical symptoms and maternal history of smoking habits were recorded. Nicotin abuse was defined when 5 or more cigarettes per day were smoked. One polycythaemic infant with clinical symptoms and hypoglycaemia was excluded from the study. Cyanosis was defined as blue colouring of the skin on the trunk and of the mucous membranes; plethora as a turgescence and dark red-purple colouring of the skin; jitteriness as the presence of brisk jerky movements and irritability; lethargy as dullness of the infant and the inability to take breast or bottle feeding; respiratory distress (RDS) as an increased breathing frequency and thoracic retractions. 


\section{Measurements}

Mean blood flow velocity was measured in anterior and mid cerebral arteries and in the brachial and femoral artery. The methods used to measure blood flow velocity are described extensively in chapter 3 . Red cell transport in cerebral and peripheral arteries was calculated as the product of mean blood flow velocity and $H c t$. The circulating volume was calculated after completion of the PPET based on exchange volume, initial Hct and resulting $\mathrm{Hct}$ as described in chapter 6 . Plasma viscosity was measured using a capillary viscometer as described in chapter 7 .

The data in the figures are presented as individual values. The data were statistically analysed by means of ANOVA. Statistical significance was considered when $p<0.05$.

\section{RESULTS}

Twenty-five of the 38 infants with a peripheral venous $\mathrm{Hct} \geq 70 \%$ had one or more clinical symptoms $(66 \%)$. Thirteen infants (34\%) had no clinical symptoms. The incidence of clinical symptoms in infants with Hct values between $65-70 \%$ is not known, because for this Hct range only infants with symptoms $(n=8)$ were included in the study. The total group of polycythaemic newborns with clinical symptoms comprised 33 infants. The distribution of clinical symptoms among the three subgroups of polycythaemic infants with Hct values $\geq 70 \%$ is presented in table 8.2 ..

table 8.2. Incidence of clinical symptoms in preterm, small- (SGA) and appropriate(AGA) for-gestational age term infants with venous $\mathrm{Hct} \geq 70 \%$.

\begin{tabular}{|c|c|c|c|c|c|}
\hline & & wit & ptoms & wit & symptoms \\
\hline & & & $\%$ & & $\%$ \\
\hline preterm infants & $(n=13)$ & 6 & $46^{*}$ & 7 & 54 \\
\hline SGA infants & $(n=9)$ & 6 & 67 & 3 & 33 \\
\hline AGA infants & $(n=16)$ & 13 & 81 & 3 & 19 \\
\hline all infants & $(n=38)$ & 25 & 66 & 13 & 34 \\
\hline
\end{tabular}


The incidence of clinical symptoms in polycythaemic preterm infants $(46 \%)$ was significantly lower than in polycythaemic SGA term infants $(67 \%)$ or AGA term infants $(81 \%)$. In all infants the clinical manifestations had disappeared after a PPET.

In table 8.3. the occurrence of specific clinical symptoms in each subgroup of polycythaemic newborn infants is listed.

table 8.3. Clinical symptoms in preterm, small- (SGA) and appropriate- (AGA) for-gestational age term infants with haematocrit values $\geq 70 \%$ and with haematocrit values between $65 \% \cdot 70 \%$.

\begin{tabular}{|c|c|c|c|c|c|c|}
\hline & Plethora & Cyanosis & RDS & $\begin{array}{l}\text { Feeding } \\
\text { problems }\end{array}$ & Jitteriness & Priapism \\
\hline $\begin{array}{l}\text { Preterm } \\
\text { Hct } \geq 70 \% \\
(n=6)\end{array}$ & 2 & & 1 & 2 & 1 & \\
\hline $\begin{array}{l}\text { Het } 65-70 \% \\
(n=2)\end{array}$ & 1 & & 1 & & 1 & \\
\hline $\begin{array}{l}\text { SGA } \\
\text { Hct } \geq 70 \% \\
(n=6)\end{array}$ & 4 & & 1 & 2 & 2 & \\
\hline $\begin{array}{l}\text { Het } 65-70 \% \\
(n=3)\end{array}$ & 1 & 1 & & & 1 & \\
\hline $\begin{array}{l}\text { AGA } \\
H c t \geq 70 \% \\
(n=13)\end{array}$ & 6 & 1 & 4 & 4 & 4 & \\
\hline $\begin{array}{l}\text { Hct } 65-70 \% \\
(n=3)\end{array}$ & 2 & 1 & & & 1 & 1 \\
\hline
\end{tabular}

Plethora and jitteriness were observed most frequently. In some infants more than one organ system was involved. In neither group the presence or absence of specific clinical symptoms was correlated with the Hct. For comparison, the data of the eight infants with Hct values between $65-70 \%$ are presented as well. 
Table 8.4. shows mean blood flow velocity and red cell transport data in cerebral and peripheral arteries in polycythaemic newborn infants with and without clinical symptoms.

table 8.4. Mean blood flow velocity and red cell transport in cerebral and peripheral arteries in polycythaemic preterm, small- (SGA) and appropriate- (AGA) forgestational age term infants with and without clinical symptoms. Values of the subgroups in peripheral arteries are pooled.

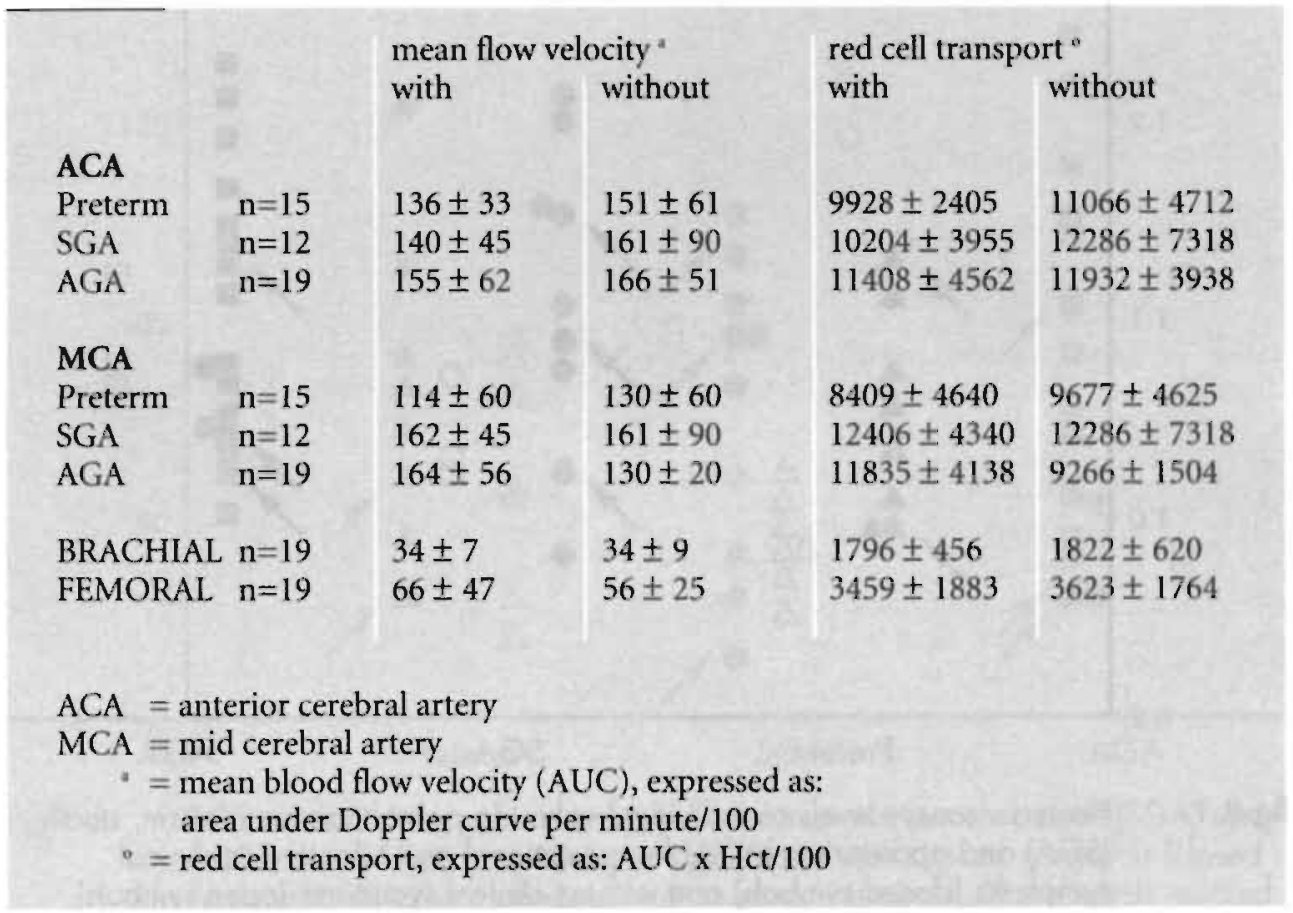

Mean blood flow velocity and red cell transport in cerebral arteries did not differ significantly between polycythaemic infants with or without clinical symptoms in any of the three subgroups (table 8.4.). In only 19 polycythaemic infants flow velocity was studied in peripheral arteries. Seventeen of these infants had Hct values $\geq 70 \%$ and two infants had Hct values of $68 \%$ and $69 \%$, respectively. Because of the small number of infants, all peripheral velocity data were pooled. No significant differences in peripheral blood flow velocity were found between polycythaemic newborn infants with clinical symptoms $(n=15)$ or without clinical symptoms $(n=4)$. 
Plasma viscosity levels in the three subgroups of polycythaemic infants with and without clinical symptoms are illustrated in figure 8.1.

Plasma viscosity was significantly higher in symptomatic preterm and SGA infants, but not in symptomatic AGA infants, when compared with their asymptomatic counterparts.

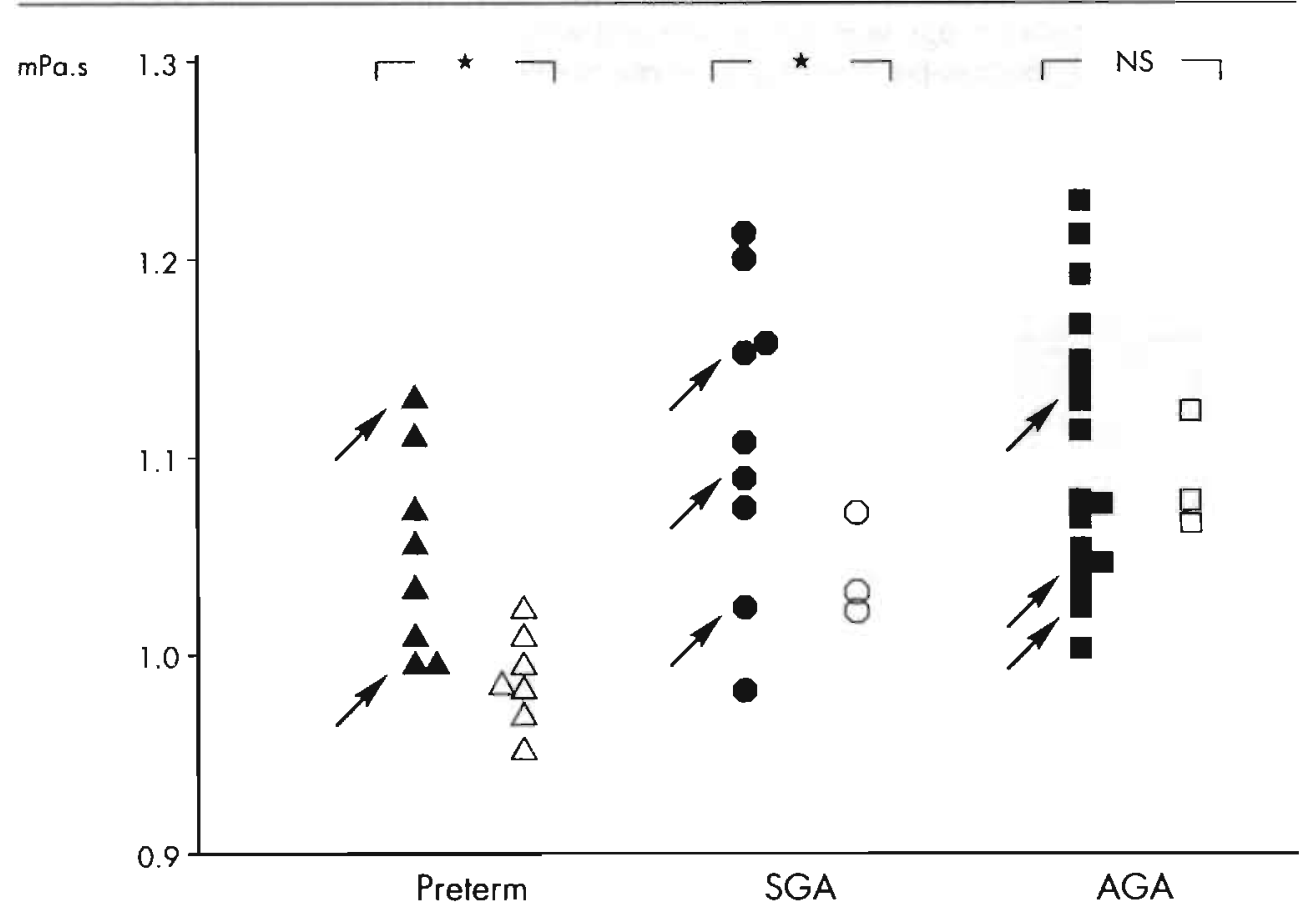

fig 8.1. Plasma viscosity levels as individual values in polycythaemic preterm, small(SGA) and appropriate-(AGA) for-gestational age infants with clinical symptoms (closed symbols) and without clinical symptoms (open symbols). The symbols marked with an arrow belong to the 8 infanls with haematocrit values between $65 \%-70 \%$. NS means not significant; * means $p<0.05$ 
Figure 8.2. shows a plot of relative circulating volume for the three subgroups of polycythaemic infants with clinical symptoms and without clinical symptoms.

Only symptomatic polycythaemic SGA infants had a reduced relative circulating volume compared to SGA infants without symptoms.

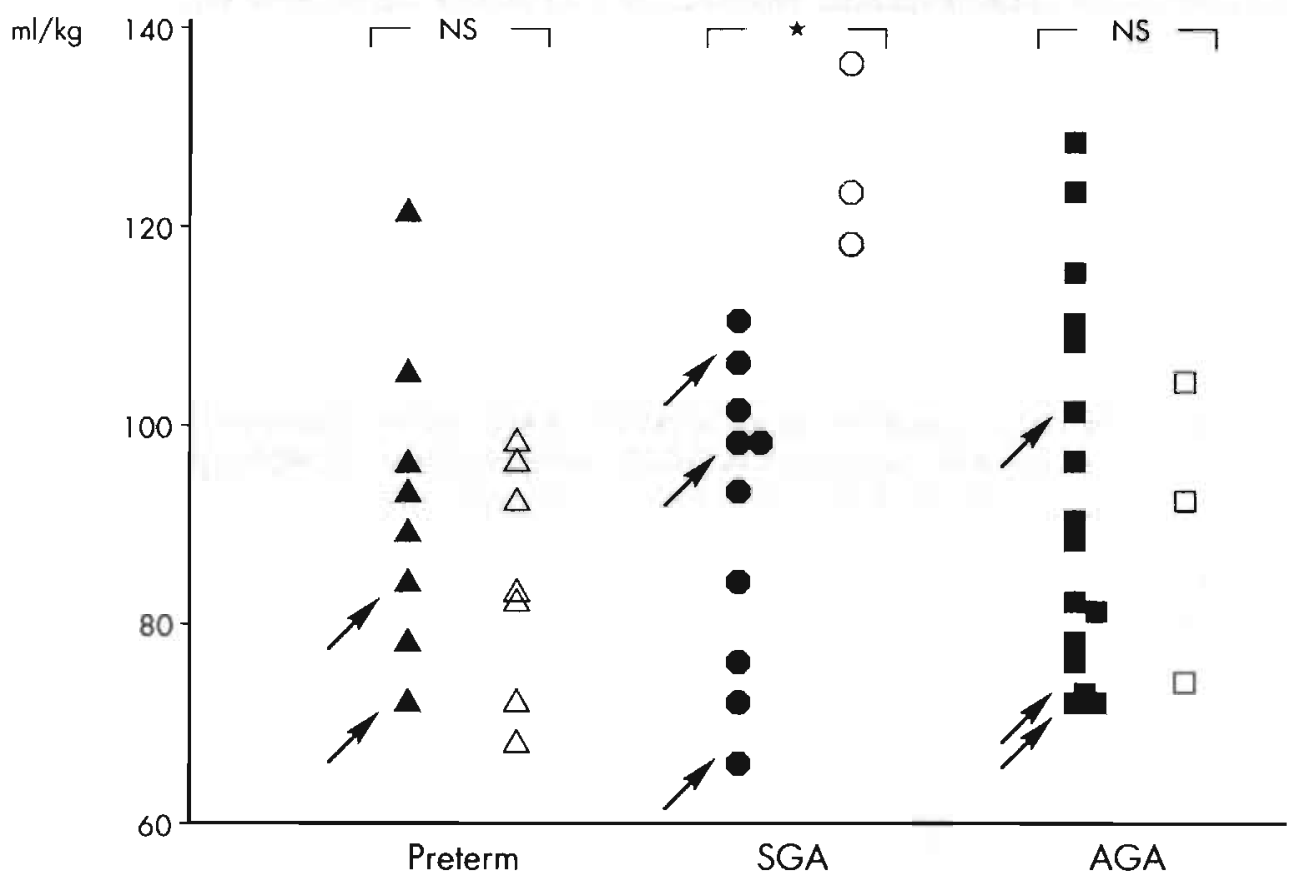

Fig 8.2. Relative circulating volume levels in polycythaemic preterm, small-(SGA) and appropriate-(AGA) for-gestational age infants with clinical symptoms (closed symbols) and without clinical symptoms (open symbols). The symbols marked with an arrow belong to the 8 infants with haematocrit values between $65 \%-70 \%$. NS means not significant; * means $p<0.05$ 
The relationship between nicotin abuse during pregnancy and clinical symptoms in the three subgroups of polycythaemic newborn infants is shown in table 8.5 ..

In polycythaemic SGA infants a significant correlation was found between smoking during pregnancy and the occurrence of clinical symptoms. In polycythaemic preterm and AGA term infants such a correlation was not found.

Plasma viscosity, relative circulating volume and maternal smoking were each separately correlated with the presence or abscence of clinical manifestations in polycythaemic SGA infants. The three SGA infants without clinical symptoms had a high relative circulating volume and a low plasma viscosity when compared with symptomatic SGA infants. These parameters were found to vary independently from each other in the group of SGA infants. Therefore, they don't seem to be mutually correlated for SGA infants with or without clinical symptoms.

table 8.5. Nicotin abuse during pregnancy related to presence or abscence of clinical symptoms in preterm, small- (SGA) and appropriate- (AGA) for-gestational age newborn infants with haematocrit values $\geq 70 \%$.

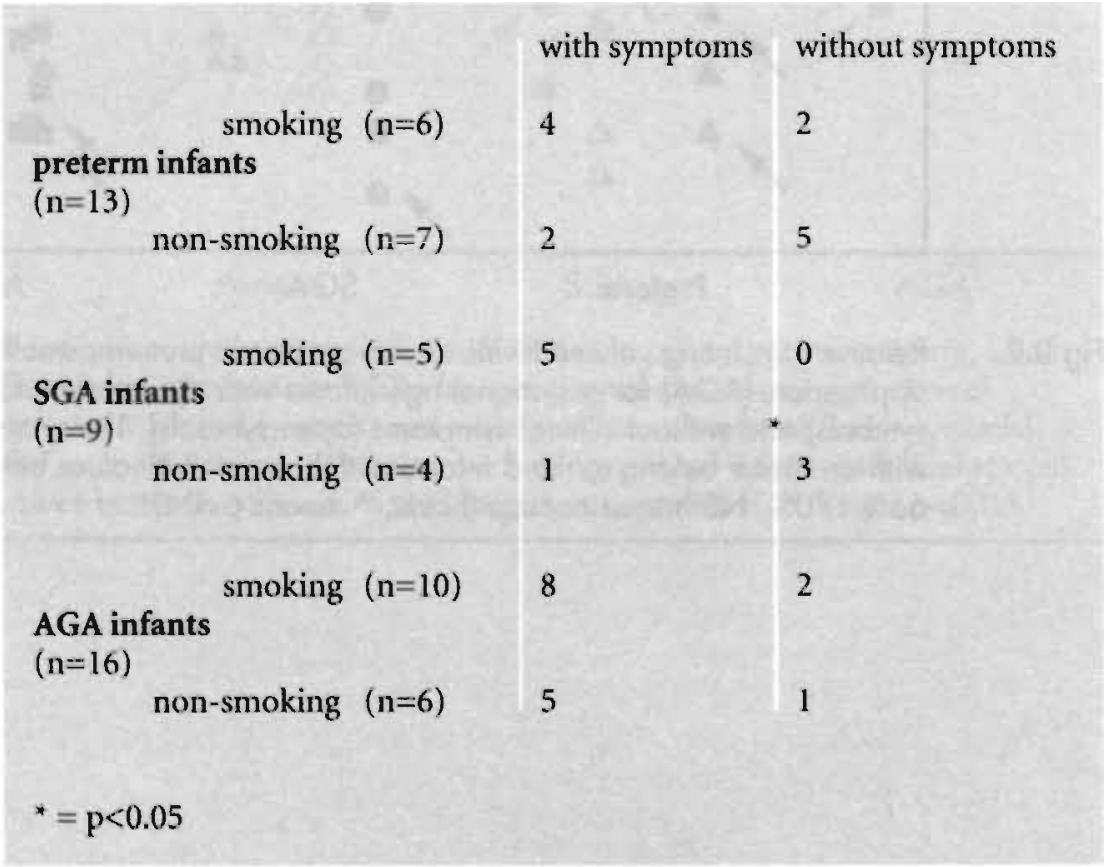




\section{DISCUSSION}

In the present study the incidence of clinical symptoms in polycythaemic newborn infants was found to increase as a function of gestational age. Blood flow velocity and red cell transport were not related with the presence of clinical symptoms. The influences of plasma viscosity, relative circulating volume and maternal smoking were variable, but a relation between those parameters separately and the occurrence of clinical symptoms was obvious for polycythaemic SGA infants.

Sixty-six percent of the newborn infants with a peripheral venous Hct $\geq 70 \%$ had overt clinical symptoms. Our data are in agreement with Wiswell and colleagues (1986) who reported an incidence of clinical symptoms of $62 \%$ in polycythaemic newborn infants. Høst and Ulrich (1982), however, reported that the majority of polycythaemic infants were free of symptoms, possibly related to the lower $\mathrm{Hct}$ levels $(65-72 \%)$ and smaller number of preterm infants as compared to our study.

The incidence of symptoms in polycythaemic newborn infants with Hct values $\geq 70 \%$ was in preterm infants (46\%) significantly lower than in SGA $(67 \%)$ or in AGA (81\%) term infants.

Mean blood flow velocity and red cell transport were not correlated with clinical symptoms. More specifically, cerebral mean flow velocity and red cell transport were not correlated with neurological symptoms and peripheral mean flow velocity and red cell transport were not correlated with plethora or cyanosis. This implies that red cell transport and, consequently, oxygen supply are not the main cause for clinical manifestations in polycythaemic newborn infants. It has to be emphasized, however, that blood flow velocity in a supplying large artery does not always correlate with blood flow in the microcirculation. At present it is uncertain to what extent hypoperfusion of the organs can be kept responsible for the clinical symptoms in polycythaemic newborn infants. An explanation for the occurrence of clinical manifestations might be that areas of hypoperfusion at the level of the microcirculation result in a decreased oxygen delivery despite an increased oxygen carrying capacity.

In contrast to the supply of blood, there was a positive correlation between plasma viscosity and the occurrence of clinical symptoms in polycythaemic newborn infants. Polycythaemic newborn infants with clinical symptoms had higher plasma viscosity levels than infants without clinical symptoms. Moreover, this correlation was still present when the increase of plasma viscosity during gestation was taken into account. Our finding that plasma viscosity levels in polycythaemic preterm infants were significantly lower than in SGA term and in AGA term infants might explain the low incidence of clinical symptoms in polycythaemic preterm infants. Low plasma viscosity indicates a low content of high molecular weight proteins and with it, a low red cell aggregation. The combination of low plasma viscosity as such and a low red cell aggregation might compensate for the flow impairing effects of a high red cell mass, resulting in favourable haemorheological properties in preterm infants (Linderkamp et al, 1984). The fact that other factors than the red cell mass, such as plasma viscosity, red cell aggregation and red cell deformability may also be important in the determination of blood fluidity is supported by the finding that similar clinical manifestations also occur in newborn infants without polycythaemia (Rosenkrantz and Oh, 1986). 
An increased plasma viscosity might be a causative factor of blood flow disturbances in the microcirculation. Another explanation for blood flow disturbances might be that the increased plasma viscosity is merely a reflection of abnormal constituents which influence red cell aggregation. Clinical symptoms disappeared after PPET in all polycythaemic infants. Because the decrease in plasma viscosity after the exchange was small in comparison to the decrease in red cell mass, the role of plasma viscosity is probably modest with respect to the improvement in post-exchange flow properties. However, specific local effects of plasma viscosity in the microcirculation cannot be excluded. Riopel and colleagues (1982) suggested that the clinical syndrome of increased blood viscosity is most likely caused by the combination of increased haematocrit and elevated plasma viscosity. However, this hypothesis is not supported by experimental evidence.

In this study we observed that a higher circulating volume seems to protect polycythaemic SGA infants from clinical symptoms due to polycythaemia. Our finding that polycythaemic SGA infants had a higher relative circulating volume than AGA infants is probably due to redistributions of placental-fetal blood volume in those growth retarded infants. The higher circulating volume in SGA infants might reflect a better adaptation to the poor nutritional conditions in the uterus and allows a better postnatal adaptation to the extra-uterine environment. Another reason for a higher circulating volume in SGA infants might be that postnatal plasma shifts are less than in AGA infants. This seems to be in conflict with the data of Saigal and Usher (1977), who found more cardio-respiratory problems in infants with a high relative circulating volume and therefore suggested that the heart of a newborn can not handle hypervolaemia. This suggestion could not be confirmed by our data, as we found no correlation between the presence of cardio-respiratory problems and the relative circulating volume. At any rate, we did not find a correlation between the relative circulating volume and one of the other parameters studied which could predict the development of clinical symptoms in any of the three subgroups.

Polycythaemic SGA infants born to smoking mothers had significantly more clinical symptoms of impaired organ perfusion than SGA infants born to non-smoking mothers. However, in polycythaemic appropriate-for-gestational age infants maternal smoking was not correlated with clinical symptoms. Placental function, which is impaired in SGA infants, could have played a role in the occurrence of clinical symptoms. No correlation was found between maternal smoking habits and neonatal plasma viscosity levels. Buchan (1984) showed that blood viscosity was significantly elevated in babies born to mothers who smoked during pregnancy. This increased whole blood viscosity was due to a raised Hct and a reduced red cell deformability. Our data and the findings of Buchan (1984) do not support the data of Dintenfass (1975) and Lowe and Barbanel (1988) who suggested that cigarette smoking causes an increase in plasma viscosity. However, these latter studies were performed in adults.

\section{Clinical implications}

It is still unsettled whether polycythaemic newborn infants benefit from a haemodilution. So far, it is not really known which factors or combination of factors affect organ perfusion most. In our study group, clinical symptoms disappeared after a PPET in all 33 symptomatic polycythaemic newborns. 
Swetnam and colleagues (1987) observed an amelioration in haemodynamic parameters after haemodilution due to a decrease in systemic and pulmonary resistance and a disappearence of clinical symptoms. Delaney-Black and colleagues (1989) reported that polycythaemic newborns at the age of seven had a significantly lower IQ, lower achievement test results, and lower gross motor skills than infants from a normocythaemic control group. When comparing polycythaemic infants treated with a PPET and a non-treated group, they found no differences in long-term outcome. In their study, however, haemodilution was performed with fresh frozen plasma obtained from adult donors and it was performed at an average age of more than 10 hours after birth. It might be possible that by their using a solution with high viscosity as exchange fluid the decrease in whole blood viscosity was less than expected. Moreover, a period of 10 hours of impaired cerebral perfusion might result in permanent neurologic sequelae.

Considering our findings, it is our impression that PPET in polycythaemic newborn infants was beneficial, as clinical symptoms disappeared without exception. In experienced hands the intervention is relatively simple and harmless. To study the possible long-term negative effects of neonatal polycythaemia and to establish the necessity of early intervention, a prospective controlled study should be performed using well-defined inclusion criteria and different subgroups of newborn infants.

In conclusion, approximately two/third of all newborns with $\mathrm{Hct}$ values $\geq 70 \%$ have clinical symptoms which disappear after a PPET. Preterm infants are less susceptible to develop symptoms than term infants. SGA term infants, especially those infants presenting high plasma viscosity, low relative circulating volume and a history of maternal smoking during pregnancy are at higher risk. to develop clinical symptoms 


\section{GENERAL DISCUSSION AND CONCLUSIONS}

In the last decade neonatal mortality has decreased considerably, even in the high risk group of very low birth weight infants. However, early neonatal morbidity that may lead to long lasting handicaps remains a problem in neonatal care units. Periventricular leucomalacia and intraventricular bleeding are the main causes of permanent neurologic damage. Both problems might be caused by changes in cerebral blood flow. Neonatal polycythaemia often results in impaired organ perfusion and is often associated with clinical symptoms. An increased red cell mass as in polycythaemia may lead to an increase in blood viscosity and to an impaired blood flow, resulting in a decreased oxygen delivery. However, it remains unknown whether flow disturbances observed in big vessels have deleterious effects at micro-circulation level. The incidence of polycythaemia is relatively high in some categories of newborn infants, such as growth retarded infants, infants of diabetic mothers and after delayed cord clamping. At present, there is no consensus as to whether treatment is needed and, if so, what type of treatment would be most appropriate. Moreover, it is not known whether the impact of polycythaemia is different in newborn infants of a different gestational age and level of maturity.

Controversy still exists about defining "neonatal polycythaemia". Haematocrit values change continuously during the first 18 hours of life, reaching a peak at 2-4 hours after birth (Shohat et al, 1984b). Haematocrit depends largely on the amount of placental transfusion, which in turn is influenced by cord clamping time (Usher et al, 1963; Usher and Lind, 1965). Moreover, there is a considerable difference in haematocrit levels both between capillary and venous samples (Linderkamp et al, 1977b), and between central venous and peripheral venous blood (Ramamurthy and Brans, 1981). Considering the influence of these factors on the haematocrit, it seems necessary to standardize all factors related to time and site of sampling, as was done in this thesis.

Our hypothesis was that polycythaemia would have a negative impact on organ perfusion. In chapter 4 we described the changes in cerebral circulation produced by polycythaemia. We found that cerebral blood flow velocity was decreased in newborns with polycythaemia. Particularly polycythaemic preterm infants in which end-diastolic flow velocities were found to be low, seemed to be at risk for impaired cerebral perfusion and compromised oxygen delivery. If viscosity should be the only causative factor of decreased blood flow velocity, we would expect to find the same effect in both cerebral and other arteries (chapter 5). However, blood flow velocity in large arteries in arm and leg was not impaired, and polycythaemic AGA term infants had even higher flow velocities than their normocythaemic counterparts. We found that in all polycythaemic infants cerebral blood flow velocity normalized after haemodilution without concomitant change in peripheral blood flow velocity. The variation in the effects of polycythaemia on the perfusion of each individual organ system in different subgroups of polycythaemic infants supports the concept that factors such as vasomotor activity, local blood flow regulation, degree of growth impairment and stage of maturation are probably more important for the haemodynamic function than whole blood viscosity. 
Another factor that might have influenced blood flow velocity was plasma viscosity. In chapter 7 we described that in all 3 subgroups of polycythaemic infants plasma viscosity was lower than in the respective control groups, possibly due to fluid redistributions between intra- and extra-vascular spaces. However, it seems unlikely that the slightly lower plasma viscosity levels in polycythaemic infants can entirely compensate for the increased whole blood viscosity caused by high haematocrit levels. Whether plasma viscosity as such has an additional effect of sufficient magnitude on blood flow remains to be elucidated. For example, we found no relation between plasma viscosity levels and blood flow velocity values in cerebral and peripheral arteries. This finding is in agreement with the generally accepted idea that the red cell mass, which is the most important determinant of whole blood viscosity, has more influence on flow velocity in major vessels than changes in other parameters. However, in the microcirculation, where the haematocrit is relatively low due to the Fåhraeus-Lindquist effect, blood viscosity is mainly determined by plasma viscosity, and in these small vessels plasma viscosity might be a more important factor than in larger vessels. In addition, plasma viscosity in combination with red cell aggregation could play a more important role. In this case it might be pointed out that plasma viscosity reflects the level of macroglobulins in the plasma, such as fibrinogen, which influence red cell aggregation.

We found that as many as $2 / 3$ of polycythaemic term infants had elinical manifestations. Although the cerebral blood flow velocity was severely impaired in the subgroup of preterm infants, the incidence of clinical symptoms in these infants was only $46 \%$. This finding suggests that at micro-circulatory level the perfusion in preterm infants was less impaired than expected. The low plasma viscosity which was found in these infants may have improved the flow properties of the blood, thus protecting these infants from hypoperfusion. Our finding is in agreement with other studies which showed that whole blood viscosity in preterm infants was lower than in term infants and adults, and that this was due to low plasma viscosity and low red cell aggregation. Nevertheless, it is still uncertain whether plasma viscosity perse plays an important role in organ perfusion, or whether plasma composition has an indirect effect on blood flow through its impact on red cell aggregation.

Flow disturbances in the microcirculation may result in a decrease in oxygen delivery and, hence, clinical manifestations (chapter 8). The incidence of clinical symptoms in our study was $66 \%$, which is in agreement with Wiswell and colleagues (1982). Host and Ulrich (1982) on the other hand, reported that the majority of polycythaemic infants were free of symptoms. Discrepancies in the incidence of clinical symptoms can be due to differences in the definition of the syndrome, or differences in the composition of the study group.

The incidence of clinical symptoms in polycythaemic newborn infants increased with gestational age. An explanation for this finding might be that in preterm infants better flow properties of the blood can compensate for the flow-impairing effects of an increased red cell mass. A relatively low level of macroglobulins in preterm infants may explain the observed low plasma viscosity and low red cell aggregation. The involvement of different organ systems in symptomatic newborn infants did not differ between the 3 subgroups of polycythaemic infants. The various clinical symptoms were not 
related to any specific haemorheological or flow velocity parameter. Flow velocity parameters, haemorheological parameters and relative circulating volume were each influenced differently in the 3 subgroups of infants in our study. We suppose that differences in "maturation" and degree of growth impairment in individual newborns are not only important factors in flow regulation, but also in the ability of the newborn to cope with disturbances in blood composition.

It is still a matter of debate whether polycythaemic newborn infants should be treated and, if so, how. In our group of polycythaemic infants we found that clinical symptoms always disappeared after haemodilution. Treatment consisted of a partial plasma exchange transfusion. To perform an accurate partial plasma exchange transfusion, it is necessary to know the circulating volume (chapter 6). The method we used to calculate the circulating volume by sequential measurement of the haematocrit after each exchange step was relatively simple and needed no further invasive techniques. The circulating blood volume in our polycythaemic preterm and AGA term infants was in agreement with values found in normocythaemic infants (Usher et al, 1963). Other studies in polycythaemic infants reported similar values, although no distinction was made between the different subgroups of infants (Usher and Lind, 1965). However, our subgroup of SGA infants showed a higher circulating volume, despite the fact that the cord clamping time did not differ from that in the AGA infants. This could indicate that in SGA infants, either prenatal fluid redistribution resulted in an increase in circulating volume, or that in these infants the fat free fraction was relatively large due to the exhaustion of energy depots. Therefore, when a partial plasma exchange transfusion was indicated we calculated the exchange volume based on a relative circulating volume of $86 \mathrm{ml} / \mathrm{kg}$ in preterm and term AGA infants, and of $106 \mathrm{ml} / \mathrm{kg}$ in SGA infants. However, it must be emphasized that the circulating volume encompasses a large range and that it is difficult to predict a circulating volume for an individual newborn.

The optimal haematocrit for maximum oxygen delivery in the tissues remains unknown. In vitro studies suggested that in newborn infants a maximum haemoglobin flux can be obtained with systemic haematocrit values of $45.50 \%$ (Linderkamp et al, 1981). However, a different level of optimal haematocrit may exist for each organ because of regional variations in vascular micro-architecture (Fan et al 1980). After haemodilution in polycythaemic newborn infants we found a slight increase in cerebral red cell transport without concomitant change in peripheral red cell transport. Swetnam and colleagues (1987) reported that systemic oxygen transport had increased by $13 \%$ after a partial plasma exchange transfusion, despite a reduction in oxygen content by $12 \%$. It is still unsettled whether changes in blood perfusion in polycythaemic infants are due to changes in oxygen content or to changes in blood viscosity (Rosenkrantz et al, 1984; Hudak et al, 1986; Massik et al, 1987). The increase in cerebral red cell transport after haemodilution in our infants suggests that the induced reduction in blood viscosity had a larger impact on organ oxygen supply than the concomitant decrease in oxygen content. If viscosity were to be a causal factor, haemodilution can be expected to have a similar effect on both cerebral and peripheral arteries. However, the effect of 
haemodilution on blood flow velocity in different organ systems differed markedly (chapter 5, this thesis; Holzmann et al, 1986), indicating that other factors, such as vasomotor activity, have an important effect.

In our study we reported that the majority of polycythaemic infants had clinical symptoms and that in all infants these symptoms disappeared after a partial plasma exchange transfusion. This suggests that critical factors in the composition of the blood, such as red cell mass or plasma components have been changed. Our study did not provide any evidence for long-term sequelae as a result of a polycythaemic episode during the early neonatal period, as all infants with haematocrit values $\geq 70 \%$ or between $65-70 \%$ and accompanied by clinical symptoms were treated. Nevertheless, on the basis of our experience we recommend to perform isovolaemic partial plasma exchange transfusion in symptomatic polycythaemic newborn infants with the purpose to reduce the haematocrit to the normal range. However, several authors question the necessity of treatment (van der Elst et al, 1980; Høst and Ulrich, 1982). At present, there are no data supporting haemodilution as the management of choice in polycythaemic infants without clinical symptoms. An important factor, which often is overlooked, is that the consequences of polycythaemia may vary with gestational age and degree of growth retardation. When considering treatment by haemodilution in a certain clinical situation, it is important not to use the haematocrit as the only criteria, but to take into account the presence of clinical symptoms, the gestational age and the degree of growth retardation of the infant, and, if possible, to include information on cerebral blood flow velocity, plasma viscosity and red cell aggregation in the decision making process. A partial plasma exchange transfusion requires invasive techniques. In experienced hands, however, it is a relatively harmless procedure provided aseptic techniques, a good catheter position, isovolaemic exchange steps and a plasma substituent with low viscosity are guaranteed. 


\section{LIST OF REFERENCES}

Amit M, and Camfield PR (1980) Neonatal polycythaemia causing multiple cerebral infarcts. Arch. Neurol. 37:109-110

Aperia A, Bergqvist G, Broberger O, Thodenius K, and Zetterström R (1974) Renal function in newborn infants with high haematocrit values before and after isovolaemic haemodilution. Acta Paediatr. Scand. 63:878-884

Bada HS, Korones SB, Pourcyrous M, Wong SP, Wilson WM, Kolni HW, and Ford DL (1992) Asymptomatic syndrome of polycythemic hyperviscosity; effect of partial plasma exchange transfusion. J. Pediatr. 120:579-585

Bada HS, Hajjar W, Chua C, and Summer DS (1979) Noninvasive diagnosis of neonatal aphyxia and intraventricular hemorrhage by Doppler ultrasound. J. Pediatr. 95:775-779

Berg K and Celander $\mathrm{O}$ (1971) Circulatory adaptation in the thermoregulation of fullterm and premature newborn infants. Acta Paediatr. Scand. 60:278-284

Bergqvist G (1974) Viscosity of the blood in the newborn infant. Acta Paediatr. Scand. 63:858-864

Bergqvist G, and Zetterström R (1974) Blood viscosity and peripheral circulation in newborn infants. Acta Paediatr. Scand. 63:865-868

Beverley DW, Chance GW, Inwood MJ, Schaus M, and Okefee B (1984) Intraventricular hemorrhage and hemostasis defects. Arch. Dis. Child. 59:444-448

Black VD, Lubchenco LO, Luckey DW, Koops BL, McGuinness GA, Powell DP, and Tomlinson AL (1982) Developmental and neurologic sequelae of neonatal hyperviscosity syndrome. Pediatrics 69:426-431

Black VD, Lubchenco LO, Koops BL, Poland RL, and Powell DP (1985) Neonatal hyperviscosity: Randomized study of effect of partial plasma exchange on longterm outcome. Pediatrics 75:1048-1053

Brans YW, Milstead RR, Bailey PE, et al (1974) Blood-volume estimates in Coombs-testpositive infants. N. Eng. J. Med 290:1450-1452

Brans YW, Shannon DL, and Ramamurthy RS (1981) Neonatal polycythaemia: II. Plasina, blood, and red cell volume estimates in relation to hematocrit levels and quality of growth. Pediatrics 68:175-182

Buchan PC (1984) Maternal and fetal blood viscosity throughout normal pregnancy. J. Obstet. Gynaecol. 4:143-150 
Calvert SA, Ohlsson A, Hosking MC, Erskine L, Fong K, and Shennan AT (1988) Serial measurements of cerebral blood flow velocity in preterm infants during the first 72 hours of life. Acta Paediatr. Scand 77:625-631

Campbell N, and Stewart I (1979) Exchange transfusion in ill newborn infants using peripheral arteries and veins. J. Pediatr. 94:820-822

Cassady G (1970) Body composition in intrauterine growth retardation. Pediatr. Clin. North Am. 77-99

Chien S, Usami S, Taylor HM, Lundberg JL, and Gregersen MI (1966) Effects of hematocrit and plasma proteins on human blood rheology at low shear rates. J. Appl. Physiol. 21:81-87

Chien S, Usami S, Dellenback RJ, and Gregersen MI (1970) Shear-dependent interaction of plasma proteins and erythrocytes in blood rheology. Am. J. Physiol. 219:143-147

Creswell JS, Warburton D, Susa JB et al (1981) Hyperviscosity in the newborn lamb produces perturbation in glucose homeostasis. Pediatrics 15:1348-1353

Delaney-Black V, Camp BW, Lubchenco LO, Swanson C, Roberts L, Gaherty P, and Swanson B (1989) Neonatal hyperviscosity association with lower achievement and IQ scores at school age. Pediatrics 83:662-667

Dintenfass L (1975) Elevation of blood viscosity, aggregation of red cells, haematocrit and fibrinogen levels in cigarette smokers. Med. J. Austr. 1: 617-620

Dintenfass L, and Kammer S (1977) Plasma viscosity in 615 subjects. Effect of fibrinogen, globulin and cholesterol in normals, peripheral vascular disease, retinopathy, and melanoma. Biorheology 14:247-251

Drayton MR, and Skidmore R (1987) Vasoactivity of the major intracranial arteries in newborn infants. Arch. Dis. Child. 62: 236-240

Driessen GK, Heidtmann H, and Schmid-Schönbein H (1979) Effect of haematocrit on red cell velocity in the capillaries of rat mesentery during haemodilution and haemoconcentration. Pfluegers Arch. 380:1-6

Dubowitz LMS, Dubowitz V, and Goldberg C (1970) Clinical assessment of gestational age in the newborn infant. J. Pediatr. 77:1-10

Fåhraeus R (1929) The suspension stability of the blood. Physiol. Rev 9:241-274

Fåhraeus R, and Lindqvist T (1931) The viscosity of blood in narrow capillary tubes. Amer. J. Physiol. 96:562-568

Foley ME, Isherwood DM, and McNicol GP (1978) Viscosity, haematocrit, fibrinogen and plasma proteins in maternal and cord plasma. British J. Obstet. Gynaecol. 85:500-504

Fouron JC, Bard H, Riopel L, de Muylder X, van Ameringen MR, and Urfer F (1985) Circulatory changes in newborn lambs with experimental polycythaemia: comparison between fetal and adult type blood. Pediatrics 75:1054-1058 
Gaehtgens P (1977) Hemodynamics of the microcirculation: physical characteristics of blood flow in the microvasculature. In: Meessen $\mathrm{H}$ (ed) Handbuch der allgemeinen Pathologie, Teil 7: Mikrozirkulation. Springer, Berlin, Heidelberg, New York pp 231-287

Gaehtgens P (1980) Flow of blood through narrow capillaries: rheological mechanisms determining capillary haematocrit and apparent viscosity. Biorheology 17:183-189

Gatti RA, Muster AJ, Cole RB, and Milton HP (1966) Neonatal polycythaemia with transient cyanosis and cardiorespiratory abnormalities. J. Pediatr. 69:1063-1072

Goldberg K, Wirth FH, Hathaway WE, Guggenheim MA, Murphy JR, Braithwaite WR, and Lubchenco LO (1982) Neonatal hyperviscosity.II. Effect of partial plasma exchange transfusion. Pediatrics 69:419-425

Gray PH, Griffin EA, Drumm JE, Fitzgerald DE, and Duignam NM (1983) Continuous wave Doppler ultrasound in evaluation of cerebral blood flow in neonates. Arch. Dis. Child. 58:677-681

Green DW, Khoury J, and Mimouni F (1992) Neonatal hematocrit and maternal glycemic control in insulin-dependent diabetes. J. Pediatr. 120:302-305

Gross GP, Hathaway WE, and McGaughey HR (1973) Hyperviscosity in the neonate. J. Pediatr. 82:1004-1011

Gupta BB, and Seshadri V (1977) Flow of red blood cell suspensions through narrow capillaries. Biorheology 14:133-143

Hakanson DO, and Oh W (1977) Necrotising enterocolitis and hyperviscosity. J. Pediatr. 90:458-461

Hakanson DO, and Oh W (1980) Hyperviscosity in the small for gestational age infant. Biol. Neonate 37:109

Hansen NB, Stonestreet BS, Rosenkrantz TS, and Oh W (1983) Validity of Doppler measurements of anterior cerebral artery blood flow velocity: correlation with brain blood flow in piglets. Pediatrics 72:526-531

Harkness J (1971) The viscosity of human blood plasma; its measurement in health and disease. Biorheology 8:171-193

Harkness J (1981) Measurements of plasma viscosity. In: Lowe Gi )O, Barbanel JC, and Forbes C eds Clinical Aspects of Blood Viscosity and Cell Deformability: Springer, Berlin, Heidelberg, New York pp 79-90

Heilman L, Siekmann U, Schmid-Schönbein H, and Ludwig H (1981) Hemoconcentration and pre-eclampsia. Arch. Gynecol. 231:7-21

Henriksson P (1979) Hyperviscosity of the blood and haemostasis in the newborn infant. Acta Paediatr.Scand. 68:701-704

Herson VC, Raye JR, Rowe JC, and Philipps AF (1982) Acute renal failure associated with polycythaemia in a neonate. J. Pediatr. 100:137-139

Hey EN (1971) The care of babies in incubators. In: Gairdner D, and Hull D (eds) Recent advances in Paediatrics. 4th edn. Churchill, London, pp 171-216

Holzman IR, 'Tabata B, and Edelstone DI (1986) Blood flow and oxygen delivery to the organs of the neonatal lamb as a function of hematocrit. Pediatr. Res.

20:1274-1279 
Høst A, and Ulrich M (1982) Late prognosis in untreated neonatal polycythaemia with minor or no symptoms. Acta Paediatr. Scand. 71:629-633

Hudak ML, Koehler RC, Rosenberg AA, Traystmann RJ, and Jones MD (1986) Effect of hematocrit on cerebral blood flow. Am. J. Physiol. 251:H63-H70

Huisman H (1986) Haemorheological changes during pregnancy. Thesis, University of Groningen, Groningen

Humphrey PRD, Marshall J, Ross Russell RW, Wetherley-Mein G, Du Boulay GH, Pearson TC, Symon L, and Zilkha E (1979) Cerebral blood flow and viscosity in relative polycythaemia. Lancet ii:873-877

Humphrey PRD (1981) Changes in cerebral blood flow relating to haematocrit and viscosity. Scand. J. Clin. Lab. Invest. 41:290

Huber H, Lewis SM, and Szur L (1964) The influence of anaemia, polycythaemia and splenomegaly on the relationship between venous haematocrit and red cell volume. Brit. J. Haemat. 10:567-575

International Committee for Standardisation in Haematology (1984) Recommendation for a selected method for the measurement of plasma viscosity. J. Clin. Pathol. $37: 1147$

Jung A, Roggenkamp HG, Schmidt J, and Kiesewetter H (1985) Das KapillarschlauchPlasmaviskometer: Methodik, Qualitätskontrolle und Referenzbereich. Biomed. Technik 30:152-158

Jung A, Roggenkamp HG, Ringelstein EB, Leipnitz G, Schneider R, Kiesewetter H, and Zeller H (1986) Effect of sex, age, body weight, and smoking on plasma viscosity. In: H Kiesewetter and Jung A (eds) Blood fluidity and endothelial influences on microcirculation, Karger, Basel, New York PP 1076-1081

Katz J, Rodriguez E, Mandani G, and Branson HE (1982) Normal coagulation findings, thrombocytopenia, and peripheral hemoconcentration in neonatal polycythaemia. J. Pediatr. 101:99-102

Kidd L, Levison H, Gemmel P, Aharon A, and Swyer PR (1966) Limb blood flow in the: normal and sick newborn. Am. J. Dis. Child. 112:402-407

Kiesewetter H, Schmid-Schönbein H, Radtke H, and Stolwerg G (1979) In vitro demonstration of collateral blood viscidation. Flow measurements in a modal of vascular networks. Microvasc. Res. 17:12-19

Kiesewetter H, Schmid-Schönbein H, Seiffge D, and Teitel P (1981 a) Problems of red cell deformability. In: (SI)O Lowe, Barbanel JC, and Forbes CD Eds. Clinical aspects of blood viscosity and cell deformability, Springer, Berlin, Heidelberg, New York pp 3-7 
Kiesewetter H, Dauer U, Gesch M, Seiffge D, Angelkort B, and Schmid-Schönbein H (1981b) A method for the measurement of the red blood cell deformability.

Scand. J. Clin. Lab. Invest. 41:229-232

Kuenzel W, and Wolf H (1970) Die Kapillar-venösen Differenzen in der

Neugeborenenperiode in ihrer Abhängigkeit von Modus der Abnabelung.

Arch. Kinderheilk. 180:150-165

Leake RD, Thanopoulos B, and Nieberg R (1975) Hyperviscosity syndrome associated with necrotising enterocolitis. Am. J. Dis. Child. 129:1192-1194

Leake RD, Chan GM, Zakkaudin S, et al (1980) Glucose perturbation in experimental hyperviscosity. Pediatr. Res. 14:1320-1323

Le Blanc MH, D'Cruz C, and Pate K (1984) Necrotising enterocolitis can be caused by polycythaemic hyperviscosity in the newborn dog. J. Pediatr. 105:804-807

Leblond PF (1987) The syndrome of polycythaemia. In: Chien S, Dormandy J, Ernst E, and Matrai A (eds) Clinical hemorheology, Martinus Nyhoff, Dordrecht pp 230-234

Linderkamp O, Holthausen H, Seifert J, Butenandt I, and Riegel KP (1977a) Accuracy of blood volume estimation in critically ill children using 125-I labelled albumin and 51-Cr labelled red cells. Eur. J. Pediatr. 125:143-151

Linderkamp O, Versmold HT, Strohhacker I, Messow-Zahn K, Riegel KP, and Betke K (1977b) Capillary-venuus hematocrit differences in newborn infants. Eur. J. Pediatr. 127:9-14

Linderkamp O, Versmold HT, Messow-Zahn K, MUller-Holve W, Riegel KP, and Betke K (1978) The effect of intra-partum and intra-uterine asphyxia on placental transfusion in premature and full-term infants. Eur. J. Pediatr. 127:91-99

Linderkamp O, Meiselman HJ, Wu PYK, and Miller FC (1981) Blood and plasma viscosity and optimal hematocrit in the normal newborn infant. Clinical Hemorheology 1:575-584

Linderkamp O, Wu PYK, and Meiselman HJ (1982) Deformability of density separeted red blood cells in normal newborn infants and adults. Pediatr. Res. 16:964-968

Linderkamp O, Versmold HT, Riegel KP, and Betke K (1984) Contributions of red cells and plasma to blood viscosity in preterm and full-term infants and adults. Pediatrics 74:45-51

Linderkamp O (1984) Frühabnabelung oder Spätabnabelung? Gynäkologe 17:281-288

Lipowsky HH, Kovalchek S, and Chien S (1978) In vitro measurements of "apparent viscosity" and microvessel haematocrit in the mesentery of the cat. Circ. Res. 43:738-749

Lister J (1858) On the early stages of inflammation. Philos. Trans. R. Soc. 148:645Lowe GDO, and Barbanel JC (1988) Plasma and blood viscosity. In: Lowe GDO (ed) Clinical blood rheology. vol I. CRC Press Boca Raton pp 11-44

Lubchenco L, Hansmann C, Dressler M, and Boyd E (1963) Intrauterine growth as estimated from liveborn birth weight data at 24 to 42 weeks of gestation. Pediatrics 32:793-800 
Maertzdorf WJ, Tangelder GJ, Slaaf DW, and Blanco CE (1989) Effects of partial plasma exchange transfusion on cerebral blood flow velocity in polycythaemic preterm, term and small for date newborn infants. Eur. J. Pediatr. 148:774-778

Maertzdorf WJ, Aldenhuijsen-Dorland W, Slaaf DW, Tangelder GJ and Blanco CE (1991) Circulating blood volume in appropriate and small for gestational age term and preterm polycythaemic infants. Acta Paediatr. Scand. 80:620-627

Massik J, Tang Y, Hudak ML, Koehler RC, Traystman RJ, and Jones D (1987) Effect of hematocrit on cerebral blood flow with induced polycythaemia. J. Appl. Physiol.62:1090-1096

McGill R, Tukey JW, and Larsen WA (1978) Variation of box plots. Amer. Statistican

Mayer GA, Fridrich J, Newell J, and Szivek J (1966) Plasma components and blood viscosity. Biorheology 3:171-176

Mentzer WC (1978) Polycythaemia and the hyperviscosity syndrome in newborn infants. Clin. Haemat. 7:63-74

Messmer K, and Schmid-Schönbein H (1971) Hemodilution, theoretical basis and clinical application. S.Karger, Basel

Miall-Allen VM, de Vries LS, Dubowitz LMS, and Whitelaw AGL (1989) Blood pressure fluctuations and intraventricular hemorrhage in the preterm infant of less than 31 weeks' gestation. Pediatrics 83:657-661

Miller GM, Black VD, and Lubchenco LO (1981) Intracerebral hemorrhage in a term newborn with hyperviscosity. Am. J. Dis. Child. 135:377-380

Mollison PL, Veall N, and Cutbush M (1950) Red cell and plasma volume in newborn infants. Arch. Dis. Child. 25:242-253

Mott JC, and Walker DW (1983) Neural and endocrine regulation of circulation in the fetus and the newborn. In: Shepherd JT, and Abboud FM (eds) Handbook of Physiology, vol III: Peripheral Circulation. Williams \& Wilkins Company, pp 837-883

Norman M, Herin P, Fagrell P, and Zetterström R (1988) Capillary blood cell velocity in full-term infants as determined in skin by videophotometric microscopy. Pediatr. Res. 23:585-588

Oh W, and Lind J (1966) Venous and capillary haematocrit in newborn infants and placental transfusion. Acta Paediatr. Scand. 55:38-40

Oh W, Blankenship W, and Lind J (1966) Further study of neonatal blood volume in relation to placental transfusion. Ann. Paediat. 207:147-159

Oski AF (1987) Disorders of erythrocyte production. In: Nathan DG, and Oski AF (eds) Haematology in Infancy and Childhood 3 de edition. W.B.Saunders, Philadelphia, pp 265-412 
Pearson TC, Humphrey PRD, Thomas DJ, and Wetherley-Mein G (1981) Haematocrit, blood viscosity, cerebral blood flow and vascular occlusion. In: Lowe GDO, Barbanel SC, and Forbes CD (eds) Clinical aspects of blood viscosity and cell deformability. Springer, Berlin, Heidelberg, and New York pp 97-107

Perlman JF, McMenamin JB, and Volpe JJ (1983) Fluctuating cerebral blood flow velocity in respiratory distress syndrome. N. Eng. J. Med.309:204-209

Perlman JM, Goodman S, Kreusser KJ, and Volpe JJ (1985) Reduction in intraventricular hemorrhage by elimination of fluctuating cerebral blood flow velocity in preterm infants with respiratory distress syndrome. N. Eng. J Med 312: 1353-1357

Philip AGS, and Teng SS (1977) Role of respiration in effecting placental transfusion at ceasarean section. Biol. Neonate 31:219-225

Phillips MJ, and Harkness J (1976) Plasma and whole blood viscosity. Brit. J. Haemat. 34:347-352

Philipps AF, Dubin JW, Matty PJ, and Raye JR (1982) Arterial hypoxemia and hyperinsulinemia in the chronically hyperglycemic lamb. Pediatr. Res 16:653-656

Philipps AF, Widness JA, Garcia JF, Raye JR, and Schwartz R (1982) Erythropoietin elevation in the chronically hyperglycemic fetal lamb. Proc. Soc. Exp. Biol. Med. 170:42-47

Pourcelot L (1974) Application cliniques de l'Examen Doppler transcutane. In: Peronneau $\mathrm{P}$ (ed) Velocimetre ultrasonore Doppler. Inserm, Paris, 213

Ramamurthy RS, and Brans YV (1981) Neonatal polycythaemia:

1. Criteria for diagnosis and treatment. Pediatrics 68:168-173

Ramamurthy RS, and Berlanga M (1987) Postnatal alteration in hematocrit and viscosity in normal and polycythemic infants. J. Pediatr. 110:929-934

Rampling MW (1981) Rouleaux formation and fibrinogen related molecules. Proceedings of 2nd European Congress on Clinical Haemorheology, London, p 201

Rampling MW, and Whittingstall P (1986) A comparison of five methods for estimating red cell aggregation. Klin. Wochenschr. 7:1084-1087

Rampling MW, Whittingstall P, Martin G, Bignall S, Rivers RPA, Lissauer TJ, and Bailey PC (1989) A comparison of the rheologic properties of neonatal and adult blood. Pediatr. Res. 25:457-460

Rawlings IS, Pettett G, Wiswell TE, and Clapper J (1982) Estimated blood volumes in polycythaemic neonates as a function of birth weight. J. Pediatr.4:594-599

Reinhart WH, Danoff SJ, King RG, and Chien S (1985) Rheology of fetal and maternal blood. Pediatr. Res. 19:147-153

Reisner SH, Mor N, Levy Y, and Merlob P (1983) Incidence of polycythaemia. Isr. J. Med. Sci. 19:848-852

Riopel L, Fouron JC, and Bard H (1982) Blood viscosity during the neonatal period: the role of plasma and red blood cell type. J. Pediatr. 100:109-120

Rivers RPA (1984) Coagulation changes associated with a high haematocrit in the newborn infant. Acta Paediatr. Scand. 64:449-454

Rosenblum WI (1972) Erythrocyte velocity and fluorescein transit time through the cerebral microcirculation in experimental polycythaemia. J. Neuropathology and Fxp. Neurology 31:126-131 
Rosenkrantz TS, and Oh W (1982) Cerebral blood flow velocity in infants with polycythemia and hyperviscosity: effects of partial exchange transfusion with plasmanate. J. Pediatr. 101:94-98

Rosenkrantz TS, Stonestreet BS, Hansen NB, Nowicki P, and Oh W (1984) Cerebral blood flow in the newborn lamb with hyperviscosity and polycythaemia. J. Pediatr. 104:276-280

Rosenkrantz TS, and Oh W (1986) Neonatal polycythaemia and hyperviscosity. In: Milunsky A, Friedman EA, and Gluck L (eds) Advances in Perinatal Medicine vol 5. Plenum, New York pp 93-123

Saigal S, O'Neill A, Surainder Y, Chua L, and Usher RH (1972) Placental transfusion and hyperbilirubinaemia in the premature. Pediatrics 49:406-419

Saigal S, and Usher Rh (1977) Symptomatic neonatal plethora. Biol. Neonate 32:62-72

Scarcella A, and Gambardella P (1986) Partial exchange transfusion using peripheral vessels in polycythaemic newborn infants. Eur. J. Pediatr. 144:545-546

Schmid-Schönbein H, Volger E, Teitel P, Kiesewetter H, Dauer U, and Heilman L (1982) New hemorheological techniques for the routine laboratory. Clin. Hemorheology 2:93-105

Schmid-Schönbein H (1988) Fluid dynamics and hemorheology in vivo: the interactions of hemodynamic parameters and hemorheological "properties" in determining the flow behavior in microvascular networks. In: Lowe G (ed) Clinical Blood Rheology, CRC Press Boca Raton pp 129-220

Senn VE, and Karlson KE (1958) Methodologic and actual error of plasma volume determination. Surgery 44:1095-1105

Shaikh BS, and Erslev AJ (1978) Thrombocytopenia in polycythemic mice. J. Lab. Clin. Med. 92:765-768

Shohat M, Merlob P, and Reisner SH (1984a) Neonatal polycythemia: I. Early diagnosis and incidence relating to time of sampling. Pediatrics 73:7-10

Shohat M, Reisner SH, Mimouni F, and Merlob P (1984b) Neonatal polycythemia: II Definition related to time of sampling. Pediatrics 73:11-13

Sisson TRC, Knutson S, and Kendall N (1973) The blood volume of infants born by cesarean section. Am. J. Obstet. Gynecol. 117:351-357

Strasburg HM, Niederhoff H, and Sauer M (1982) Die Doppler sonographische Registrierung der Durchblutung intracranieller Gefässe beim Säugling. Monatsschr. Kinderheilk. 130:608-612

Swetnam SM, Yabek SM, and Alverson DC (1987) Hemodynamic consequences of neonatal polycythemia. J. Pediatr. 110:443-447 
Takenaka K, Sakomoto T, Waffarn F, Dabestani A, Gardin JM, and Henry WL (1988) Acute changes in hematocrit: their effects on flows in the great arteries of newborns. J. Cardiol. 18:765-774

Usher R, Shephard M, and Lind J (1963) The blood volume of the newborn infant and placental transfusion. Acta Paediatr. Scand. 52:497-512

Usher R, and Lind J (1965) Blood volume of the newborn premature infant. Acta Paediatr. Scand. 54:419-431

Van der Elst CW, Molteno CD, Malan AF, and de V Heese H (1980) The management of polycythaemia in the newborn infant. Early Hum. Dev. 4:393-403

Voerman HJ, and Groeneveld ABJ (1989) Blood viscosity and circulatory shock. Intensive Care Med. 15:72-78

Volpe JJ, Perlman JM, Hill A, and Menahim MC (1982) Cerebral blood flow velocity: the value of its determination. Pediatrics $70: 147-152$

Waffarn F, Tolle CD, and Huxtable RF (1984) Effects of polycythemia and hyperviscosity on cutaneous blood flow and transcutaneous $\mathrm{pO} 2$ and $\mathrm{pCO} 2$ in the neonate. Pediatrics 74:389-394

Walker CHM (1988) Rheology of the newborn and their disorders. In: Lowe GDO (ed) Clinical Blood Rheology, vol II. CRC Press, Boca Raton, pp 213-232

Wells RE, Denton R, and Merrill EW (1961) Measurement of viscusity of biologic fluids by cone plate viscometer. J. Lab. Clin. Med. 57:646-656

Widness JA, Garcia JA, Oh W, and Schwartz R (1982) Cord serum erythropoietin values and disappearance rates after birth in polycythemic mice. Pediatr. Res. 16:218A

Wigglesworth JS, and Pape KE (1980) An integrated model for haemorhagic and ischaemic lesions in the newborn brain. Early Hum. Develop. 2:179-199

Wirth FH, Goldberg KE, and Lubchenco LO (1979) Neonatal hyperviscosity: I. Incidence. Pediatrics 6.3:83.3-836

Wiswell TE, Cornish JD, and Northam RS (1986) Neonatal polycythemia: frequency of clinical manifestations and other associated findings. Pediatrics 78:26-30

Wu PYK, Wong WH, Guerra G, Mirando R, Godoy RR, Preston B, Schoentgen S, and Levan NE (1980) Peripheral blood flow in the neonate. I. Changes in total, skin, and muscle blood flow with gestational and postnatal age. Pediatr. Res. 14: $1374-1378$ 
Yao AC, Hirvensalo M, and Lind J (1968) Placental transfusion rate and uterine contractions. Lancet I:380-384

Yao AC, Moinian M, and Lind J (1969) Distribution of blood between infants and placenta after birth. Lancet II:871-873

Yao AC, and Lind J (1972) Blood volume in the asphyxiated term neonate. Biol. Neonate 21:199-209

Yao AC, and Lind J (1974) Placental transfusion. Am. J. Dis. Child. 127:128-141

Younkin DP, Reivich M, Jaggi JL, Obrist WD, and Delivoria-Papadopoulos M (1987) The effect of hematocrit and systolic blood pressure on cerebral blood flow in newborn infants. J. Cereb. Blood Flow Metab. 7:295-299

van Zeben-van der Aa DMCB (1989) Outcome at two years of age in very preterm and very low birthweight infants in the Netherlands. Thesis. State University Leiden

Zetterström R, Norman M, and Herin P (1989) Haematocrit and peripheral circulation in newborn infants. In: Stern L (ed) Physiologic foundations of perinatal care. Elsevier, New York pp 142-150

Zilow EP, and Linderkamp O (1989) Viscosity reduction of red blood cells from preterm and full-term neonates and adult in narrow tubes (Fåhraeus-Lindqvist effect) Pediatr. Res. 25:595-597 
Haemorheology is an interdisciplinary field in which basic knowledge on the biophysical behaviour of the constituents of blood and their interaction with the vascular system has been applied to elucidate the pathophysiology of clinical disorders and to provide a rational basis for therapy. In newborn infants the red cell mass is the most important determinant of whole blood viscosity and, hence, plays a major role in organ perfusion. Impaired organ perfusion can result in clinical manifestations and may be associated with permanent neurological sequelae:

Neonatal polycythaemia is usually defined as a peripheral venous haematocrit of more than $65 \%$. Several investigators have studied the problem of neonatal polycythaemia, but at present it is still a matter of debate whether or not polycythaemia requires treatment with haemodilution. In this thesis we studied the influence of polycythaemia and the treatment with haemodilution on some haemodynamic and haemorheological parameters in preterm, smalland appropriate-for-gestational age term polycythaemic newborn infants (chapter 1).

Chapter 2 reviews the current knowledge regarding the neonatal hyperviscosity syndrome and its management. This chapter also summarises the basic principles of haemorheology and describes the different determinants of the flow properties of the blood: red cell mass, plasma viscosity, red cell aggregation and red cell deformability.

Chapter 3 describes the assessments and methods used in this thesis. Peripheral venous blood was used for haematocrit determination. Blood flow velocities and red cell transport in cerebral arteries, and in brachial and femoral arteries were determined by means of the Continuous Wave Doppler ultrasound technique. Plasma viscosity was measured by means of a capillary tube viscometer. All measurements were performed before and after haemodilution. Haemodilution was achieved by means of a partial plasma exchange transfusion with an albumin $5 \%$ solution.

Cerebral blood flow velocity in polycythaemic newborn infants was significantly lower than in matched controls (chapter 4). It normalized after partial plasma exchange transfusion and clinical symptoms subsided in all infants. The favourable effect of haemodilution on cerebral blood flow velocity lasted for at least 24 hours.

Chapter 5 demonstrates that, although haemodilution did influence blood flow velocities in cerebral arteries, this was not the case in peripheral arteries. We suggest that the different effects of haemodilution on blood flow velocity in different organ systems indicate that changes in flow velocity are not simply caused by changes in blood viscosity or oxygen content, but that vasomotor-activities also may play an important role. Moreover, we found that normocythaemic appropriate-for-gestational age term infants had a significantly lower peripheral blood flow velocity than normocythaemic preterm or small-for-gestational age infants. We hypothesize that gestational age and level of maturity are important determinants for the capacity to regulate blood flow. 
Chapter 6 describes a method which makes it possible to calculate the circulating volume of a polycythaemic newborn infant who has undergone a partial plasma exchange transfusion. The method is based on repetitive haematocrit determinations after every exchange step. Using a regression line between the number of exchange steps and the haematocrit values before the procedure and after each exchange step, we found that the average relative circulating volume in appropriate-for-gestational age polycythaemic infants was $86 \mathrm{ml} / \mathrm{kg}$, whereas it was $106 \mathrm{ml} / \mathrm{kg}$ in small-for-gestational age polycythaemic infants. We speculate that increased erythropoiesis or redistributions of the placental-fetal blood volume are responsible for the increased circulating volume in growth retarded infants.

Since plasma viscosity is a major determinant in blood flow at microcirculatory level, we investigated the relation between plasma viscosity and haematocrit in preterm, small-for-gestational age and appropriate-forgestational age term infants. Data presented in chapter 7 demonstrate that plasma viscosity increased with gestational age and that polycythaemic infants had significantly lower plasma viscosity values than normocythaemic infants in all subgroups. Within the group of infants with polycythaemia no relation was found between plasma viscosity and haematocrit levels.

Chapter 8 demonstrates that the incidence of clinical symptoms in polycythaemic newborn infants increased with gestational age. Blood flow velocity and oxygen supply did not correlate with the presence or abscence of clinical manifestations. However, flow velocities and red cell transport in large arteries do not obviously correlate with organ perfusion at micro-circulatory level. Plasma viscosity was found to be higher in low birth weight infants with clinical symptoms than in infants without symptoms. However, whether a low plasma viscosity might protect polycythaemic infants against developing clinical symptoms leaves room for speculation. We speculate that plasma viscosity might be a causative factor of flow disturbances in the microcirculation, but another explanation might be that plasma viscosity is a reflection of abnormal constituents which influence red cell aggregation. Albumin 5\% is recommended as exchange solution, since plasma obtained from adult donors may lead to an incraese in plasma viscosity and so reverse the effects of haemodilution.

In the closing chapter 9 we recommend a partial plasma exchange transfusion in all newborn infants with clinical symptoms. Studying all factors which influence the micro-circulation is necessary to find an answer to the question whether polycythaemia in newborn infants might result in impaired organ perfusion with possibly permanent sequelae. 
Haemorheologie houdt zich bezig met het bestuderen van het stroomgedrag van bloed en met de interacties tussen het bloed en de vaatwand. Samenwerking tussen basiswetenschappers en clinici heeft er toe geleid dat de pathofysiologie van haemorheologische ziektebeelden beter begrepen wordt en dat er therapeutische oplossingen voor deze ziektebeelden gevonden kunnen worden.

Bij pasgeborenen is de haematocriet de belangrijkste parameter voor de viscositeit van het bloed en is daarom mede verantwoordelijk voor de doorstroming van de weefsels. Ischaemie van de diverse orgaansystemen kan de oorzaak zijn van ziekteverschijselen met eventueel blijvende schade. In de dagelijkse praktijk worden pasgeborenen met een haematocriet hoger dan $65 \%$ beschouwd als polycythaemisch. Tot op heden bestaat er nog geen duidelijkheid over de behandeling van neonatale polycythaemie. Wij bestudeerden de invloed van polycythaemie en van een haemodilutie op enkele haemodynamische en haemorheologische aspecten bij premature, en in hun groei geretardeerde en normaal geproportioneerde voldragen polycythaemische pasgeborenen (hoofdstuk l).

Hoofdstuk 2 geeft een overzicht van de huidige inzichten over het "neonataal hyperviscositeits syndroom" en verwijst naar de diverse ideeën omtrent de behandeling. Dit hoofdstuk bevat tevens een korte samenvatting van de basisprincipes in de haemorheologie en een bespreking van de invloeden van de haematocriet, de plasma viscositeit, de erythrocyten aggregatie en de deformabiliteit van de erythrocyten op de volbloed viscositeit.

Hoofdstuk 3 beschrijft de meet- en behandelingsmethoden die in deze studie zijn gebruikt. De haematocriet werd bepaald in het perifeer veneuze bloed. Bloedstroomsnelheden in cerebrale en perifere arteriën zijn gemeten middels Continuous Wave Doppler ultrageluid. Het erythrocyten transport is berekend uit de gemiddelde stroomsnelheid en de haematocriet. De plasma viscositeit werd gemeten via een tube viscometer. Alle metingen zijn uitgevoerd vóór en na een isovolaemische partiële wisseltranfusie met een colloidale oplossing bestaande uit albumine $5 \%$.

De stroomsnelheid in cerebrale vaten was in pasgeborenen met een polycythaemie significant lager dan in een controlegroep (hoofdstuk 4). Premature pasgeborenen met een polycythaemie hadden bovendien een significant nòg lagere stroomsnelheid dan voldragen pasgeborenen. Een haemodilutie normaliseerde de cerebrale stroomsnelheid en de eventueel aanwezige klinische verschijnselen verdwenen bij alle kinderen. Het gunstige effect van een haemodilutie bleef bestaan tot 24 uur na de geboorte.

Hoofdstuk 5 laat zien dat een haemodilutie geen invloed had op de stroomsnelheid en het erythrocyten transport in perifere vaten - dit in tegenstelling tot de cerebrale vaten. Omdat de effecten van een haemodilutie verschillend waren in diverse orgaansystemen is de veronderstelling, dat veranderingen in stroomsnelheid niet alleen veroorzaakt worden door veranderingen in de viscositeit of het zuurstofgehalte van het bloed, maar dat 
aanpassingen van de vaatwand - met als gevolg veranderingen in de diameter van het vat - ook van belang zijn. Nornnaal voldragen pasgeborenen zonder polycythaemie hadden een significant lagere perifere stroomsnelheid dan premature of dysmature pasgeborenen. We suggereren dat het o.a. van de rijpheid van een pasgeborene afhangt in hoeverre het autoregulatiemechanisme betreffend de weefselperfusie actief is.

Hoofdstuk 6 beschrijft een mathematisch model voor de berekening van het circulerend volume tijdens het uitvoeren van een partiële wisseltransfusie bij polycythaemische pasgeborenen. Het relatief circulerend volume in dysmature pasgeborenen $(106 \mathrm{ml} / \mathrm{kg}$ ) was significant hoger dan in normaal geproportioneerde pasgeborenen $(86 \mathrm{mnl} / \mathrm{kg}$ ). De oorzaak hiervan kan zijn een toename van de erythropoiese tijdens groeiretardatie of van redistributies van het foeto-placentair bloed volume ten gunste van de foetus.

Omdat de plasma viscositeit in belangrijke mate de stroomsnelheid in de micro-circulatie bepaalt, is een onderzoek gedaan naar de relatie tussen polycythaemie en plasma viscositeit bij premature pasgeborenen en bij groeigeretardeerde en normaal geproportioneerde voldragen pasgeborenen. Hoofdstuk 7 toont aan dat de plasma viscositeit toenam met de zwangerschapsduur en dat pasgeborenen met een polycythaennie een significant lagere plasma viscositeit hadden dan de diverse controle groepen. In de groep polycythaemische pasgeborenen werd echter geen correlatie gevonden tussen de haematocriet en de plasma viscositeit.

In hoofdstuk $\mathbf{8}$ is beschreven dat de incidentie van klinische symptomen bij polycythaemische pasgeborenen toenam met de duur van de zwangerschap. Bloedstroomsnelheid en zuurstof-transporterend vermogen waren niet gecorreleerd aan het optreden van klinische symptomen. Het is echter van belang zich hierbij te realiseren dat stroomsnelheid en zuurstoftransport in grote arterièn niet automatisch coñieleren met de doorstroming op het niveau van de micro-circulatie. Polycythaemische pasgeborenen met een hoge plasma viscositeit hadden een significant hogere incidentie van klinische symptomen dan pasgeborenen met een lage plasma viscositeit. Het is echter speculatief om te veronderstellen dat dit het directe gevolg is van invloed van de plasma viscositeit op de micro-circulatie. Een andere verklaring zou kumnen zijn dat de stoornissen in de micro-circulatie het gevolg zijn van abnormale eiwitcomponenten in het bloed. Deze componenten kunnen een toenane van de erythrocyten aggregatie tot gevolg hebben en de verhoogde plasma viscositeit is dan slechts een weerspiegeling vañ de abnormale eiwitsamenstelling. Omdat plasma verkregen uit het bloed van volwassen donoren een van pasgeborenen afwijkende samenstelling heeft, tot uiting komende in de hogere plasma viscositeit en de hogere erythrocytenaggregatie bij volwassenen, wordt geadviseerd om bij het uitvoeren van een partiële wisseltransfusie bij polycythaemische pasgeborenen gebruik te maken van een albumine 5\% oplossing.

Hoofdstuk 9 gaat in op de vraag wanneer bij polycythaemische pasgeborenen een haemodilutie geïndiceerd is. Het advies gebaseerd op deze studie is om bij alle polycythaemische pasgeborenen met klinische symptomen 
een partiële wisseltransfusie te verrichten. Om een antwoord te vinden op de vraag via welk mechanisme de micro-circulatie bij polycythaemische pasgeborenen in gevaar komt en in hoeverre dat blijvende gevolgen kan hebben, is het noodzakelijk om verder onderzoek te doen naar alle factoren die een rol spelen bij de regulatie van de bloeddoorstroming en om vervolgonderzoek te doen bij alle pasgeborenen met stoornissen in de weefselperfusie. 
De totstandkoming van dit proefschrift is mogelijk geweest door de medewerking van velen.

Allereerst wil ik Prof. Dr. C.E. Blanco bedanken. Beste Carlos, je bent eerst mijn opleider in de neonatologie geweest en daarna de promotor van dit onderzoek. Je manier van leiding geven aan de kliniek, het initiëren van onderzoek en de wijze waarop je onze afdeling bestuurt zijn uitzonderlijk. Het is voor mij dan ook een voorrecht je tot mijn vrienden te mogen rekenen.

Dr. D.W. Slaaf en Dr. G.J. Tangelder, beste Dick en Geert Jan (en dit alles in alfabetische volgorde), het was een positieve ervaring om als clinicus zo te mogen samenwerken met een biofysicus en een fysioloog. Onze gemeenschappelijke besprekingen zijn de basis geweest van wat nu voor ligt. Overigens, ik begrijp nog steeds niet dat jullie zagen wat ik niet zag.

Prof. Dr. R.S. Reneman, beste Rob, aan jou heb ik destijds als eerste mijn ideeën en vraagstellingen voorgelegd. Jouw positieve reactie is de stimulans geweest om aan dit onderzoek te beginnen. Extra dank, dat je als voorzitter van de beoordelingscommissie een belangrijke bijdrage hebt geleverd.

Prof. Dr. H.A.J. Lemmens, beste Jos, jij hebt me enthousiast gemaakt voor de haemorheologie. Ook na je emeritaat ben je altijd belangstellend gebleven. Dank daarvoor.

Beste Wilma, jouw bijdrage aan de diverse metingen was van groot belang. Jouw enthousiasme en nauwgezetheid zouden een voorbeeld moeten zijn.

Beste Sabrina, als ik het niet meer wist dan zei jij: "Ach, dat doe ik wel" en korte tijd later was er weer een figuur klaar. Bedankt.

Beste Marleen en Manon, wat zou ik met een computer moeten beginnen als jullie er niet waren. Bedankt voor de verzorging van de diverse manuscripten en de algehele tekstverwerking.

Aan alle mensen van de afdeling Klinische Neurofysiologie (Hoofd: Prof. Dr. F. Spaans), dank voor het gebruik mogen maken van jullie apparatuur.

Dank ook aan mijn vriend Will Wintjens. Met een goed glas wijn binnen handbereik en Maria Callas op de achtergrond, heb je me geleerd leesbaar Engels te schrijven.

Aan alle leden van de beoordelingscommissie, dank voor het kritisch doorlezen van het manuscript en de suggesties ter verbetering.

Bedankt collega's op de afdeling Neonatologie: alleen als de sfeer is zoals bij ons, kan er iets goeds uitkomen.

Tot slot dank aan mijn vriend André Snijders wiens bureau dit boekje zo'n verzorgd uiterlijk heeft gegeven en aan mijn thuisfront waar ik altijd op begrip kon rekenen voor mijn veelvuldige afwezigheid. 


\section{CURRICULUM VITAE}

Willem Johannes (Wicl) Macrtzdorf

Geboren te Schaesberg op 11 decomber 1940

(iymnasium $\beta$ aan het St. Bernardinuscollege te Heerlen $1953-1960$

Studie Geneeskunde aan de Rijksuniversiteit van Utrecht 1960-1967

Militaire dienstplicht

1968-1969

Opleiding Kindergeneskunde in het Wilhelmina Kinder/iekenhuis te Utrecht (opleiders Prof. Dr. A. Weijers en Prof. Dr. J.J. Stoop)

1969-1973

Chef de Clinique Kindergeneeskunde in het St. Annadal ziekenhuis te Maastricht (Dr. Th.M. van der Kleij en Dr. L.H.J. Ramaekers)

1973-1977 daarna deel uitmakend van de maatschap

Opleiding Neonatologie (opleider Prof. Dr. C.E. Blanco) aan de geacademiseerde kinderafdeling (Hoofd: Prof. Dr. L.H.J. Ramaekers) te Maastricht

1982-1984

Additionele opleiding tot kinderarts-neonatoloog in de afdeling Neonatologie van de Frauenklinik van het Universitäts Kantonsspital te Zürich (Hoofd: Prof. Dr. G. Duc)

1985

Thans stafmedewerker afdeling Neonatologie en deeluitmakend van de vakgroep Kindergeneeskunde (Hoofd: Prof. Dr. R. Kuijten) aan de Rijksuniversiteit Limburg te Maastricht 
